Supplementary information for

\title{
Stabilizing highly-active Ru sites by suppressing lattice oxygen participation in acidic water oxidation
}

Yunzhou Wen ${ }^{1} \uparrow$, Peining Chen ${ }^{1,2} \uparrow$, Lu Wang ${ }^{3,4} \uparrow$, Shangyu Li ${ }^{1} \uparrow$, Ziyun Wang ${ }^{2}$, Jehad Abed $^{2,5}$, Xinnan Mao ${ }^{3}$, Yimeng Min ${ }^{2}$, Cao Thang Dinh ${ }^{6}$, Phil De Luna ${ }^{2}$, Rui Huang ${ }^{1}$, Longsheng Zhang ${ }^{1}$, Lie Wang ${ }^{1}$, Liping Wang ${ }^{1}$, Robert J. Nielsen ${ }^{4}$, Huihui $\mathrm{Li}^{2}$, Taotao Zhuang ${ }^{2}$, Changchun $\mathrm{Ke}^{7}$, Oleksandr Voznyy ${ }^{2}$, Yongfeng $\mathrm{Hu}^{8}$, Youyong $\mathrm{Li}^{3}$, William A. Goddard III ${ }^{4}$, Bo Zhang ${ }^{1 *}$, Huisheng Peng ${ }^{1 *}$, and Edward H. Sargent ${ }^{2 *}$

${ }^{1}$ State Key Laboratory of Molecular Engineering of Polymers, Department of Macromolecular Science and Laboratory of Advanced Materials, Fudan University, Shanghai 200438, China.

${ }^{2}$ Department of Electrical and Computer Engineering, University of Toronto, 10 King's College Road, Toronto, Ontario, M5S 3G4, Canada.

${ }^{3}$ Institute of Functional Nano \& Soft Materials (FUNSOM) and Jiangsu Key Laboratory for Carbon-Based Functional Materials \& Devices, Soochow University, Suzhou, 215123, China.

${ }^{4}$ Materials and Process Simulation Center (MSC) and Joint Center for Artificial Photosynthesis (JCAP), California Institute of Technology, Pasadena, California 91125, United States.

${ }^{5}$ Department of Materials Science \& Engineering, University of Toronto, 27 King's College Circle, Toronto, Ontario, M5S 1A1, Canada.

${ }^{6}$ Department of Chemical Engineering, Queen's University, Kingston, Ontario K7L $3 N 6$, Canada.

${ }^{7}$ Institute of Fuel Cell, Shanghai Jiao Tong University, 800 Dongchuan Rd., Shanghai 200240, China.

${ }^{8}$ Canadian Light Source Inc., Saskatoon, SK S7N 0X4, Saskatchewan, Canada.

These authors contributed equally to this work. 
1 *Correspondence and requests for materials should be addressed to Edward $H$.

2 Sargent (ted.sargent@utoronto.ca) (E.H.S.), Huisheng Peng (penghs@fudan.edu.cn)

3 (H.S.P.) and Bo Zhang (bozhang@fudan.edu.cn) (B.Z.).

4 


\section{Contents}

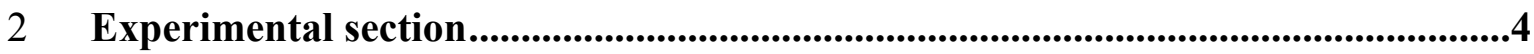

3 Supplementary Notes ...........................................................................................................9

$4 \quad$ Supplementary Note 1: Turnover frequency (TOF) calculations ............................10

$5 \quad$ Supplementary Note 2: XAS measurements and analysis ....................................10

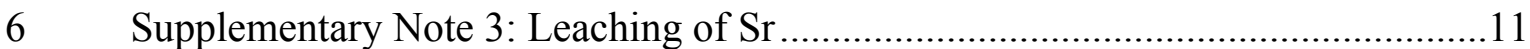

$7 \quad$ Supplementary Note 4: The effect of solvent in DFT calculations.........................12

8 Supplementary Figures (Supplementary Figure 1-Supplementary Figure 46)....13

9 Supplementary Tables (Supplementary Table 1-Supplementary Table 15) .........40

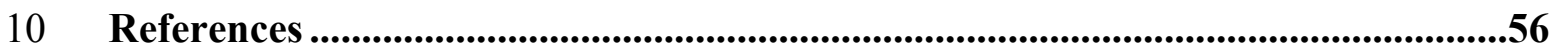




\section{Experimental section}

2 Computational details. The computational high-throughput screening was performed 3 by density functional theory (DFT) calculations. All computations were performed in 4 the VASP package using the projector augmented wave (PAW) method to account for core-valence interactions. The PBE functional was used for the screening of structures and the PBE functional including the D3 van der Waals correction was used for the OER electrocatalytic calculations. The kinetic energy cutoff for plane wave expansions was set to $400 \mathrm{eV}$. The method of Methfessel-Paxton (MP) was applied and the width of the smearing is chosen as $0.2 \mathrm{eV}$. All the geometric structures and lattice parameters are optimized until they converge to within $3 \times 10^{-2} \mathrm{eV} / \AA$ for maximal components of forces. For the optimization of the crystals, reciprocal space was sampled using the $\Gamma$ centered $3 \times 3 \times 4$ k-point mesh, while for the OER calculations on the surface structures, the K-points was used by $3 \times 6 \times 1$ mesh. The electronic density of states (DOS) was calculated using the tetrahedron method.

The OER reaction steps in the acidic solution and the calculated OER overpotential 16 ( $)$ are as following:

$$
\begin{gathered}
H_{2} O+* \rightarrow O H *+H^{+}+e^{-} \\
\Delta G_{1}=G(O H *)+\frac{1}{2} G\left(H_{2}\right)-G\left(H_{2} O\right)-G(*) \\
O H * \rightarrow O *+H^{+}+e^{-} \\
\Delta G_{2}=G(O *)+\frac{1}{2} G\left(H_{2}\right)-G(O H *) \\
\Delta G_{3}=G(O O H *)+\frac{1}{2} G\left(H_{2}\right)-G(O *)-G\left(H_{2} O\right) \\
O *+H_{2} O \rightarrow O O H *+H^{+}+e^{-} \\
O O H * \rightarrow O_{2}+*+H^{+}+e^{-} \\
\Delta G_{4}=4.92-\Delta G_{1}-\Delta G_{2}-\Delta G_{3} \\
\eta \frac{\max \left\{\Delta G_{1}, \Delta G_{2}, \Delta G_{3}, \Delta G_{4}\right\}}{e}-1.23 V
\end{gathered}
$$

17

The $\mathrm{OOH}^{*}, \mathrm{O}^{*}$, and $\mathrm{OH}^{*}$ are the OER intermediates adsorbed on the catalyst surface. For each step of OER, the Gibbs free energy $(\Delta \mathrm{G})$ is given by $\Delta \mathrm{G}=\Delta \mathrm{E}_{\mathrm{DFT}}+\Delta \mathrm{ZPE}-$ $\mathrm{T} \Delta \mathrm{S}$, where $\Delta \mathrm{E}_{\mathrm{DFT}}, \Delta \mathrm{ZPE}$, and $\Delta \mathrm{S}$ are the changes in DFT total energy, zero-point energy, and entropy, respectively. The values of $\triangle \mathrm{ZPE}$ and $\triangle \mathrm{S}$ for the gaseous phase of $\mathrm{H}_{2}$ and $\mathrm{H}_{2} \mathrm{O}$ are obtained from the NIST-JANAF thermodynamics table. 
The $2 \times 2 \times 2$ supercell of rutile structure is adopted in our calculations for $\mathrm{RuO}_{2}$ and ternary SrRuIr oxide compounds. We have considered ten different ratios for the ternary SrRuIr oxide compounds. 2,201 geometric configurations were optimized to search for the most stable SrRuIr oxide structures with various Sr-Ru-Ir ratios. Based on the stable crystal structures, we cleaved the (110) surface for further evaluating the OER activity. As proposed by Nørskov et al., we have calculated the free energies for the OER intermediates $(\mathrm{OH}, \mathrm{O}$ and $\mathrm{OOH})$ adsorbed on the SrRuIr oxide surface to obtain the OER overpotential.

To identify the stability of the ternary SrRuIr oxide compounds in an aqueous environment, we have calculated the Pourbaix diagrams. In a Pourbaix diagram, stable phases are mapped as a function of $\mathrm{pH}$ and electrochemical potential. We combined the calculated DFT energies (for the solid states) with experimentally measured dissolution energies (for the dissolved phases) to generate the Pourbaix diagram by using the ASE module. The concentration of soluble species used in the Pourbaix diagram is $10^{-6} \mathrm{~mol}$ $\mathrm{L}^{-1}$. The thermodynamic data of involved ions was obtained from the ASE database and listed in Supplementary Table 3.

Materials. Strontium chloride hexahydrate $\left(\mathrm{SrCl}_{2} \cdot 6 \mathrm{H}_{2} \mathrm{O}\right)$, ruthenium chloride hydrate, $\left(\mathrm{RuCl}_{3} \cdot \mathrm{xH}_{2} \mathrm{O}\right)$ and sodium hexachloroiridate hydrate $\left(\mathrm{Na}_{3} \mathrm{IrCl}_{6} \cdot \mathrm{xH}_{2} \mathrm{O}\right), \mathrm{Nafion}^{\circledR}(5 \mathrm{wt} \%$ in a mixture of lower aliphatic alcohols and water), iridium (IV) chloride hydrate $\left(\mathrm{IrCl}_{4} \cdot \mathrm{xH}_{2} \mathrm{O}\right)$ and ruthenium oxide $\left(\mathrm{RuO}_{2}\right)$ and were purchased from Sigma-Aldrich or Adamas-beta. Iridium oxide $\left(\mathrm{IrO}_{2}\right)$ was provided by PERIC Inc. and $40 \% \mathrm{Pt} / \mathrm{C}$ was purchased from Johnson Matthey. N, N-dimethylformamide (DMF), ethanol, isopropanol, and acetone were purchased from Sinopharm Chemical Reagent Co., Ltd. The $\mathrm{H}_{2}{ }^{18} \mathrm{O}(99 \%)$ was purchase from Nukem Isotopes. Carbon black (20 nm) were purchased from Suzhou Tanfeng Co., Ltd. The TGP-H-060 carbon paper (CP) was purchased from Toray. Freudenberg H23C9 gas diffusion layers were purchased from Fuel Cell Store. All chemicals were used without any further purification.

Synthesis of catalysts. A series of Sr-Ru-Ir ternary catalysts were synthesized by modifying previously reported sol-gel methods ${ }^{1}$. A typical synthesis procedure is as follows: metal salt precursors $\left(0.3 \mathrm{mmol} \mathrm{SrCl}_{2} \cdot 6 \mathrm{H}_{2} \mathrm{O}, 0.5 \mathrm{mmol} \mathrm{RuCl}_{3} \cdot \mathrm{xH}_{2} \mathrm{O}\right.$, and 0.1 mmol $\mathrm{Na}_{3} \mathrm{IrCl}_{6} \cdot \mathrm{xH}_{2} \mathrm{O}$ ) were first dissolved in $2 \mathrm{~mL}$ DMF to form solution A. $2 \mathrm{~mL}$ DMF and $0.18 \mathrm{~g} \mathrm{H}_{2} \mathrm{O}$ were mixed to form solution $\mathrm{B}$. Both solution A and solution $\mathrm{B}$ were sealed and chilled in a refrigerator for $2 \mathrm{~h}$. Then, a clean stirring bar was put into solution A. $1 \mathrm{~mL}$ solution B and $0.5 \mathrm{~mL}$ propylene oxide were simultaneously dripped into solution A under stirring. The mixed solution was then sealed and aged for 1 day and black precipitates would appear. After that, the solution and precipitates were transferred into a vial and were immersed in acetone for 3 days, followed by 
1 propylene oxide. The as-prepared powder was dried in vacuum and then ground 2 carefully. Afterward, the black powder was placed into a tube furnace and annealed at $500^{\circ} \mathrm{C}$ in the air for $1 \mathrm{~h}$ to obtain the SrRuIr oxide catalysts. The synthesis of catalysts

4 with different Sr:Ru:Ir ratios used the same procedure with SrRuIr. The total amount of metal salt precursors was kept as $0.9 \mathrm{mmol}$ and the ratio of different precursors was varied. For the RuIr (feed ratio 5:1) and SrRu (feed ratio 3:5) samples, the same synthesis procedure was used.

Characterizations of catalysts. The high-resolution transmission electron microscopy (HR-TEM) images and corresponding energy-dispersive X-ray spectroscopy (EDX) elemental mapping were obtained from a JEOL-2100F TEM equipped with an Oxford energy disperse spectrometer. The high-angle annular dark-field scanning transmission electron microscopy (HAADF-STEM) images and corresponding EDX mappings were captured on a JEOL JEM-ARM200F aberration-corrected TEM. The X-ray photoelectron spectroscopy (XPS) measurements were conducted on a PHI 5300 X-ray photoelectron spectrometer, with a monochromatic $\mathrm{Mg} \mathrm{K} \alpha \mathrm{X}$-ray sources (1253.6 eV). The XPS data was further analyzed using CasaXPS software. The binding energy was calibrated by C $1 \mathrm{~s}(284.6 \mathrm{eV})$.

Electrochemical measurements. Electrochemical measurements were performed in a three-electrode system by a potentiostat (Metrohm Autolab M204), using saturated $\mathrm{Hg} / \mathrm{Hg}_{2} \mathrm{SO}_{4}$ electrode $\left(\mathrm{E}^{\theta}=0.652 \mathrm{~V}\right.$ vs. $\mathrm{RHE}$ at $\left.25^{\circ} \mathrm{C}\right)$ as the reference electrode and platinum foil as the counter electrode. To prepare the catalyst film on glassy carbon electrodes (GCE, $3 \mathrm{~mm}$ in diameter), $5 \mathrm{mg}$ catalyst and $2 \mathrm{mg}$ carbon black were dispersed in $1 \mathrm{~mL}$ mixture of water and ethanol $(4: 1, v / v)$, and then $40 \mu \mathrm{L}$ of $5 \mathrm{wt} . \%$ Nafion ${ }^{\circledR}$ solution was added. The suspension was immersed in an ultrasonic bath for at least 60 min to obtain a homogeneous ink. After that, $4.5 \mu \mathrm{L}$ of the catalyst ink was carefully deposited onto the GCE (catalyst loading $0.32 \mathrm{mg} \mathrm{cm}^{-2}$ ). For electrochemical measurements on CPs, the catalysts were sprayed onto CPs using an airbrush. $15 \mathrm{mg}$ catalysts and $3 \mathrm{mg}$ carbon black were first dispersed in $2 \mathrm{~mL}$ isopropanol, and then 30 $\mu \mathrm{L}$ of 5 wt. \% Nafion ${ }^{\circledR}$ solution was added. After at least 60 min sonication, the homogeneous ink was sprayed onto $2 \mathrm{~cm} \times 2 \mathrm{~cm} \mathrm{CP}$ heated to $70^{\circ} \mathrm{C}$. The $\mathrm{CPs}$ were weighed before and after airbrush and the total catalyst loading were controlled at $c a$. $1.5 \mathrm{mg} \mathrm{cm}^{-2}$.

To assess the OER catalytic activity, the working electrode was first scanned from 0.2 to $0.9 \mathrm{~V} v s . \mathrm{Hg} / \mathrm{Hg}_{2} \mathrm{SO}_{4}$ at a rate of $50 \mathrm{mV} \mathrm{s}^{-1}$ for 10 cycles to achieve stable cyclic voltammetry $(\mathrm{CV})$ scans in $0.5 \mathrm{M} \mathrm{H}_{2} \mathrm{SO}_{4}(\mathrm{pH}=0.3)$. Then linear sweep voltammetry 38 (LSV) with a rate of $10 \mathrm{mV} \mathrm{s}^{-1}$ was measured. All measurements were conducted at 39 room temperature. All potentials were referred to the reversible hydrogen electrode (RHE) by the following calculations: 


$$
E_{\mathrm{RHE}}=E_{\mathrm{Hg}_{\mathrm{H}} \mathrm{Hg}_{2} \mathrm{SO}_{4}}+0.652+0.0591 \times p H=E_{\mathrm{Hg} / \mathrm{Hg}_{2} \mathrm{SO}_{4}}+0.6697
$$

All the potentials were applied a $95 \%$ iR compensation. The uncompensated solution resistances were measured by electrochemical impedance spectra (EIS), which were conducted at a bias of $1.40 \mathrm{~V} v \mathrm{~s}$. RHE in the frequency range from $100 \mathrm{kHz}$ to $10 \mathrm{mHz}$ with an amplitude of $5 \mathrm{mV}$.

The steady-state Tafel plots were measured by chronoamperometry on rotation disk electrodes $(1,600 \mathrm{rpm})$. The sample was held at constant potential from $1.25 \mathrm{~V}$ to $1.75 \mathrm{~V}$ $v s$. RHE with a step of $20 \mathrm{mV}$. Each potential step was retained for $10 \mathrm{~s}$ to reach stable and the final current was recorded.

10 ECSA was deduced from electrochemical double-layer capacitance $\left(\mathrm{C}_{\mathrm{dl}}\right)$ by dividing 11 a factor of $0.035 \mathrm{mF} \mathrm{cm} \mathrm{cm}^{-2}$, according to the previous report ${ }^{2}$. The measurement of $\mathrm{C}_{\mathrm{dl}}$ 12 was carried out by cyclic voltammetry (CV) at the non-Faradic region. The catalysts 13 were scanned at a range of +0.25 to $+0.35 \mathrm{~V} v s$. $\mathrm{Hg} / \mathrm{Hg}_{2} \mathrm{SO}_{4}$ using elevated scan rates. 14 Both anodic and cathodic current at $0.3 \mathrm{~V}$ vs. $\mathrm{Hg} / \mathrm{Hg}_{2} \mathrm{SO}_{4}$ were plotted against scan rates (Error! Reference source not found. and Error! Reference source not found.). Then, linear fitting was adopted to these points, and the average slope of anodic and cathodic plots represented the value of $\mathrm{C}_{\mathrm{dl}}$.

To eliminate the interference of bubble accumulation and mechanical peeling of catalysts, the OER stability was evaluated on carbon paper by chronopotentiometry at $10 \mathrm{~mA} \mathrm{~cm}^{-2}$ geo. The electrochemical cell was placed in a $25^{\circ} \mathrm{C}$ thermostatic water bath. The electrolyte was replaced every four days to keep the $\mathrm{pH}$ of the electrolyte stable. All v-t plots were $95 \%$ iR-compensated. To verify the stability of our test platform in harsh acidic conditions, we first carried out the chronopotentiometry on $\mathrm{IrO}_{2}$. The overpotential of $\mathrm{IrO}_{2}$ was quite stable. We manually stopped the test after $70 \mathrm{~h}$. This result confirms that the decay of activity mainly comes from the catalysts in our experiments. In the calculation of the degradation rate, we regarded the first $10 \%$ of the total test time as burning time, ensuring the catalysts reaching stable.

The stability number (S-number) was calculated according to ref. ${ }^{3}$, using the following equation:

$$
S_{-} \text {number }=\frac{n_{o_{2}}}{n_{\text {noble metal }}}
$$

Where $n_{\mathrm{O}_{2}}$ is the molar number of total oxygen evolved within a certain period of time (calculated from total charge), $n_{\text {noble metal }}$ is the total noble metal dissolved measured by ICP-OES.

ICP-OES analysis of the ion dissolution. The dissolution of catalysts during OER process was quantified by inductively coupled plasma optical emission spectrometry (ICP-OES, iCAP7400, Thermo Fisher). The catalyst was air-brushed onto carbon paper with a catalyst loading of $c a .1 .5 \mathrm{mg} \mathrm{cm}^{-2}$ and electrolysis at $10 \mathrm{~mA} \mathrm{~cm}{ }^{-2}$ (Specifically, the sample demonstrated in Figure $2 \mathrm{f}$ was $1 \mathrm{~cm}^{2}$ in area). A low volume $(10 \mathrm{~mL})$ of 
1 electrolyte was used to fulfill the limit of detection of the equipment. The electrolyte

2 was sampled after $0.5 \mathrm{~h}, 2 \mathrm{~h}, 6 \mathrm{~h}, 12 \mathrm{~h}$ and $24 \mathrm{~h}$ electrolysis. At each sampling point, $4 \mathrm{~mL}$

3 of electrolyte was taken out for ICP measurement and refilled to $10 \mathrm{~mL}$ with clean

4 electrolyte before the next sampling period.

X-ray absorption spectroscopy. Ex-situ $\mathrm{Ru} \mathrm{K}$-edge and $\mathrm{Ir} \mathrm{L}_{3}$-edge XANES and EXAFS of post-OER catalysts were performed in fluorescent mode at BL14W1 beamline of Shanghai Synchrotron Radiation Facility (SSRF), using a Si(311) monochromator. The in situ $\mathrm{Ru} \mathrm{K}$-edge and $\mathrm{Ir} \mathrm{L}_{3}$-edge measurements were carried out at 1W1B beamline in Beijing Synchrotron Radiation Facility (BSRF). A home-made triangular electrochemical cell was used, which was equipped with a three-electrode configuration. The electrochemical cell was placed in the middle of the optical path with an incident angle of $45^{\circ}$. The working electrodes were prepared by spray coating the catalysts on carbon paper. During the in-situ measurements, chronoamperometry processes at $1.35 \mathrm{~V} v s$. RHE were employed and the fluorescent mode was used to acquire data. The energy of Ru K-edge was calibrated by Ru foil and the energy of Ir $\mathrm{L}_{3}$-edge was calibrated by $\mathrm{Pt}$ foil. The in-situ $\mathrm{Ru} \mathrm{L}_{3}$-edge XAS spectra were acquired at SXRMB beamline in Canadian Light Source (CLS), Canada. To perform the in-situ soft X-ray measurements, the electrochemical cell was carefully sealed and placed in the helium atmosphere to reduce X-rays attenuation. All XAS data were processed and normalized by ATHENA software included in IFEFFIT software package ${ }^{4}$. As to the fitting and simulation of EXAFS data, the ARTEMIS software and FEFF8.5 codes were used. The detailed discussion of EXAFS fitting is presented in Supplementary note 2.

Differential electrochemical mass spectroscopy (DEMS) measurements. DEMS measurements were carried out to determine the ${ }^{18} \mathrm{O}$-labeled volatile reaction products of SrRuIr and $\mathrm{RuO}_{2}$ catalysts during OER process using a QAS 100 device (Linglu Instruments, Shanghai). A saturated $\mathrm{Ag} / \mathrm{AgCl}$ electrode and a $\mathrm{Pt}$ wire were used as reference electrode and counter electrode, respectively. The working electrodes were prepared by sputtering Au onto $50 \mu \mathrm{m}$ thick porus PTFE films. Then, the catalysts were drop cast onto the Au with a loading mass of $0.65 \mathrm{mg} \mathrm{cm}^{-2}$. First, the catalysts were labeled with ${ }^{18} \mathrm{O}$ isotopes by performing $5 \mathrm{CV}$ cycles at a scan rate of $5 \mathrm{mV} / \mathrm{s}$ in ${ }^{18} \mathrm{O}$-labed $0.5 \mathrm{M} \mathrm{H}_{2} \mathrm{SO}_{4}$ (Since the activity of SrRuIr was much higher than $\mathrm{RuO}_{2}$, so the potential window was $1 \mathrm{~V}-1.35 \mathrm{~V}$ vs. $\mathrm{Ag} / \mathrm{AgCl}$ for $\mathrm{SrRuIr}$ and $1 \mathrm{~V}-1.6 \mathrm{~V}$ vs. $\mathrm{Ag} / \mathrm{AgCl}$ for $\mathrm{RuO}_{2}$. So that both catalysts can reach a similar current for direct comparison.). Afterwards, ${ }^{18} \mathrm{O}$-labeled electrodes were rinsed with ${ }^{16} \mathrm{O}$ water for five times to remove the remaining $\mathrm{H}_{2}{ }^{18} \mathrm{O}$. Finally, the electrodes were carried out $\mathrm{CV}$ cycles in ${ }^{16} \mathrm{O} \mathrm{H}_{2} \mathrm{SO}_{4}$ solution at the above potential window and scan rate. At the mean time, gas products of different molecular weights generated during OER process were measured in real time by mass spectroscopy. Since catalysts were thoroughly rinsed 
with ${ }^{16} \mathrm{O}$ water after ${ }^{18} \mathrm{O}$-labelling, it is unlikely that ${ }^{18} \mathrm{O}$ species adsorbed on the surface

2 contribute substantially to the observed ${ }^{34} \mathrm{O}_{2}\left({ }^{16} \mathrm{O}^{18} \mathrm{O}\right)$ signals. Thus, it can be determined to investigate the participation of lattice oxygen from catalysts in OER by measuring the ${ }^{34} \mathrm{O}_{2}$ signals.

In situ Raman spectroscopy. The in situ electrochemical Raman spectroscopy measurements were carried out to investigate the participation of lattice oxygen during OER. The spectra were acquired by a Horiba XploRA Raman spectrometer equipped with a $50 \times$ objective and $20 \mathrm{~mW} 532 \mathrm{~nm}$ laser. The collection was carried out at $20 \mathrm{~s}$ exposure time averaged over 5 exposures. A home-made PTFE electrochemical cell was used in the in situ measurements. The thickness of the electrolyte layer was controlled at $\sim 0.6 \mathrm{~mm}$. A saturated $\mathrm{Ag} / \mathrm{AgCl}$ electrode and a $\mathrm{Pt}$ wire were used as reference electrode and counter electrode, respectively. The working electrodes were prepared by drop-casting the catalysts ink onto a $0.25 \mathrm{~mm}$ thick Ti foil (Alfa Aesar). The Raman spectra were collected along with the chronoamperometry measurements. The applied potential was elevated from OCP to $1.4 \mathrm{~V}$ vs. RHE. For each potential, at least three different points were measured. The above measurements were carried out in both ordinary $0.5 \mathrm{M} \mathrm{H}_{2} \mathrm{SO}_{4}$ and ${ }^{18} \mathrm{O}$ labeled $\mathrm{H}_{2} \mathrm{SO}_{4}$ solution.

PEM electrolyzer test. A catalyst-coated membrane (CCM) method was used to prepare the anode layer of the membrane electrode assembly (MEA). The anode catalyst was first dispersed in a mixture of isopropanol and Nafion ${ }^{\circledR}$ solution, and the ionomer amount was $20 \mathrm{wt}$. \%. After adequate sonication, the homogeneous inks were sprayed onto a piece of $50 \mu \mathrm{m}$ polytetrafluoroethylene (PTFE) film. The CCM was obtained by transferring the catalyst layer from the PTFE film to a Nafion ${ }^{\circledR}$ NR212 membrane using the decal method $\left(140^{\circ} \mathrm{C}, 2.5 \mathrm{Mpa}\right.$ for $\left.2 \mathrm{~min}\right)$. The CCM was then boiled in $0.5 \mathrm{M} \mathrm{H}_{2} \mathrm{SO}_{4}$ and DI water to remove impurities. For cathode, a catalystcoated diffusion layer was used. $40 \% \mathrm{Pt} / \mathrm{C}$ was used as a cathodic catalyst and sprayed onto a Freudenberg H23C9 gas diffusion layer. The ionomer amount in the cathode was 30 wt. \%. The mass loadings were controlled at $2 \mathrm{mg}_{\mathrm{cat}} \mathrm{cm}^{-2}$ and $0.2 \mathrm{mg}_{\mathrm{Pt}} \mathrm{cm}^{-2}$ for anodic and cathodic catalysts, respectively. A porous sintering Ti plate was used as porous transport layer (PTL) for anode. Finally, the cell was integrated by pressing cathodic diffusion layer, CCM, PTL and two Ti end-plate with flow field together. The active area was regarded as $2.85 \mathrm{~cm}^{2}$, which was the area covered by the serpentine flow channel. During the test, the cell was maintained at $80^{\circ} \mathrm{C}$, and the pre-heated DI water was fed to the anode at a flow rate of $40 \mathrm{ml} \mathrm{min}^{-1}$. Before the polarization test, the cell was activated for $1 \mathrm{~h}$ at $1 \mathrm{~A} \mathrm{~cm}^{-2}$. The steady-state polarization curve was collected at galvanostatic mode from 0.1 to $2 \mathrm{~A} \mathrm{~cm}^{-1}$. Each step was $0.1 \mathrm{~A} \mathrm{~cm}^{-1}$ and maintained for 1 min until the cell voltage was stable. 


\section{Supplementary Notes}

\section{Supplementary Note 1: Turnover frequency (TOF) calculations}

In this work, the measurements of TOF for different catalysts were carried out on glassy carbon electrodes (GCE).

TOF is defined as the frequency of reaction on per active site, which is used to compare the intrinsic activity of different catalysts. TOF value in this study was calculated by the equation:

$$
\text { TOF }=\frac{j \times A \times \eta}{4 \times e \times n}
$$

where $j$ is the current density at overpotential $=300 \mathrm{mV}$ after $95 \% \mathrm{iR}$ compensation and capacitance current correction, $A$ is the geometric area of GCE $\left(0.0706 \mathrm{~cm}^{2}\right), \eta$ is the Faradic efficiency and $e$ is the charge of electron $\left(1.602 \times 10^{-19} \mathrm{C}\right)$ and $n$ is the number of active site.

We determined the active site number $n$ via the total loading mass by assuming all nobel metall atoms as active sites (underestimating case), according to the following equation:

$$
n_{\text {mass }}=\frac{m_{\text {loading }} \times N_{A}}{M w} \times n_{R u}
$$

where $m_{\text {loading }}$ is the loading mass. $N_{A}$ is Avogadro's constant $\left(6.022 \times 10^{23} \mathrm{~mol}^{-1}\right)$, $M w$ is the molecular weight of catalysts and $n_{R u}$ is the number of Ru atom per molar of catalysts.

As can be seen in Supplementary Table 5, the activity trends are SrRuIr $\geq \operatorname{SrRu} \geq$ $\mathrm{RuIr} \geq \mathrm{RuO}_{2} \geq \mathrm{IrO}_{2}$. The above result verified the high intrinsic activity of SrRuIr.

\section{Supplementary Note 2: XAS measurements and analysis}

For Ru K-edge data, the absorption edge energy $\mathrm{E}_{0}$ of pure $\mathrm{Ru}$ foil was aligned to $22117 \mathrm{eV}$. $\mathrm{E}_{0}$ of $\mathrm{Ru}$ foil was assigned by the first maximum of first-derivative X-ray absorption near-edge structures (XANES) spectrum. All data were aligned according to the standard $\mathrm{Ru}$ foil. For $\mathrm{Ir}_{3}$-edge data, a Pt foil was used as a standard sample. The $\mathrm{E}_{0}$ of $\mathrm{Pt}_{\mathrm{L}_{3}}$-edge was assigned to $11564 \mathrm{eV}$. All Ir $\mathrm{L}_{3}$-edge data was calibrated according to the standard Pt sample. The spectra plotted in $k$-space demomstrated good signal-tonoise ratio (Supplementary Figure 44).

The wavelet transform of extended X-ray absorption fine structure (WT-EXAFS) analysis is a useful method to identify scatters from different elements with similar bond lengths, which were very suitable to the multi-metal system like SrRuIr ${ }^{5-6}$. In this work, the WT-EXAFS diagram was performed by WTEXAFS software written by Zhaoming Xia ${ }^{7}$. We used the Morlet wavelet to perform the transformation of EXAFS. Two parameters $\eta$ and $\sigma$ can be adjusted in the Morlet wavelet function to achieve the best spatial resolution. Usually, the range of parameters is $4 \leq \eta \leq 15,0.4 \leq \sigma \leq 2$, respectively ${ }^{6}$. We adopted $\eta=6.8, \sigma=0.5$ for Ru K-edge and $\eta=8.5, \sigma=1$ for Ir $L_{3^{-}}$ 
1 edge during the analysis of SrRuIr. Besides, combining ab initio FEFF calculation with

2 WT analysis could achieve more accurate results ${ }^{8}$. Unfortunately, due to the similar atomic number and small doping quantity, the $\mathrm{Ru}-\mathrm{Sr}$ scattering could hardly be identified from WT-EXAFS, as was illustrated by ab initio calculation of scattering paths (Supplementary Figure 19).

The simulation of the EXAFS spectra of SrRuIr was carried out by the FEFF 8.5 codes embedded in the Artemis software. The crystallographic information file (CIF) of $\mathrm{RuO}_{2}$, was used as primary models to calculate raw scattering paths ${ }^{9}$. Ru-Ir, Ru-Sr, and Ir-Ru scattering paths were created by replacing corresponding $\mathrm{Ru}$ atoms in the FEFF input file (Supplementary Figure 45 and Supplementary Figure 46). The experimental spectra were fitted by raw scattering paths at a k-range of 3.5 to $13.5 \AA^{-1}$, and selected path and fitting parameters are presented in Supplementary Table 9.

The following criteria were adopted during the fits to rationalize and simplify the process:

(i) The passive electron reduction factor $\mathrm{S}_{0}^{2}$ was set as the same for all paths;

(ii) Energy shifts of $\mathrm{E}_{0}$ for $\mathrm{Ru}$, Ir, and $\mathrm{Sr}$ were set as the same;

(iii) One mean squared displacement $\sigma_{\mathrm{i}}{ }^{2}$ was used for $\mathrm{Ru}$, $\mathrm{Ir}$, and $\mathrm{Sr}$;

(iv) For the first shell fitting of Ru K-edge, two O scattering paths were used, and the degeneracy $(\mathrm{N})$ ratio was set as 1:2, representing two kinds of oxygen atoms in the octahedron;

(v) The $\mathrm{N}$ ratio of $\mathrm{Ru}$ :Ir was set as 4:1, according to atomic ratio $\mathrm{Ru}: \mathrm{Ir}=5: 1$ (the scattering center was the fifth $\mathrm{Ru}$ atom);

(vi) The degeneracy of second shell $\mathrm{O}$ was fixed at 4 .

(vii) The $\mathrm{N}$ value of $\mathrm{Sr}$ after reaction could hardly be determined, so we set $\mathrm{N}_{\mathrm{Sr}}=0.25 \times \mathrm{N}_{\mathrm{Ru}}$, which was the most stable ratio according to the theoretic Pourbaix diagram.

(viii) The Ir-Sr scattering path was not considered in $\mathrm{Ir}_{3}$-edge fitting, for the possibility of Ir-Sr scattering was very low at such low doping concentration.

\section{Supplementary Note 3: Leaching of $\mathrm{Sr}$}

Leaching of $\mathrm{Sr}$ and its impact are discussed in many papers involving $\mathrm{Sr}$ oxides and perovskites. For example, Seitz et al. argued that the $\mathrm{Sr}$-deficient $\mathrm{IrO}_{\mathrm{x}} / \mathrm{SrIrO}_{3}$ surface was highly active towards OER ${ }^{10}$, while Chang et al. pointed out that the chemical corrosion of $\mathrm{Sr}$ atom was induced by the formation of unstable $\mathrm{Ru}^{\mathrm{n}+}(\mathrm{n}>4)$ in Strontium Ruthenate ${ }^{11}$.

In this work, we examined the status of $\mathrm{Sr}$ in SrRuIr both theoretically and experimentally. During the DFT materials screening, we found that the doping of Ir does not alter the $\mathrm{RuO}_{2}$ lattice significantly while increasing the doping of $\mathrm{Sr}$ will induce the structural distortion (Supplementary Figure 38). This is reasonable since the similar lattice parameters of Ru oxides and Ir oxides, but Sr oxides are much different. 
1 This hinted that the structural order may increase once $\mathrm{Sr}$ leached from the materials.

2 In the Pourbaix diagram calculations, we noticed that the most OER active $\operatorname{Sr}_{2} \mathrm{Ru}_{5} \mathrm{Ir}_{1} \mathrm{O}_{16}$

3 phase is not stable under OER condition, part of $\mathrm{Sr}$ will leach into the solution and form

4 a stable $\mathrm{Sr}-\mathrm{Ru}$-Ir ternary phase $\left(\mathrm{Sr}_{1} \mathrm{Ru}_{6} \mathrm{Ir}_{1} \mathrm{O}_{16}\right.$ phase in our DFT prediction).

To verify the DFT predictions, we carefully examined the content of $\mathrm{Sr}$ in $\mathrm{SrRuIr}$ catalyst after OER. According to the time-dependent ICP-OES data (Figure 2f), the content of Sr in the material didn't change significantly after 12 h OER. The Sr:Ru:Ir ratio was around 0.33:5:1 after $24 \mathrm{~h}$ OER. The XPS survey of Sr 3d demonstrated similar results: The surface $\mathrm{Sr}: \mathrm{Ru}$ :Ir ratio is 0.44:5:1.95 after 12-h OER and 0.38:5:1.60 after $24 \mathrm{~h}$ (Supplementary Table 12). Along with the OER process, surface Sr decreased and almost disappeared after 24 hours, while most of the lattice $\mathrm{Sr}$ were retained after 24 h OER $^{12}$ (Supplementary Figure 39). The STEM-EDX mapping of SrRuIr after 24 $\mathrm{h}$ OER also demonstrated the presence of $\mathrm{Sr}$ in the catalysts (Supplementary Figure 17), the $\mathrm{Sr}: \mathrm{Ru}: \mathrm{Ir}$ ratio was quantified as $0.36: 5: 1.14$. All three methods showed similar results on the content of $\mathrm{Sr}$, which indicated that a stable $\mathrm{Sr}$ - $\mathrm{Ru}$-Ir ternary phase may form during OER process, as was predicted by DFT calculations. The composition of this phase can be roughly described as $\mathrm{Sr}_{0.35} \mathrm{Ru}_{5} \mathrm{Ir}_{1.2} \mathrm{O}_{\mathrm{x}}$ (calculated according to the average ratio of ICP, EDX and XPS).

The effect of $\mathrm{Sr}$ leaching towards the electronic structure of active $\mathrm{Ru}$ sites was then examined by the theoretical PDOS calculations (Figure 4c). As Sr decreased, the donation of the unoccupied $e_{\mathrm{g}}$ state into $\mathrm{Ru} \mathrm{d}$ band decreased accordingly. The Bader charge of the active Ru sites also decreased (Supplementary Table 13), indicating less high-valence Ru sites could form, thus leading to the drop of OER activity. Additionally, as indicated by the HR-TEM and EXAFS after OER (Supplementary Figure 17 and Supplementary Figure 21), the leaching of Sr may lead to an increase in the size and crystallinity of SrRuIr catalysts, which may also account for the activity loss.

\section{Supplementary Note 4: The effect of solvent in DFT calculations}

To investigate the effect of solvent during OER and its impact on the dissolution of $\mathrm{Sr}$ and $\mathrm{Ru}$ ions, we calculated the OER pathway of $\mathrm{RuO}_{2}$ based on explicit solvent models (Supplementary Figure 36). These models include two monolayers of $\mathrm{H}_{2} \mathrm{O}$ molecules. The energetics of these models are presented in Supplementary Figure 37. The theoretical overpotential does not change significantly compared to the models without solvent.

The effect of solvent on OER is also discussed by Norskov et al. on the (110) surface of $\mathrm{IrO}_{2}$ using explicit solvent models ${ }^{13}$. They concluded that the energetics of the reaction pathway are relatively unchanged with the inclusion of explicit solvent, which is close to our results. The predictions of OER activity by DFT are not strongly affected by solvent. 
1 Supplementary Figures (Supplementary Figure 1-

2 Supplementary Figure 46)

3
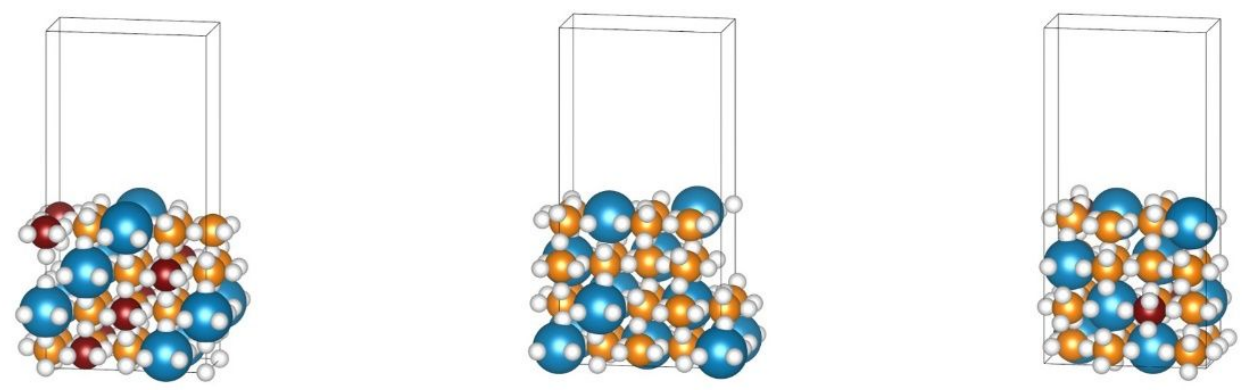

$\mathrm{Sr}_{1} \mathrm{Ru}_{6} \mathrm{Ir}_{1} \mathrm{O}_{16}$

$$
\mathrm{Sr}_{2} \mathrm{Ru}_{6} \mathrm{O}_{16}
$$

$\mathrm{Sr}_{2} \mathrm{Ru}_{5.5} \mathrm{Ir}_{0.5} \mathrm{O}_{16}$
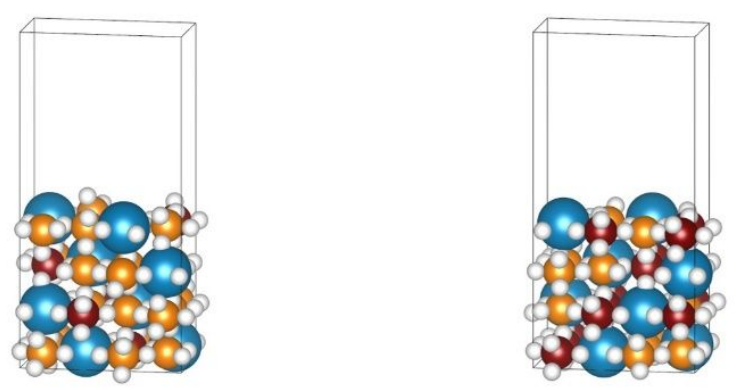

$\mathrm{Sr}_{2} \mathrm{Ru}_{5} \mathrm{Ir}_{1} \mathrm{O}_{16}$

$\mathrm{Sr}_{2} \mathrm{Ru}_{3.5} \mathrm{Ir}_{2.5} \mathrm{O}_{16}$

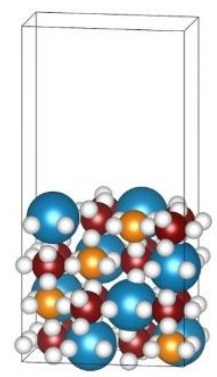

$\mathrm{Sr}_{2} \mathrm{Ru}_{1.5} \mathrm{Ir}_{4.5} \mathrm{O}_{16}$
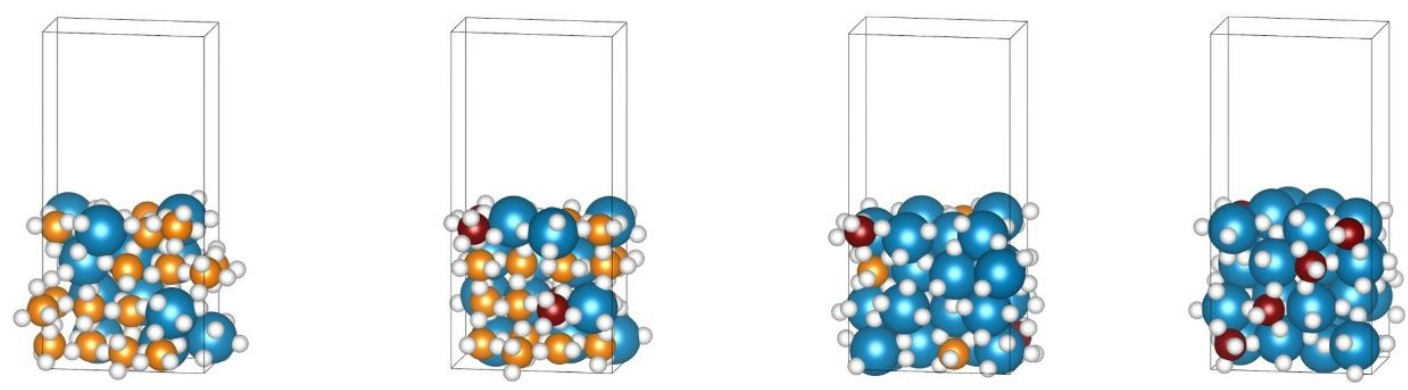

$$
\mathrm{Sr}_{3} \mathrm{Ru}_{5} \mathrm{O}_{16}
$$

$\mathrm{Sr}_{3} \mathrm{Ru}_{4} / \mathrm{r}_{1} \mathrm{O}_{16}$

$\mathrm{Sr}_{6} \mathrm{Ru}_{1} \mathrm{Ir}_{1} \mathrm{O}_{16}$

$\mathrm{Sr}_{6} \mathrm{Ir}_{2} \mathrm{O}_{16}$

5 Supplementary Figure 1 | Optimal surface structures of SrRuIr oxide with

6 different $\mathrm{Sr}-\mathrm{Ru}-\mathrm{Ir}$ ratios. Blue balls $-\mathrm{Sr}$, orange balls $-\mathrm{Ru}$, brown balls $-\mathrm{Ir}$, white 7 balls $-\mathrm{O}$. 


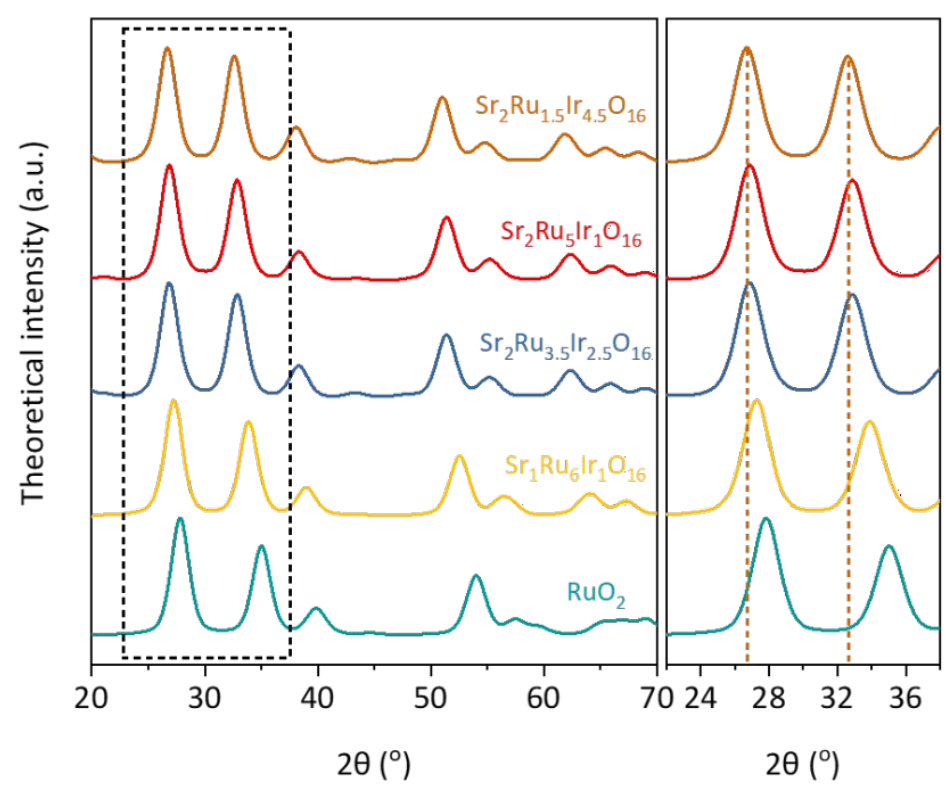

1

2 Supplementary Figure 2 | Simulated XRD patterns from the DFT models. Crystal 3 sizes of $50 \mathrm{~nm} \times 50 \mathrm{~nm} \times 50 \mathrm{~nm}$ are used to calculate peak broadening. The dot lines 4 at $27^{\circ}$ and $33^{\circ}$ represent (110) and (101) diffraction of rutile, respectively. 5

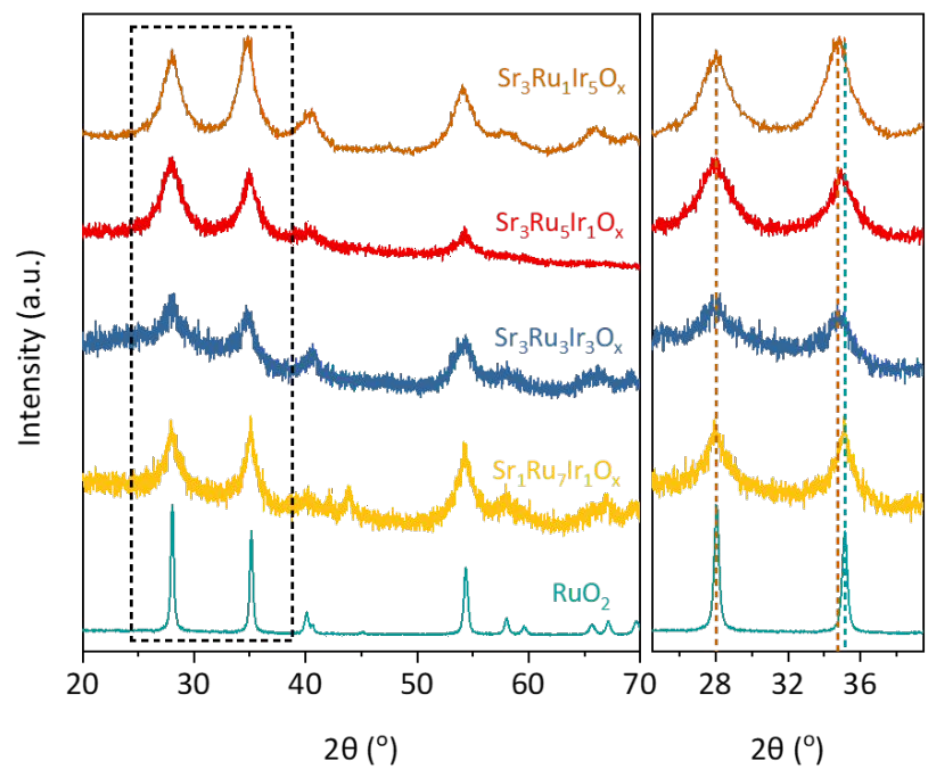

7 Supplementary Figure 3 | XRD patterns of a series of Sr-Ru-Ir ternary oxide 8 catalysts. Note that the $\mathrm{Sr}-\mathrm{Ru}$-Ir ratios are the feed ratios during catalyst synthesis. The 9 dot lines at $28^{\circ}$ and $35^{\circ}$ represent (110) and (101) diffraction of rutile, respectively. 

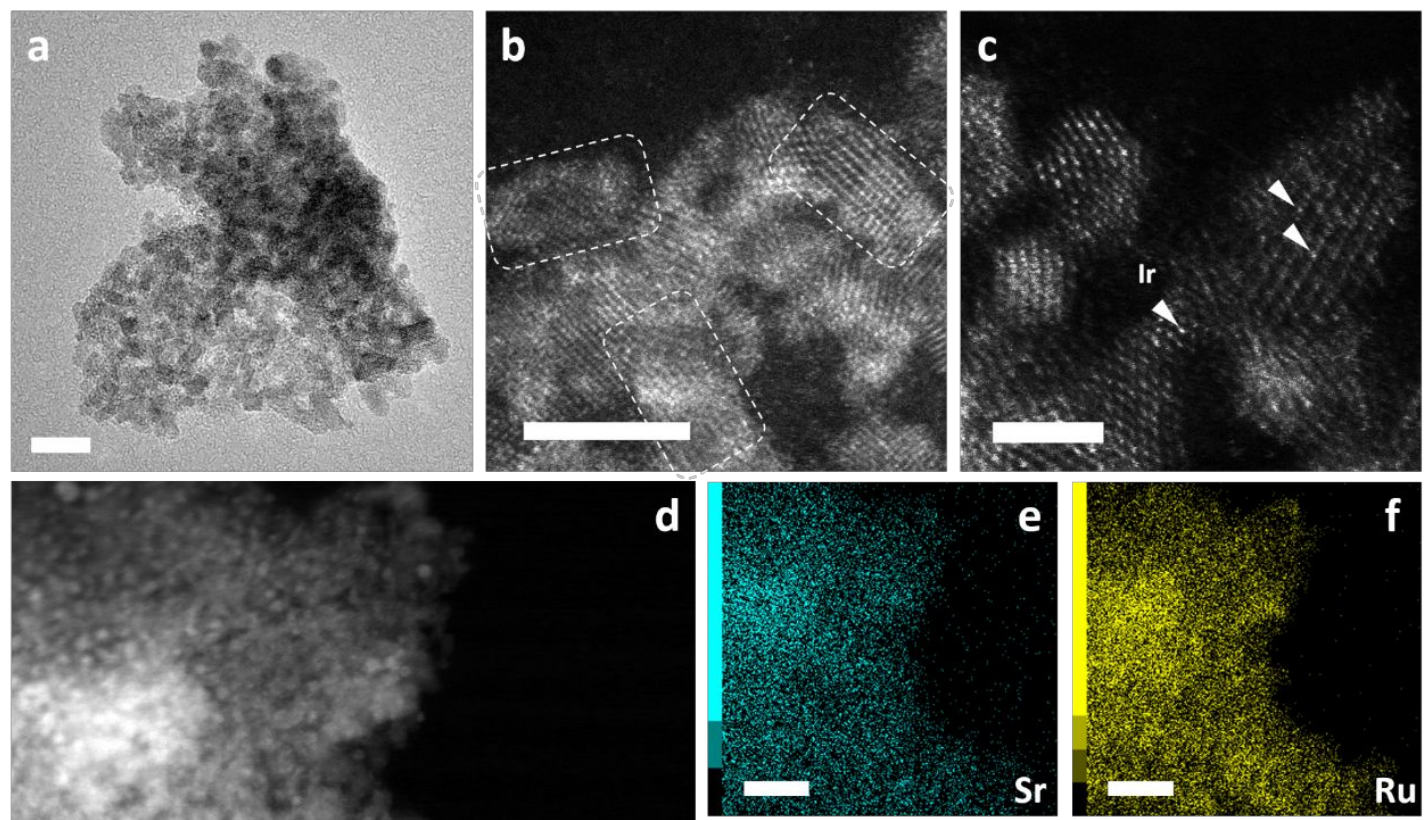

e
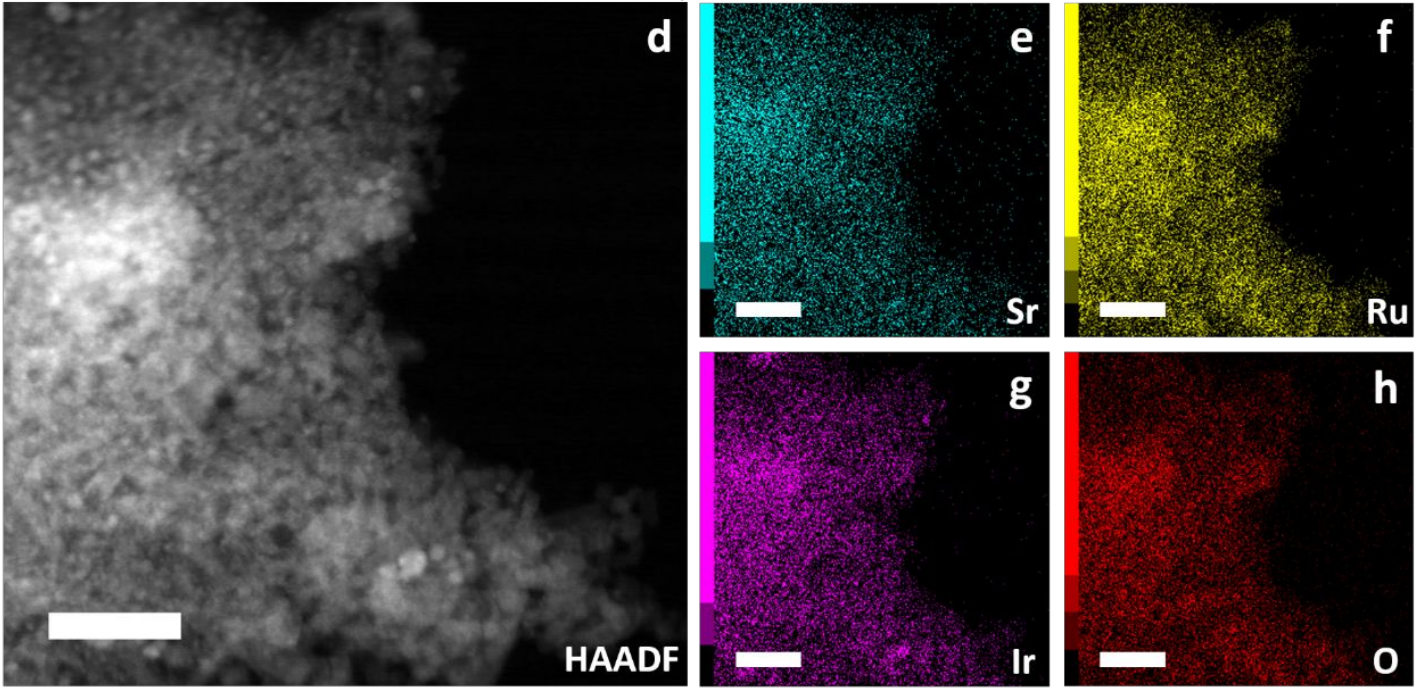

Supplementary Figure 4 | Morphology of as-prepared SrRuIr oxide catalysts. (a)

3 HR-TEM image of SrRuIr. Scale bar: $10 \mathrm{~nm}$. (b-c) Atomic resolution HAADF-STEM

4 image of SrRuIr. Scale bar: $5 \mathrm{~nm}$ for $\mathbf{b}$ and $2 \mathrm{~nm}$ for $\mathbf{c}$. The bright spot in the lattice can

5 be assigned to Ir dopants. Note that some oxide particles were reduced to metallic $\mathrm{Ru}$

6 (or Ir) due to beam damage. (d-h) HAADF-STEM image and corresponding EDX

7 elemental mapping.

8 

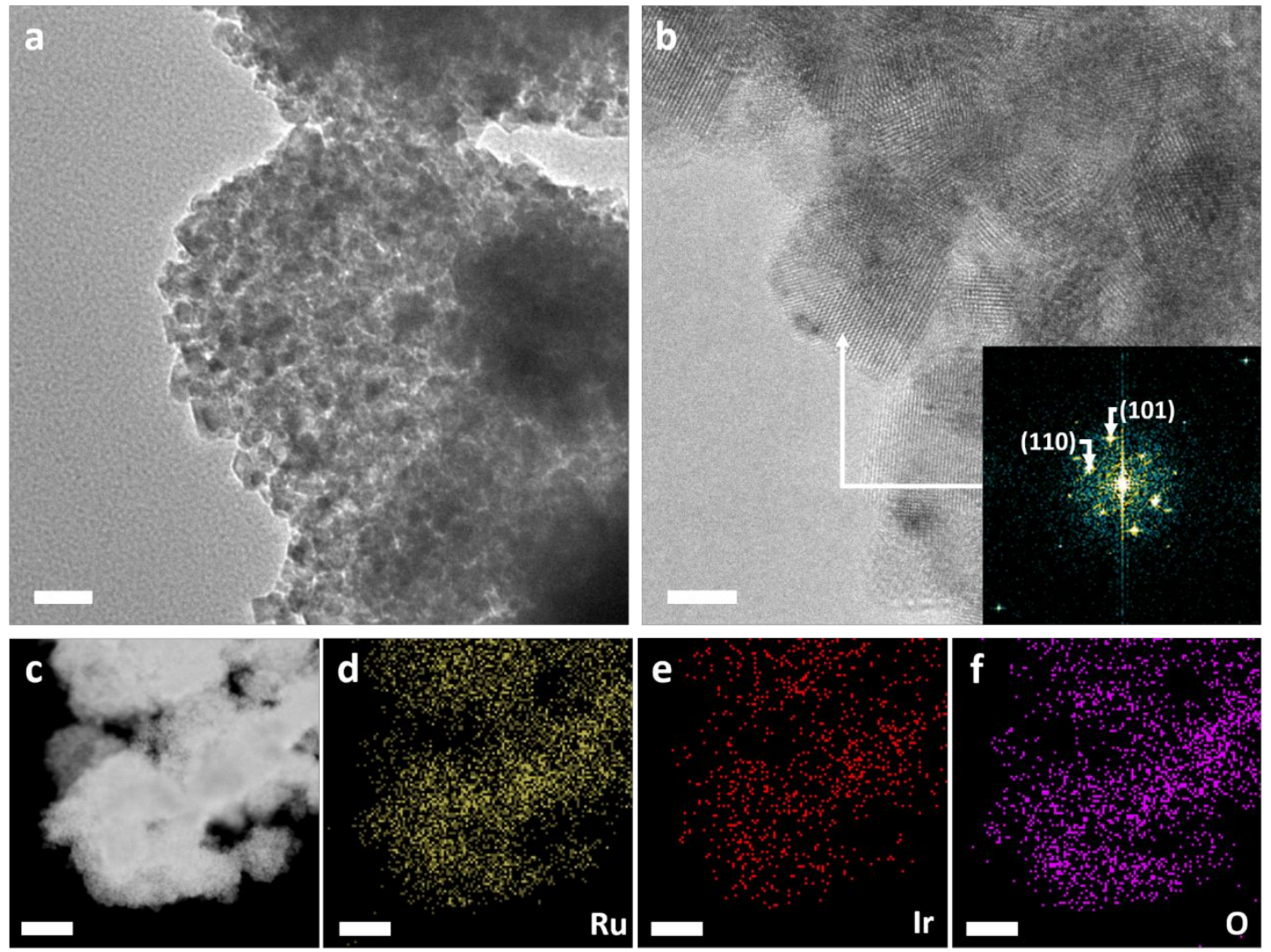

2 Supplementary Figure 5 | The TEM images RuIr oxide catalysts. (a) The TEM 3 image of RuIr oxide. Scale bar: $20 \mathrm{~nm}$. (b) The HR-TEM image of RuIr. Inset: The fast 4 Fourier transformed (FFT) pattern from the nanoparticle can be indexed to (110) and 5 (101) plane of rutile structure. Scale bar: $5 \mathrm{~nm}$ (c-f) HAADF-STEM image and 6 corresponding EDX elemental mapping indicated a homogeneous dispersion of $\mathrm{Ru} \mathrm{Ir}$ 7 and O. Scale bar: $100 \mathrm{~nm}$. 

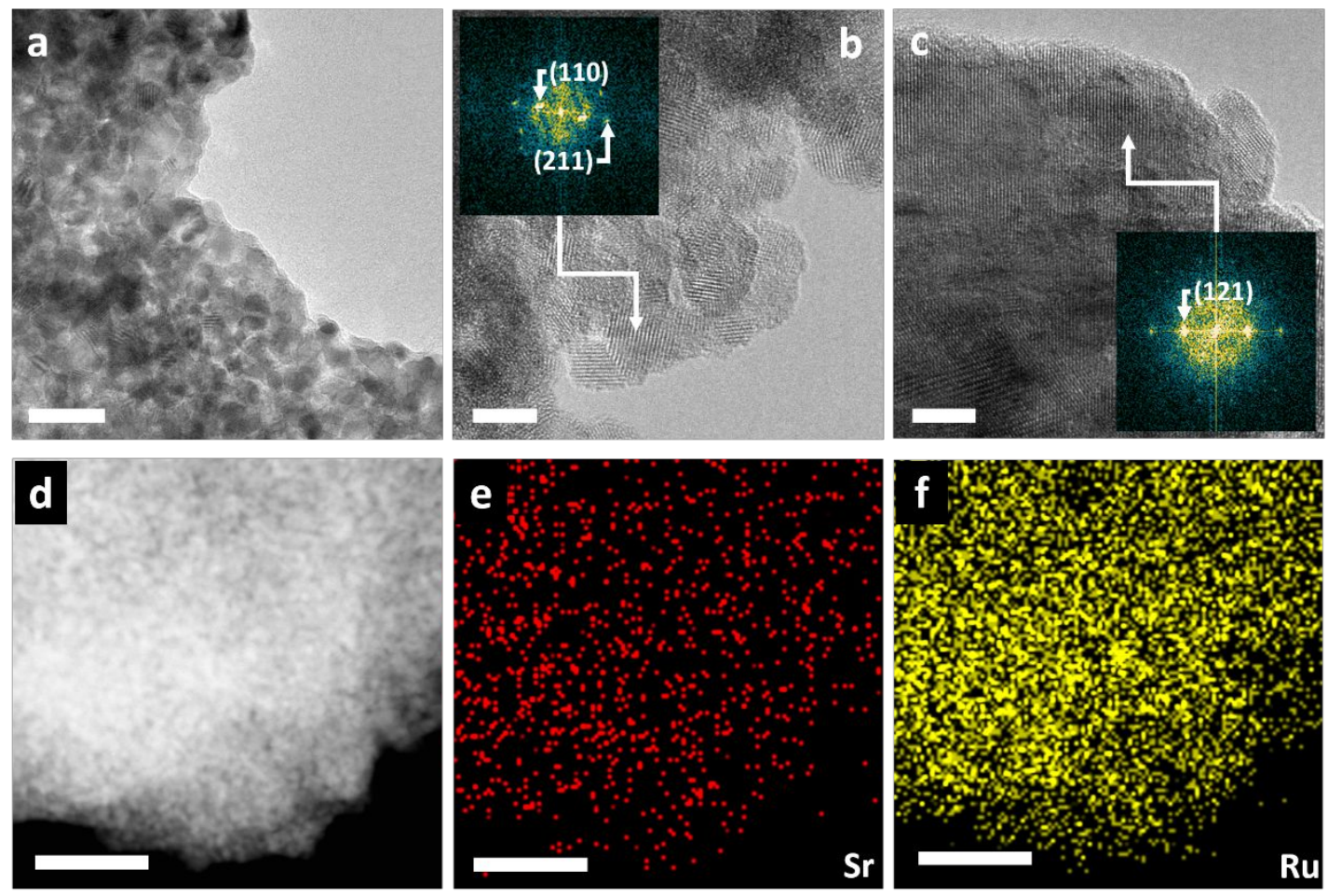

Supplementary Figure 6 | The TEM images of SrRu oxide catalysts. (a) The TEM 3 image of SrRu oxide. Scale bar: $20 \mathrm{~nm}$. (b) The HRTEM image of rutile part. Inset: 4 The FFT pattern from the nanoparticle can be indexed to (110) and (211) planes of 5 rutile structure. Scale bar: $5 \mathrm{~nm}$ (c) The HRTEM image of perovskite part. Inset: Scale bar: $5 \mathrm{~nm}$. (d-f) HAADF-STEM image and corresponding EDX elemental mapping indicating a homogeneous dispersion of $\mathrm{Sr}$ and $\mathrm{Ru}$. Scale bar: $50 \mathrm{~nm}$.

a

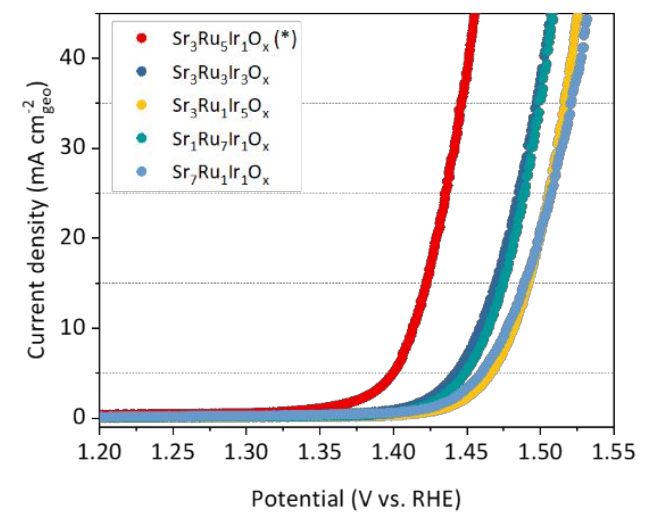

b

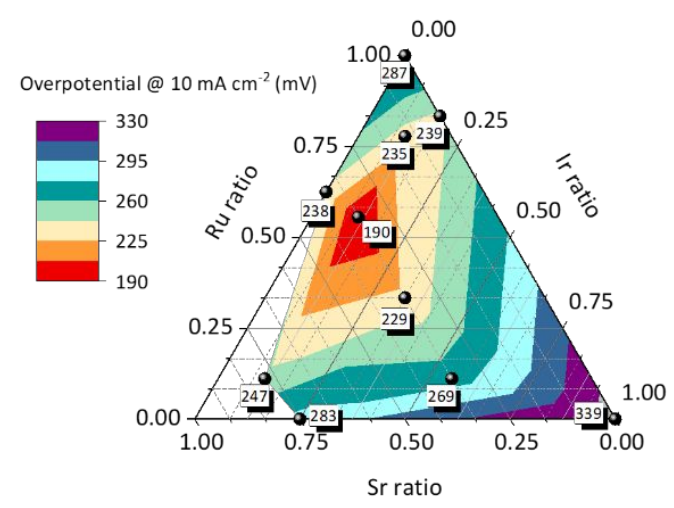

Supplementary Figure 7 | OER polarization curves of Sr-Ru-Ir catalysts with different ratios. (a) The OER polarization curves of representative ternary catalysts. The marked (*) feed ratio was denoted SrRuIr in the main text. (b) Summary of the overpotential of different catalysts. Measured at $10 \mathrm{mV} \mathrm{s}^{-1}$ scan rate, with $95 \%$ iRcompensation. 
a

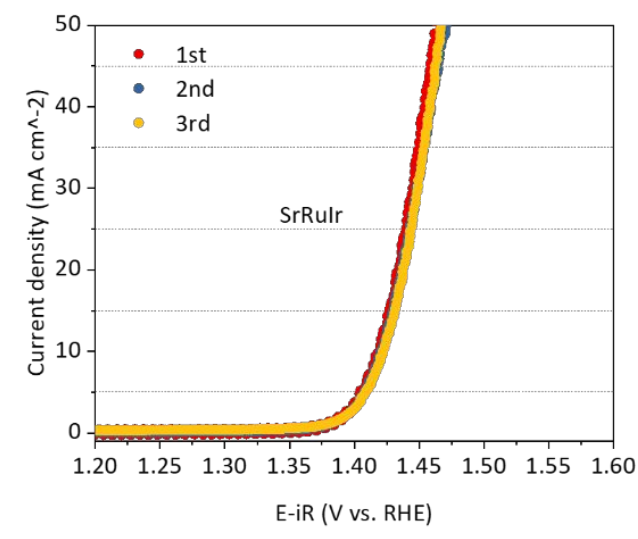

c

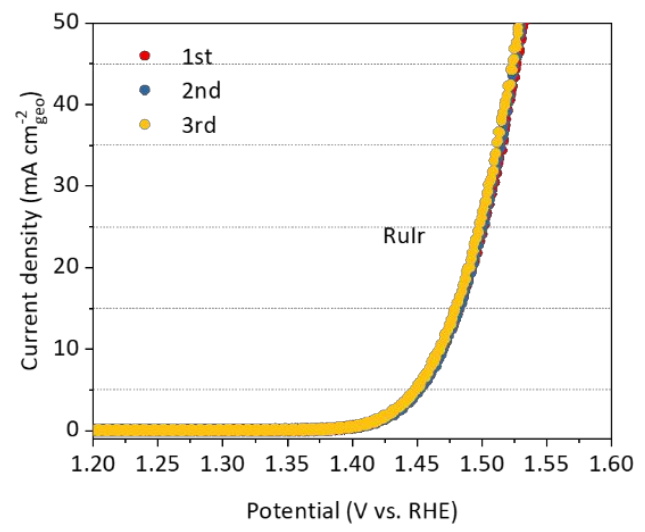

e

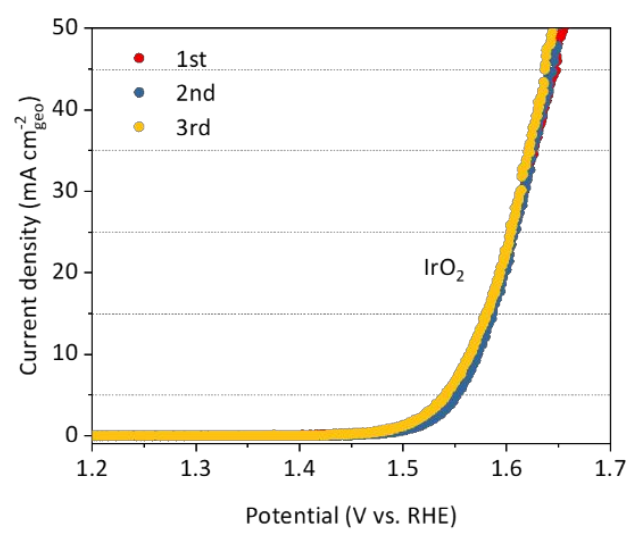

b

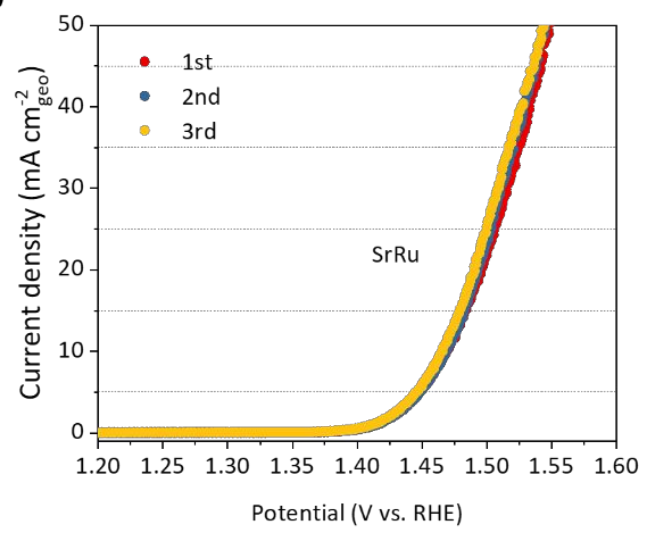

d

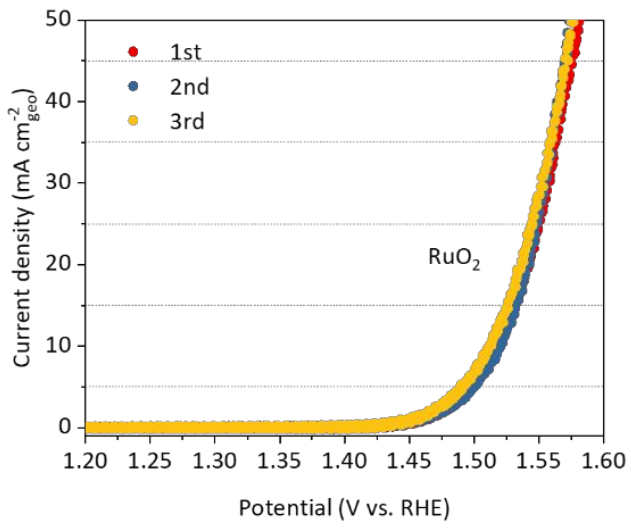

Supplementary Figure 8 | Repeatability of linear sweep voltammetry (LSV) scans

3 for different catalysts. (a) $\mathrm{SrRuIr}$, (b) SrRu, (c) $\mathrm{RuIr}$, (d) $\mathrm{RuO}_{2}$ and (e) $\mathrm{IrO}_{2}$. Measured

4 on GCE. Scan rate: $10 \mathrm{mV} \mathrm{s}^{-1}$, with $95 \%$ iR-compensation. At least three independent scans were carried out on different catalysts. The average overpotential at $10 \mathrm{~mA} \mathrm{~cm}^{-2}$ was reported in the main text. 


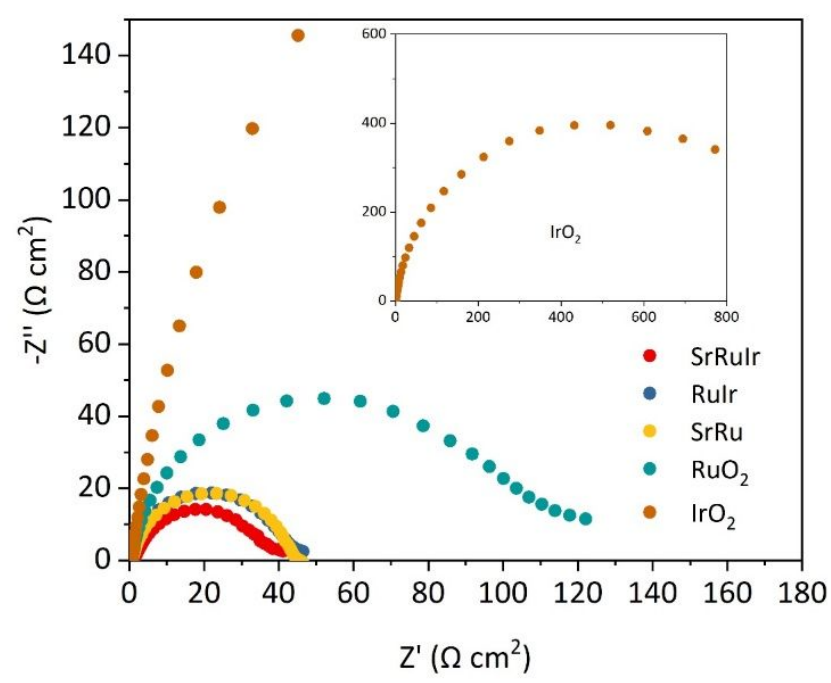

2 Supplementary Figure 9 | EIS spectra of different catalysts. Measured at $1.40 \mathrm{~V} v \mathrm{~s}$.

3 RHE. Inset: Full range spectrum of $\mathrm{IrO}_{2}$.

4

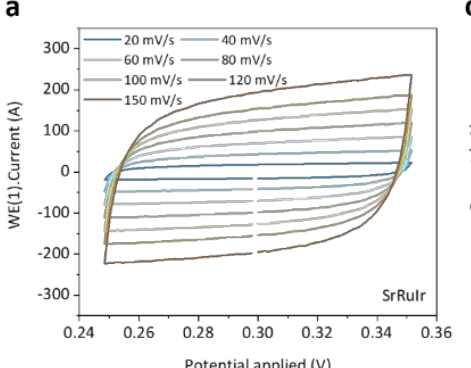

b

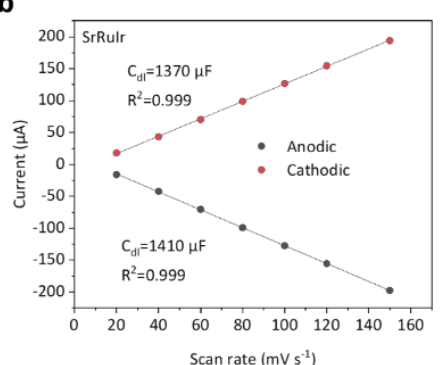

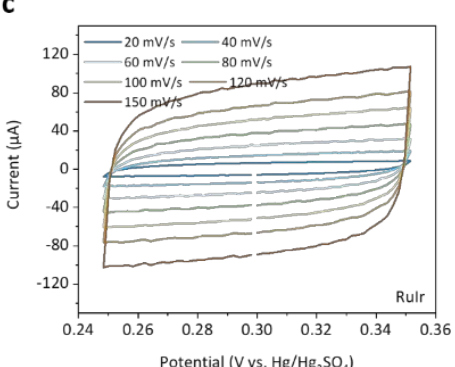

d

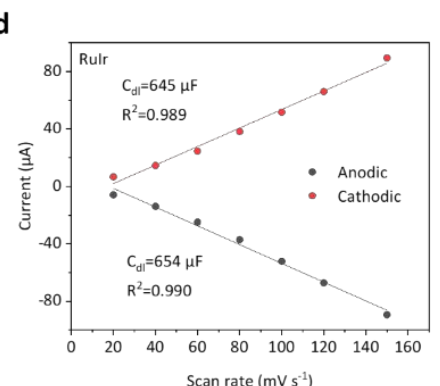

e

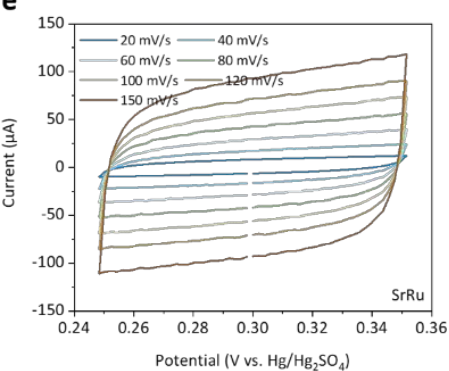

f

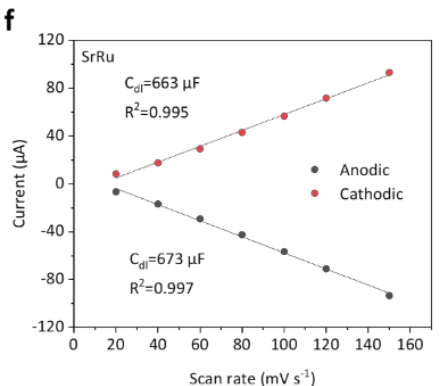

Supplementary Figure 10 | The measurement of $\mathbf{C}_{\mathrm{dl}}$ on different catalysts. The 7 ECSA for each electrode is (a-b) $39.7 \mathrm{~cm}^{2}$ for SrRuIr. (c-d) $18.6 \mathrm{~cm}^{2}$ for RuIr. (c-d) $8 \quad 19.1 \mathrm{~cm}^{2}$ for $\mathrm{SrRu}$. A specific capacitance of $35 \mu \mathrm{F} \mathrm{cm}-2$ was used in the calculations. 

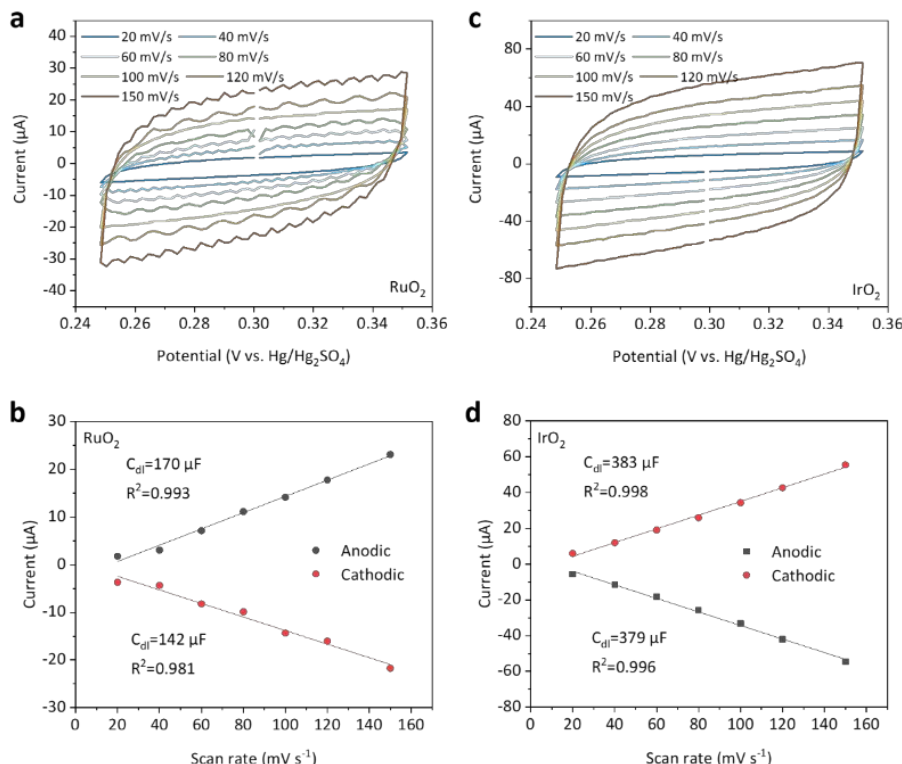

Supplementary Figure 11 The measurement of $\mathbf{C}_{\mathrm{dl}}$ on commercial catalysts. The 3 ECSA for each electrode is (a-b) $10.9 \mathrm{~cm}^{2}$ for $\mathrm{IrO}_{2}$. (c-d) $4.4 \mathrm{~cm}^{2}$ for $\mathrm{RuO}_{2}$. A specific 4 capacitance of $35 \mu \mathrm{F} \mathrm{cm} \mathrm{cm}^{-2}$ was used in the calculations.

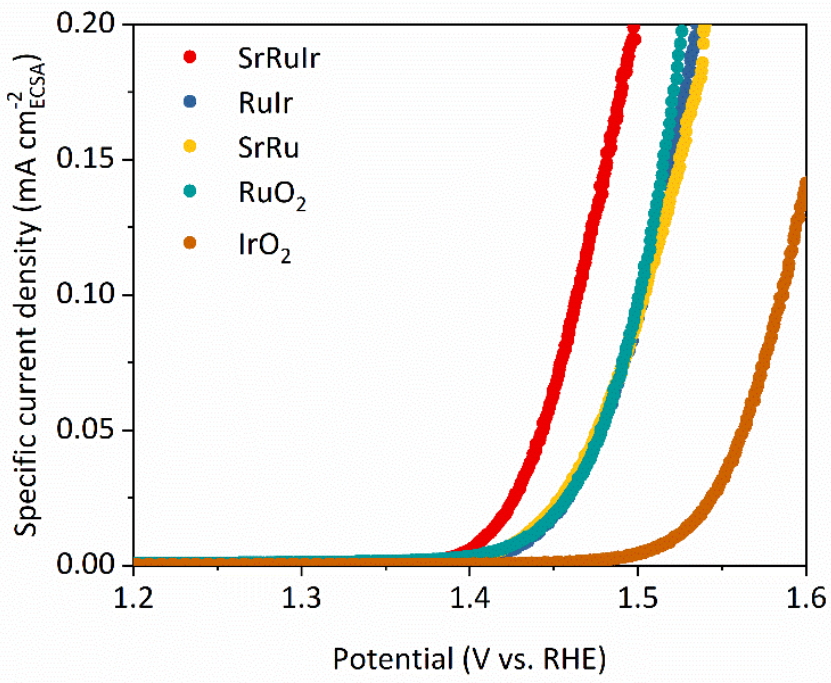

Supplementary Figure 12 | LSV curves normalized by ECSA of different catalysts.

8 The ECSA values were obtained from the double layer capacitance $\left(\mathrm{C}_{\mathrm{dl}}\right)$. The $\mathrm{C}_{\mathrm{dl}}$ values

9 were measured by conducting $\mathrm{CV}$ cycles at non-Faradic potential range at different scan 10 rate. 


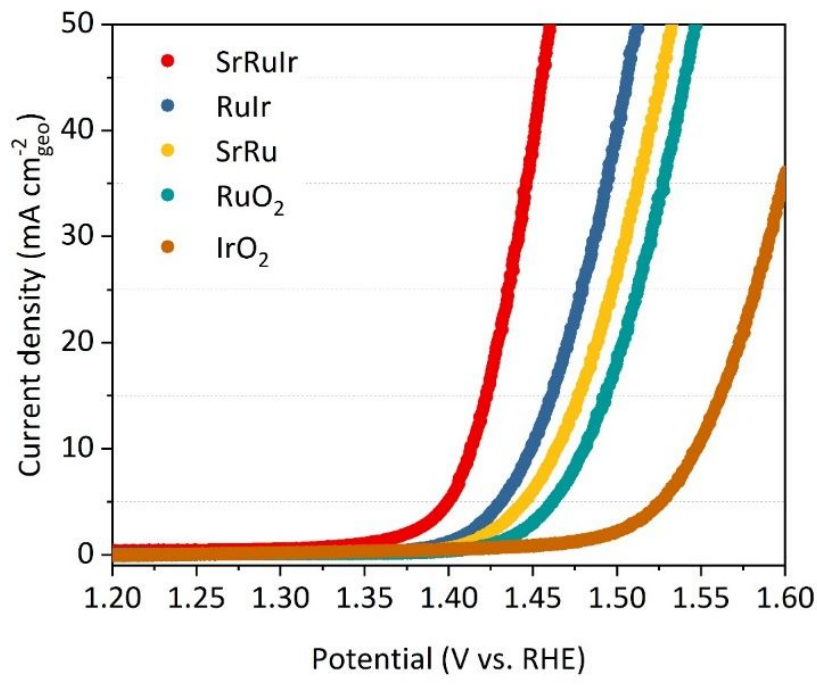

2 Supplementary Figure 13 | OER polarization curves of different catalyst measured 3 on carbon paper. Measured at $10 \mathrm{mV} \mathrm{s}^{-1}$ scan rate, $\mathrm{iR}$ compensated and capacitive 4 current corrected.

5

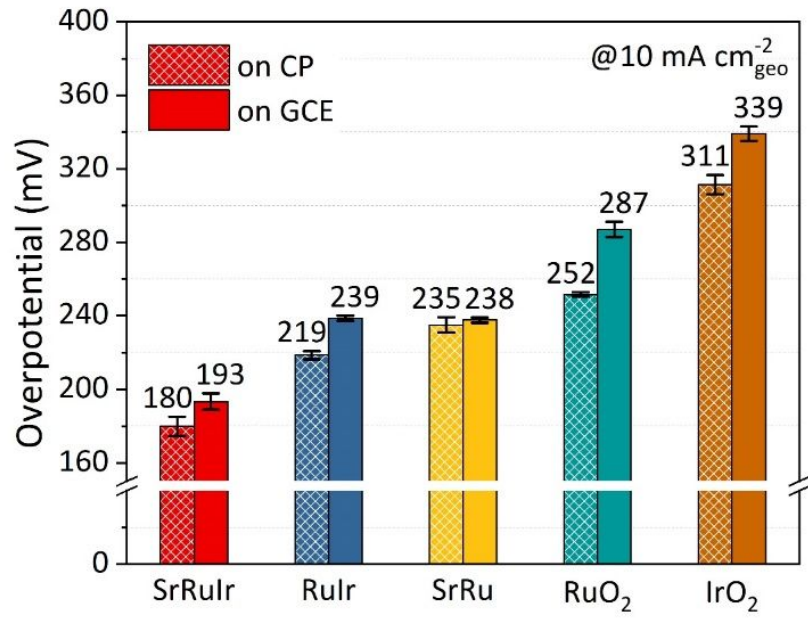

6

7 Supplementary Figure 14 | Summary of overpotential at $10 \mathrm{~mA} \mathrm{~cm}^{-2}$ geo on different 8 catalysts.

9 


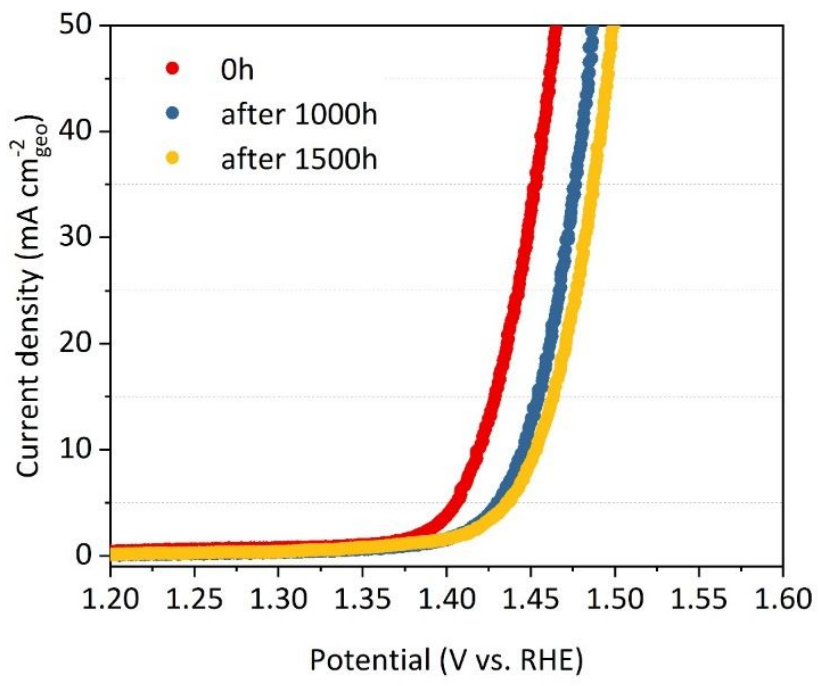

2 Supplementary Figure 15 | OER polarization curves of SrRuIr after long-term 3 operation.

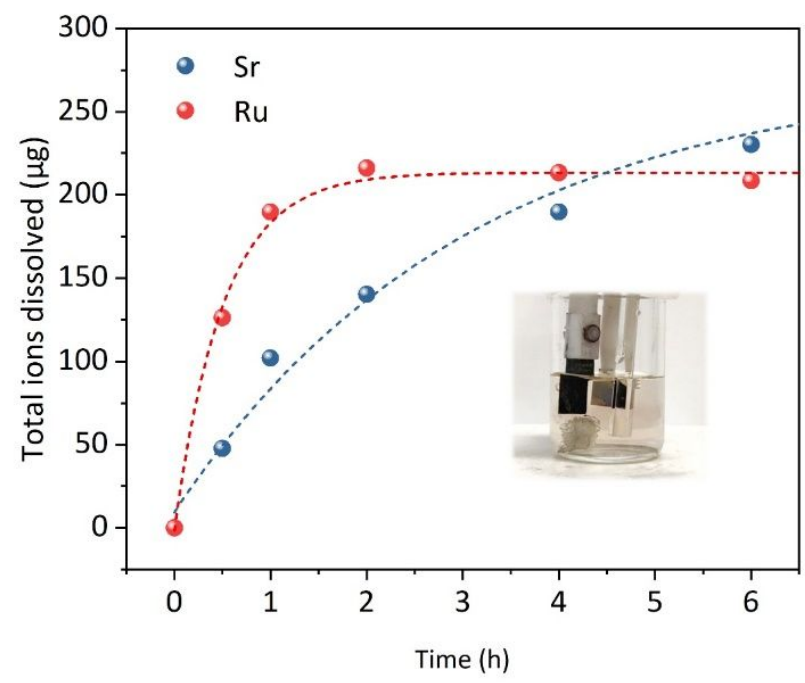

6 Supplementary Figure 16 | Ion dissolution of $\mathrm{SrRu}$ oxide. Both $\mathrm{Sr}$ and $\mathrm{Ru}$ were 7 leaching rapidly in SrRu. The solution even turned to brownish red after electrolysis, 8 indicating the formation and dissolution of high-valence $\mathrm{Ru}$ species (likely $\left.\mathrm{RuO}_{4}{ }^{2-}\right)^{14}$.

9 A low volume of electrolyte was used to (1) increase the concentration of ions for better 10 ICP-OES sensitivities and (2) make the color change of the electrolyte clearer. 

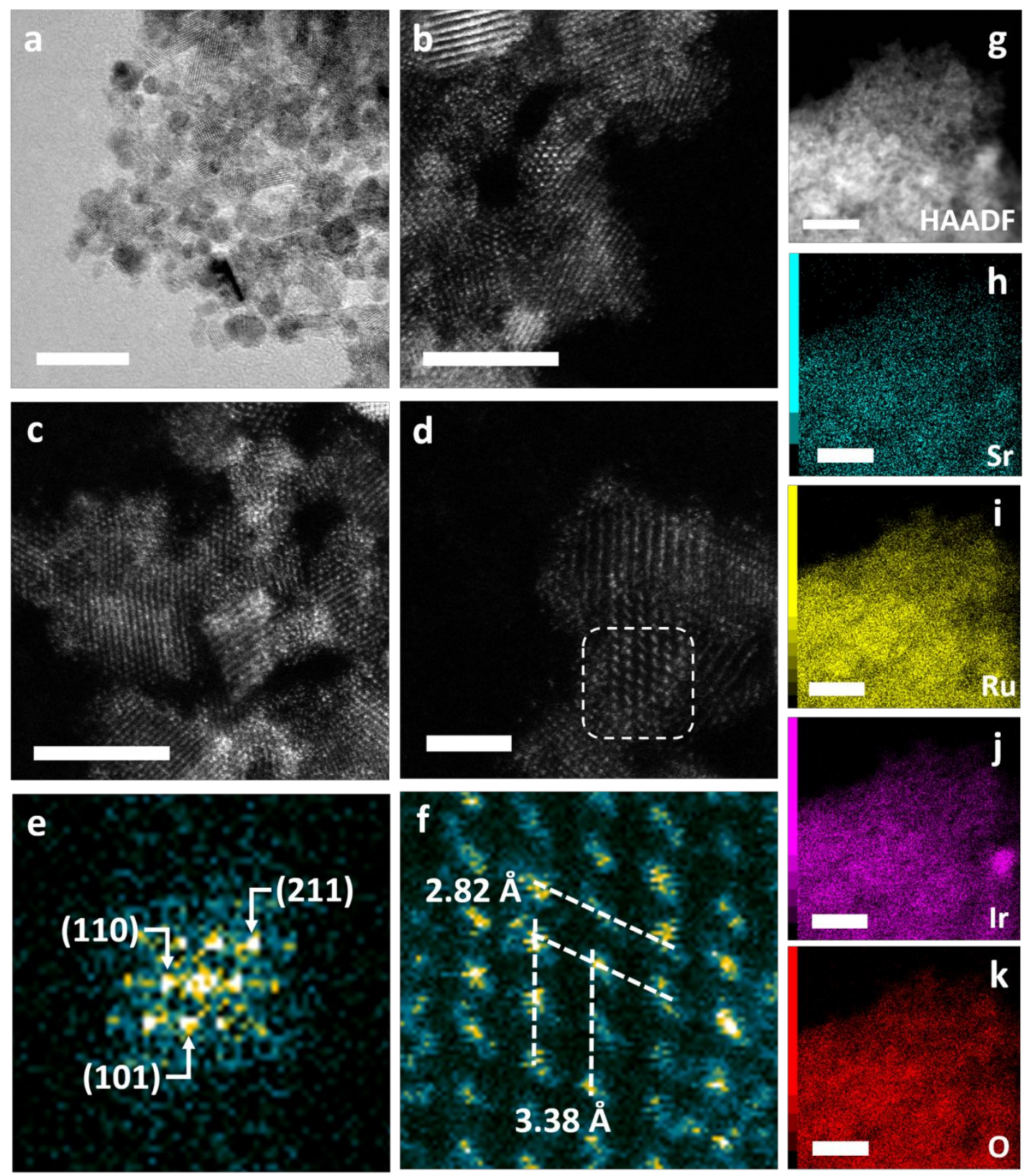

2 Supplementary Figure 17 | TEM study of SrRuIr catalysts after 24 h OER. (a) The

3 high-resolution TEM image of SrRuIr. Scale bar: $10 \mathrm{~nm}$ (b-d) Atomic resolution 4 HAADF-STEM image of SrRuIr. Scale bar: $5 \mathrm{~nm}$ for $\mathbf{b}, \mathbf{c}$ and $2 \mathrm{~nm}$ for $\mathbf{d}$. Note that 5 some oxide particles were reduced to metallic $\mathrm{Ru}$ (or Ir) due to beam damage. (e) The $6 \quad$ FFT of selected area in d. (f) The inverse FFT of e. The $d$-spacing were $3.38 \AA$ and 2.82 $7 \AA$ for (110) and (101) plane, respectively. These values are larger than the pristine $\mathrm{RuO}_{2}$ 8 (3.18 $\AA$ and $2.56 \AA$ ), which can be ascribed to the incorporation of $\mathrm{Sr}$ and Ir. (g-k) 9 HAADF-STEM image and corresponding EDX elemental mapping. Scale bar: $20 \mathrm{~nm}$. 


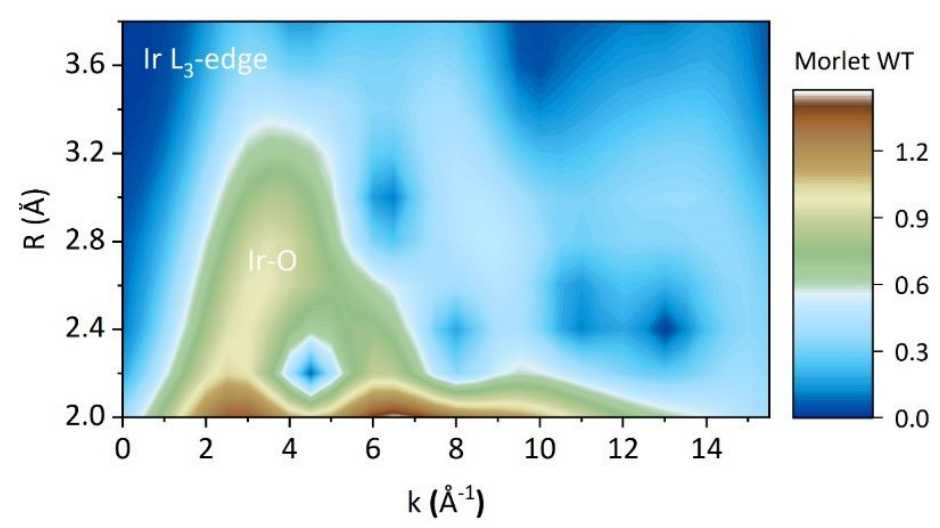

2 Supplementary Figure $18 \mid$ WT-EXAFS of $\operatorname{IrO}_{2}$. The Morlet function parameter was $3 \eta=7.4, \sigma=1$. In $\mathrm{IrO}_{2}$, the peak at $\mathrm{R} \approx 3.2 \AA, \mathrm{k} \approx 8.5 \AA^{-1}$ did not appear, indicating the $4 \mathrm{R} \approx 3 \AA, \mathrm{k} \approx 8.5 \AA^{-1}$ peak in SrRuIr came from $\mathrm{Ru}-\mathrm{Ir}$ scattering.

5

a

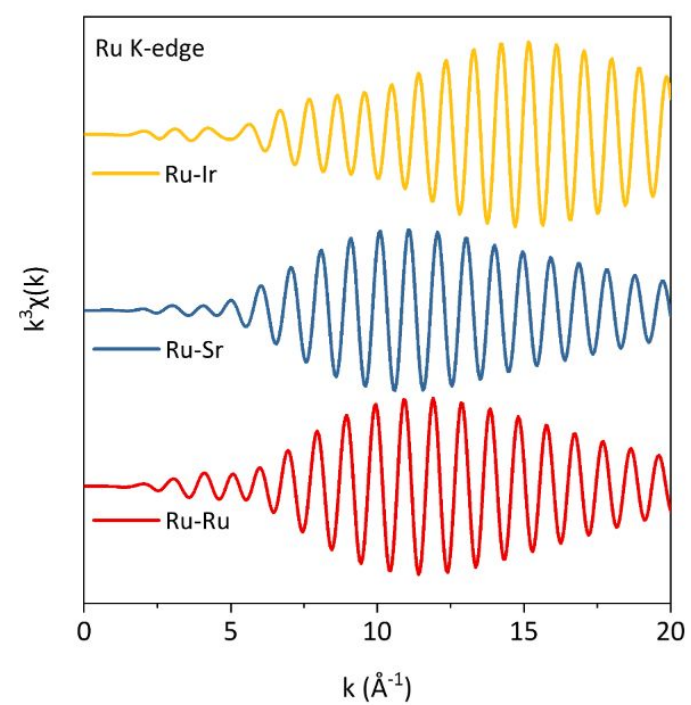

b

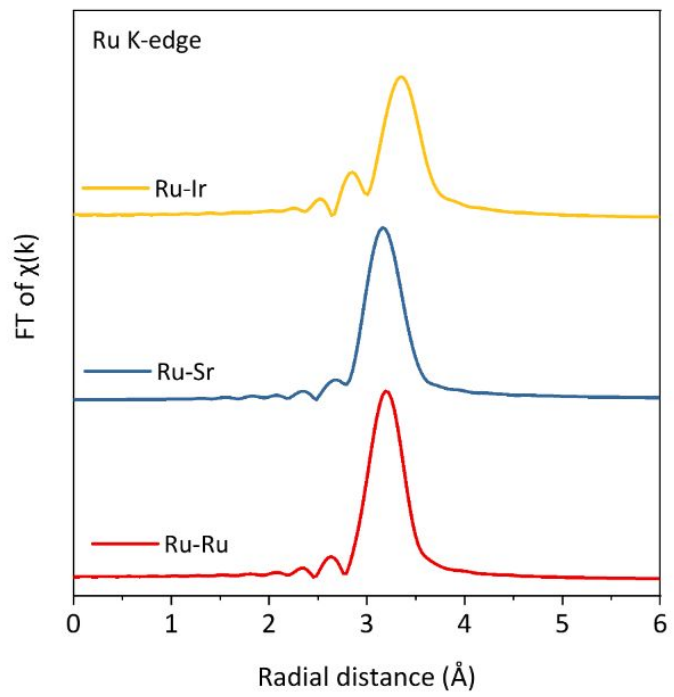

6

Supplementary Figure 19 | EXAFS scattering paths of Ru-Ru, Ru-Sr, Ru-Ir obtained by ab initio calculations. (a) The scattering path in $k$-space. (b) The scattering path in $R$-space. The maximum of $\mathrm{Ru}-\mathrm{Ru}$ and $\mathrm{Ru}-\mathrm{Sr}$ scattering path were both located at $\mathrm{k} \approx 11 \AA^{-1}, \mathrm{R} \approx 3.2 \AA$. While $\mathrm{Ru}$-Ir scattering path was located at $\mathrm{k} \approx 15$ $\AA^{-1}, \mathrm{R} \approx 3.5 \AA$. The difference between the maximum value of FT-EXAFS path and WT-EXAFS is due to the k-weight factor ${ }^{6}$. 
a

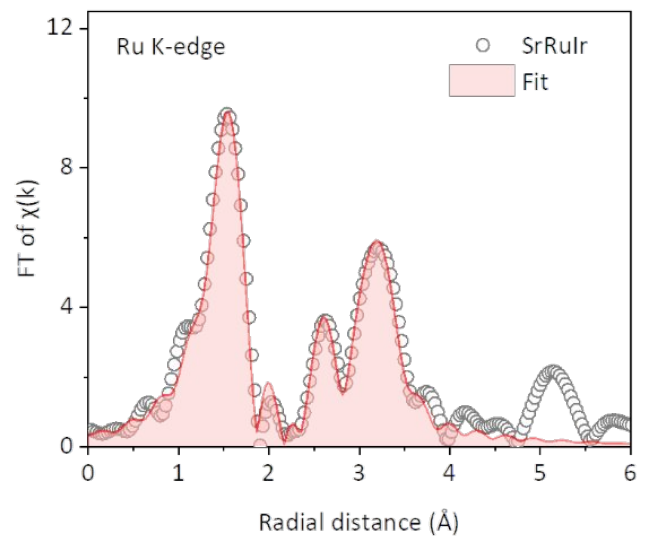

b

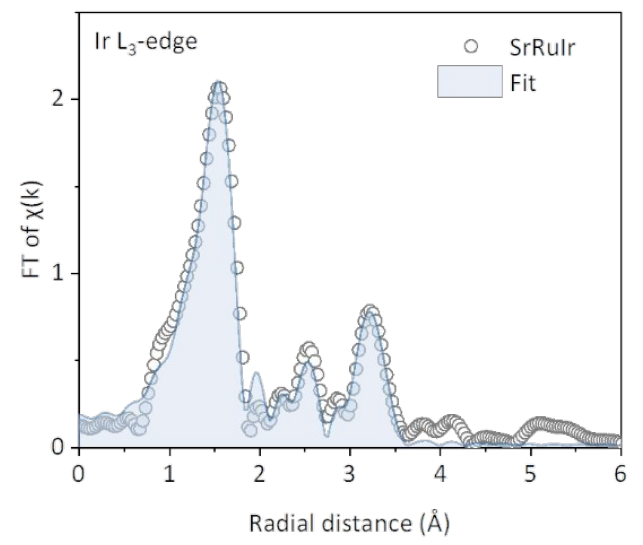

Supplementary Figure 20 | The EXAFS fitting of SrRuIr. (a) Ru K-edge (k weight=3). (b) Ir $\mathrm{L}_{3}$-edge ( $\mathrm{k}$ weight=2).

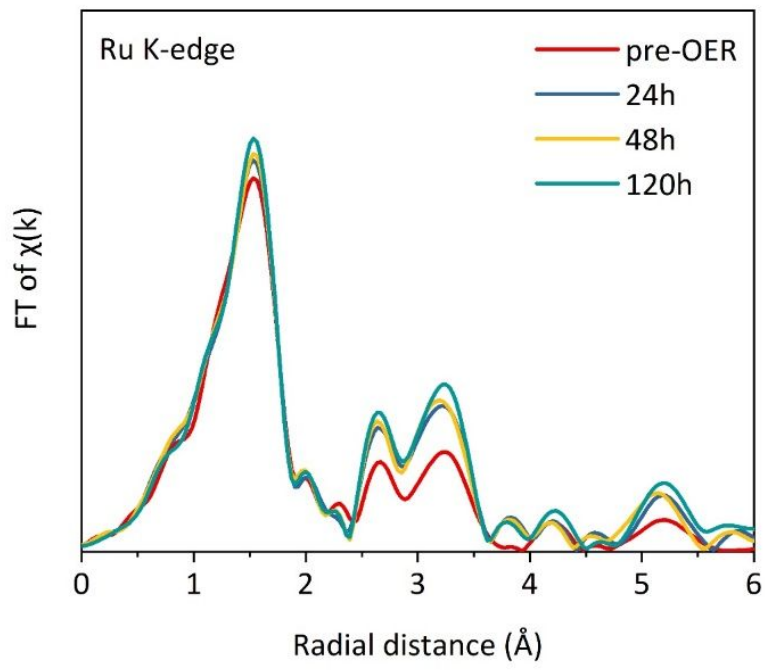




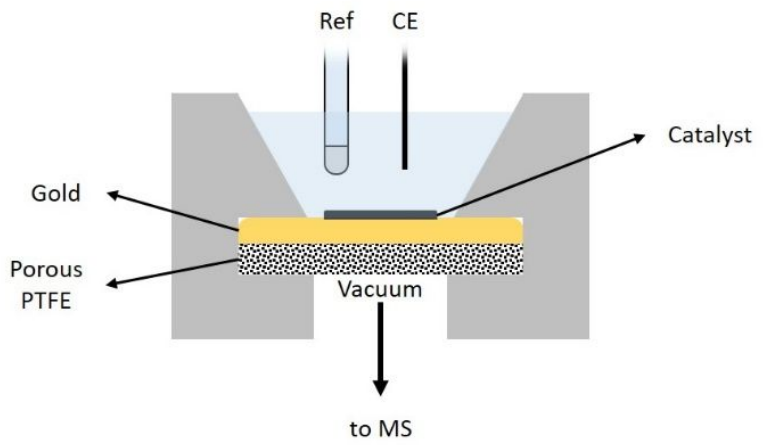

2 Supplementary Figure 22 | The electrochemical cell configuration used in DEMS measurements.

4

a

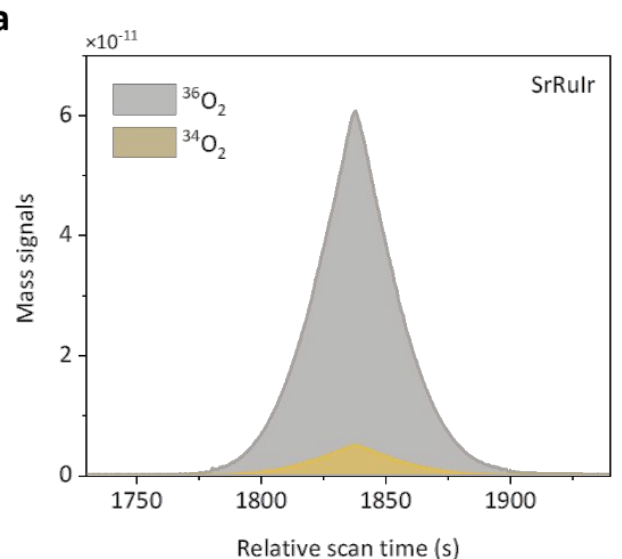

b

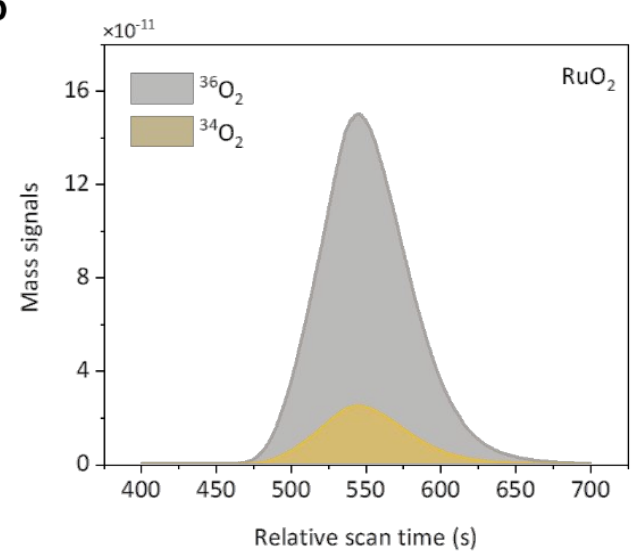

5

6

7

8 9

4

Supplementary Figure 23 DEMS signals of ${ }^{34} \mathrm{O}_{2}$ and ${ }^{36} \mathrm{O}_{2}$ from the reaction products cycled in $\mathrm{H}_{2}{ }^{18} \mathrm{O}$ aqueous sulfuric acid electrolyte. (a) SrRuIr; (b) $\mathrm{RuO}_{2}$. From the area ratio of ${ }^{34} \mathrm{O}_{2}$ and ${ }^{36} \mathrm{O}_{2}$, the amount of LOM can be quantified.

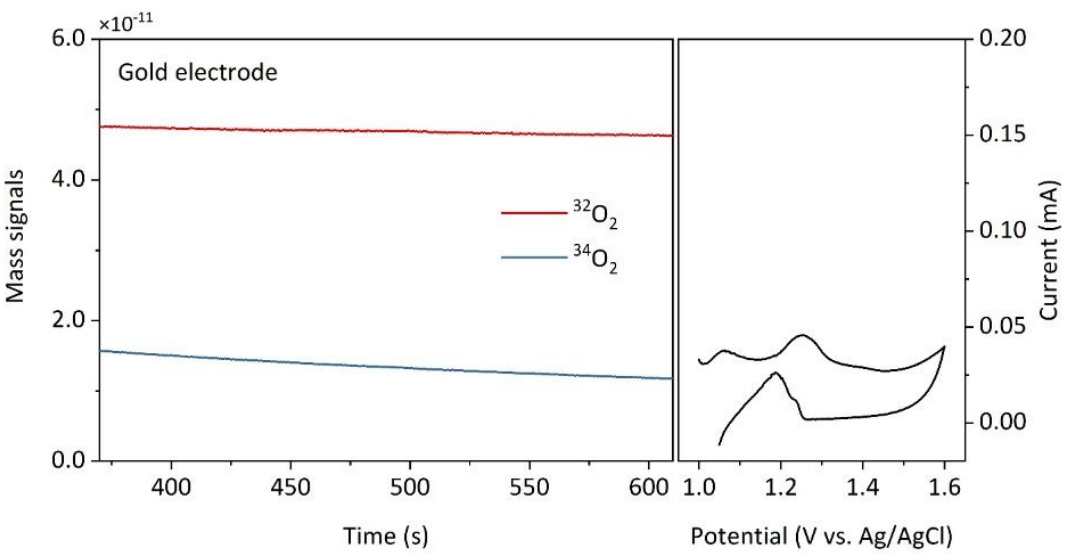

Supplementary Figure 24 | The DEMS measurement on clean Au electrode. No ${ }^{32} \mathrm{O}_{2}$ or ${ }^{34} \mathrm{O}_{2}$ signal was observed under applied potential, which indicated that all ${ }^{34} \mathrm{O}_{2}$ signals measured were contributed by catalyst. 


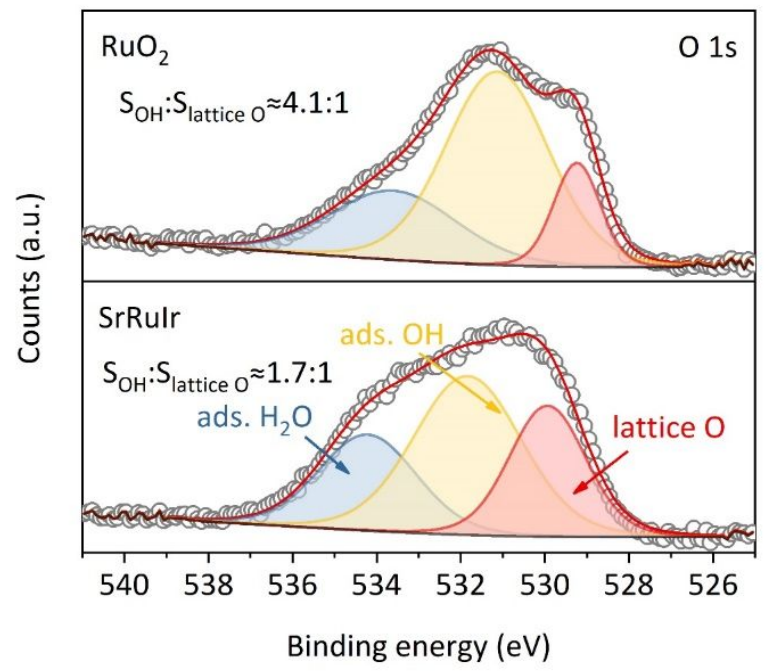

2 Supplementary Figure 25 | The $\mathrm{O}$ 1s XPS spectra after 12h OER. The area ratio 3 between adsorbed $\mathrm{OH}$ and lattice oxygen was much higher in $\mathrm{RuO}_{2}$ than in SrRuIr, 4 which means the surface oxygen was more easily to be protonated in $\mathrm{RuO}_{2}$, leading to 5 higher possibility to participate LOM. This find supported the results of DEMS.

a

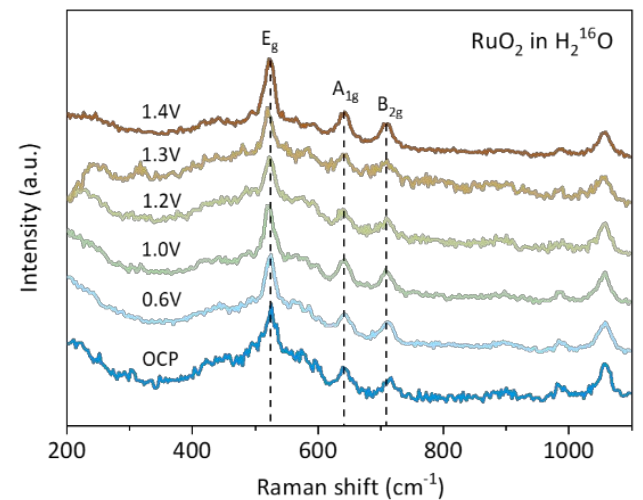

C

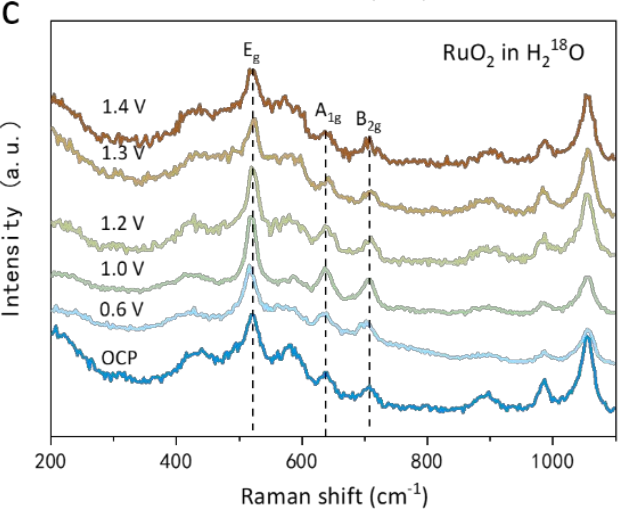

b

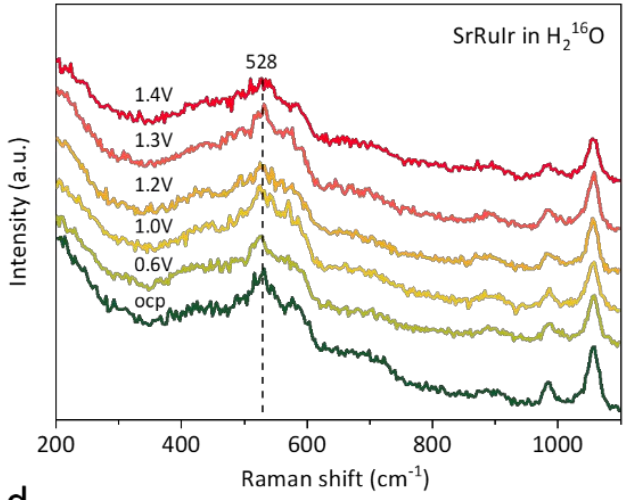

d

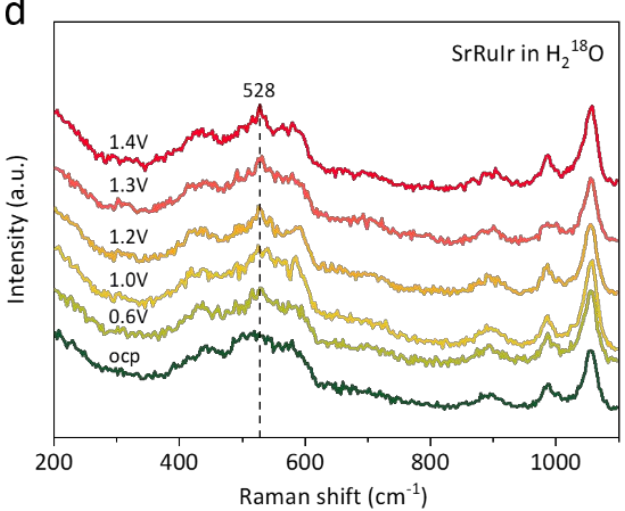

Supplementary Figure 26 | The in situ Raman spectroscopy of SrRuIr and $\mathrm{RuO}_{2}$.

9 (a-b) Spectra in ordinary $0.5 \mathrm{M} \mathrm{H}_{2} \mathrm{SO}_{4}$. (c-d) Spectra in $\mathrm{H}_{2}{ }^{18} \mathrm{O}$ labeled $0.5 \mathrm{M} \mathrm{H}_{2} \mathrm{SO}_{4}$. 
1 Note that the peak at $435 \mathrm{~cm}^{-1}, 580 \mathrm{~cm}^{-1}$ and $895 \mathrm{~cm}^{-1}$ came from the oxidation of Ti 2 substrate. The peak at $985 \mathrm{~cm}^{-1}$ and $1055 \mathrm{~cm}^{-1}$ came from $\mathrm{SO}_{4}{ }^{2-}$.
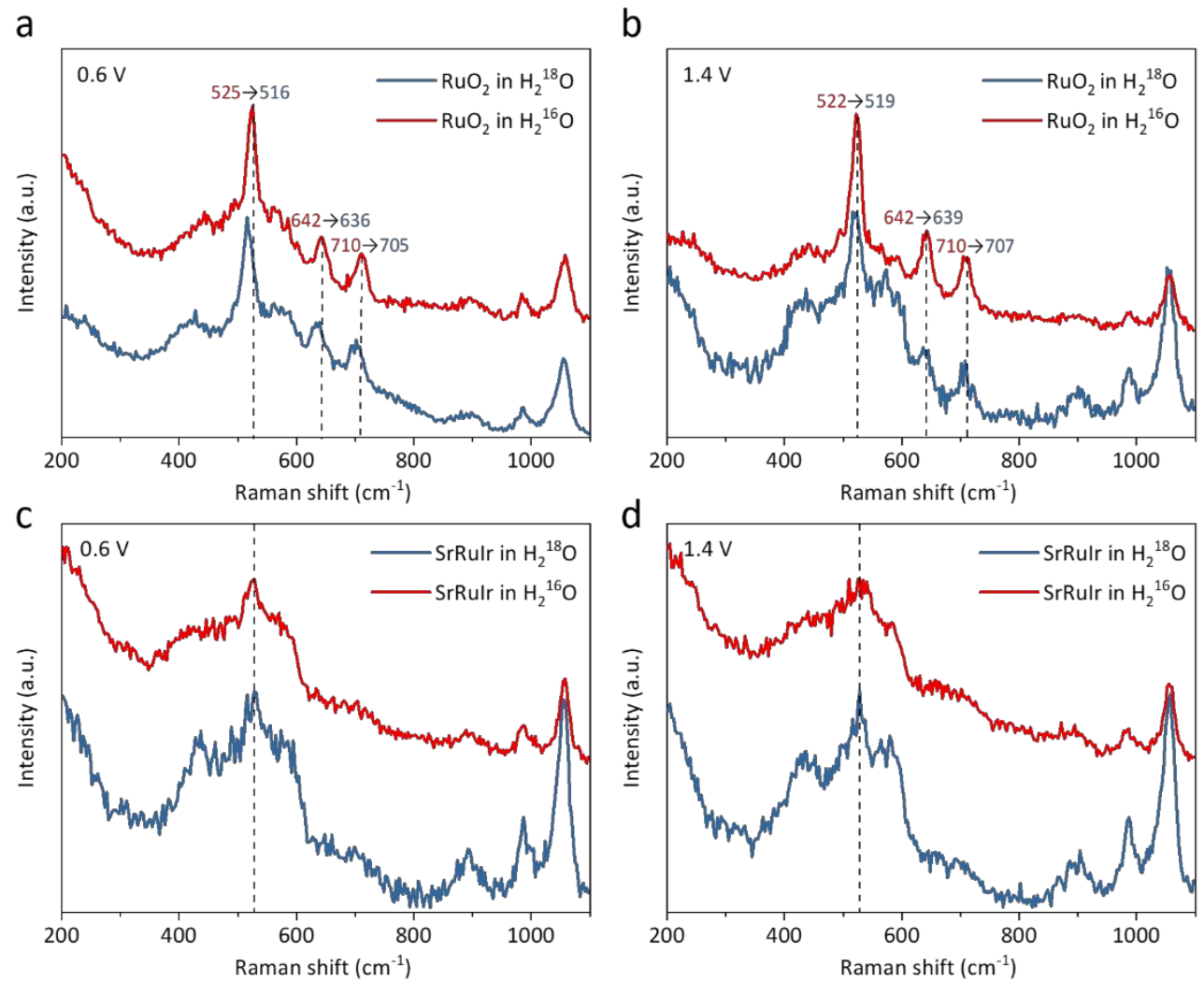

Supplementary Figure 27 | The in situ Raman spectra of SrRuIr and $\mathrm{RuO}_{2}$. (a \&

c) $\mathrm{RuO}_{2}$ at $0.6 \mathrm{~V}$ and $1.4 \mathrm{~V}$ vs. RHE, respectively. (b \& d) SrRuIr at $0.6 \mathrm{~V}$ and $1.4 \mathrm{~V}$ vs. RHE, respectively. Note that the peak at $435 \mathrm{~cm}^{-1}, 580 \mathrm{~cm}^{-1}$ and $895 \mathrm{~cm}^{-1}$ came from the oxidation of Ti substrate. The peak at $985 \mathrm{~cm}^{-1}$ and $1055 \mathrm{~cm}^{-1}$ came from $\mathrm{SO}_{4}^{2-}$. 

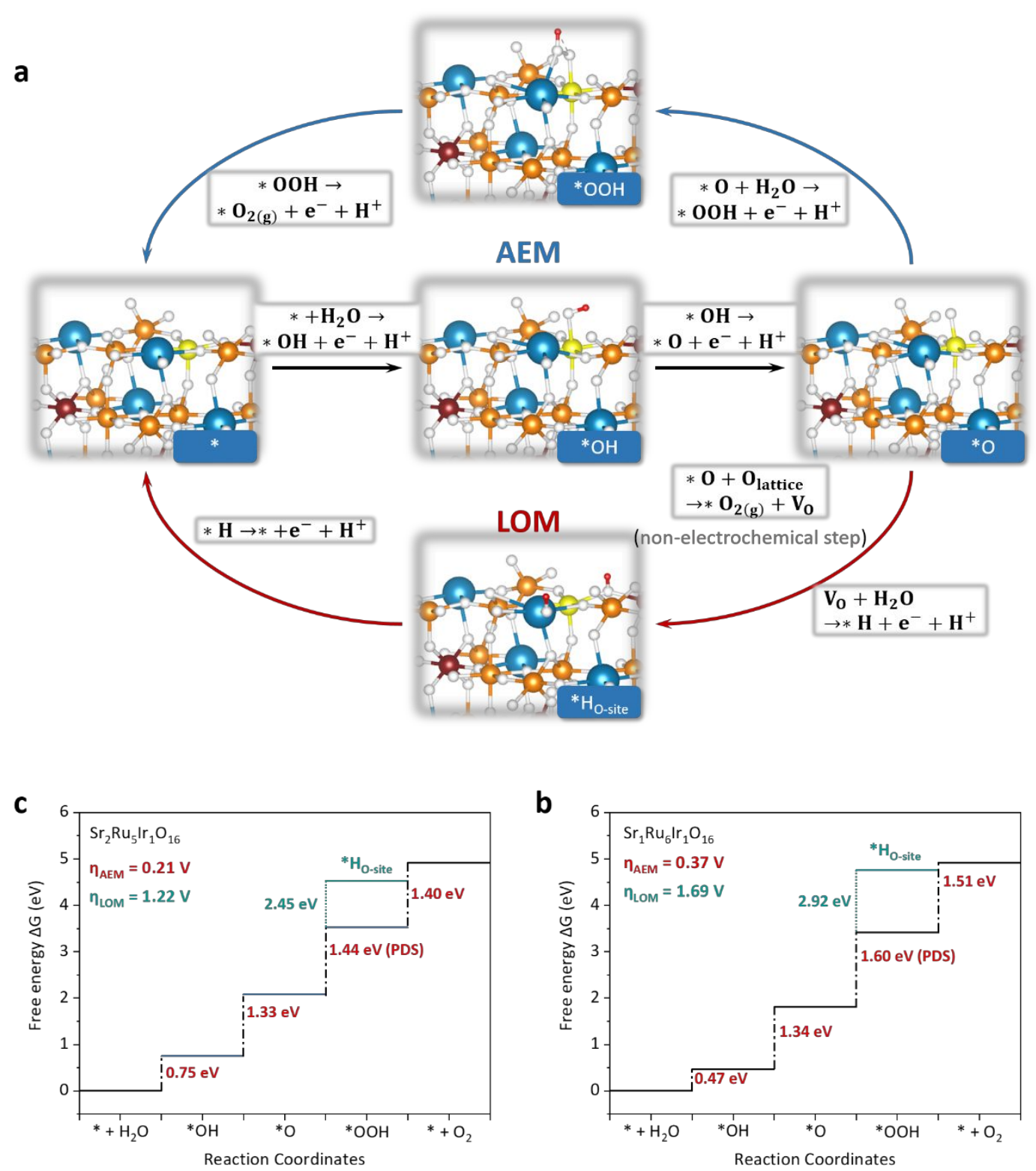

2 Supplementary Figure 28 | Different OER pathways on SrRuIr oxide catalysts. (a)

3 The schematics of OER pathways. The LOM pathway is refer to ref. ${ }^{15}$. (b) The OER

4 energetics of $\mathrm{Sr}_{2} \mathrm{Ru}_{5} \mathrm{Ir}_{1} \mathrm{O}_{16}$. (c) The OER energetics of $\mathrm{Sr}_{1} \mathrm{Ru}_{6} \mathrm{Ir}_{1} \mathrm{O}_{16}$. The overpotential 5 of LOM pathway is much higher than the AEM pathway on both models. While with 6 the decrease of $\mathrm{Sr}$, the overpotential of LOM increased accordingly. This result well 7 coincide with our experiment that the catalyst is getting stable after Sr leaching. 


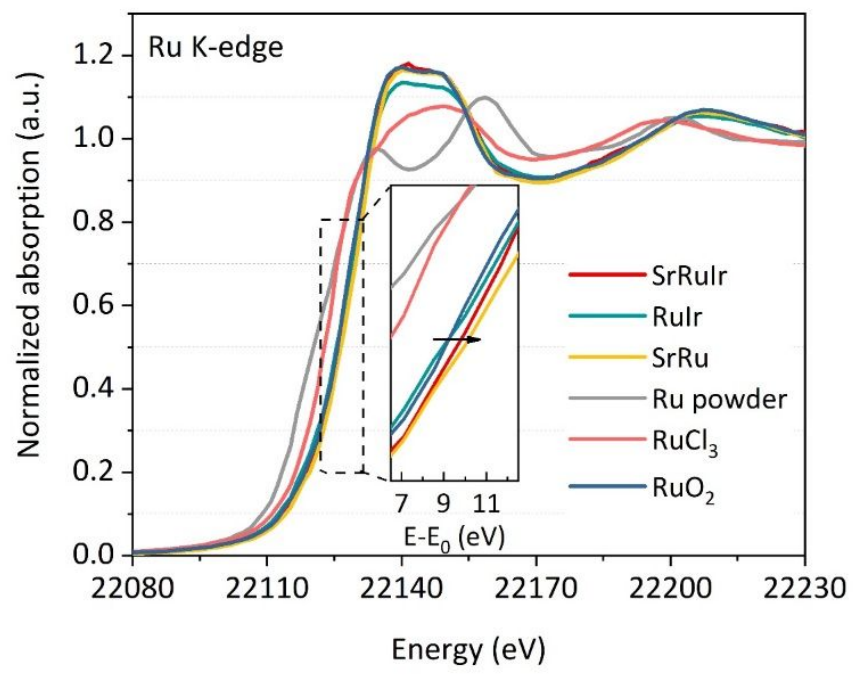

2 Supplementary Figure 29 | In-situ Ru K-edge XANES of different catalysts. The 3 XANES measurements were conducted at $1.35 \mathrm{~V} v s$. RHE. The absorption edge of both 4 SrRuIr and SrRu moved to higher energy, indicating a $\mathrm{Ru}$ valence of $\mathrm{Ru}^{\mathrm{n}+}(\mathrm{n}>4)$, while 5 the $\mathrm{Sr}$-free RuIr oxide was kept as $\mathrm{Ru}^{4+}$, the same as $\mathrm{RuO}_{2}$ standard.

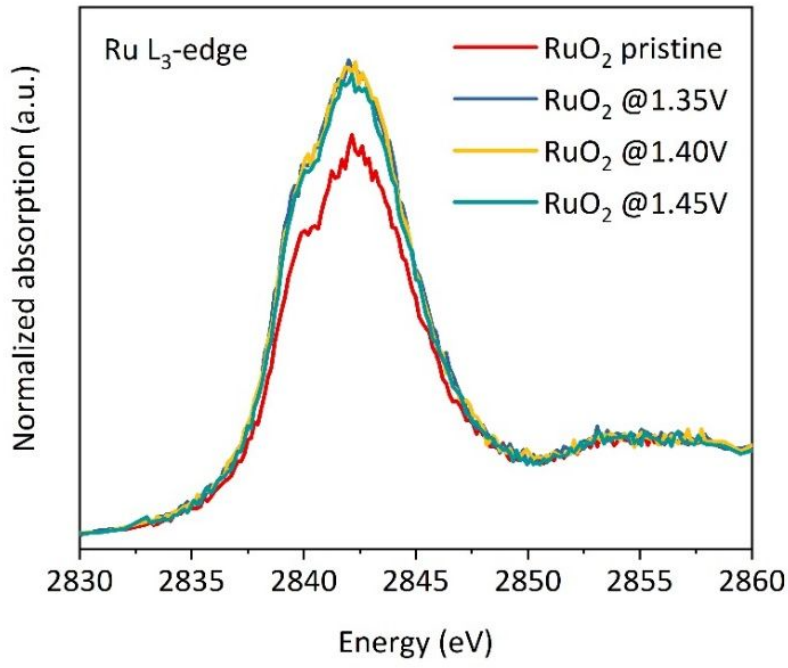

8 Supplementary Figure 30 | The in situ $\mathrm{Ru} \mathbf{L}_{3}$-edge XAS spectra of $\mathrm{RuO}_{2}$. The white9 line peak did not vary significantly under different potential. 


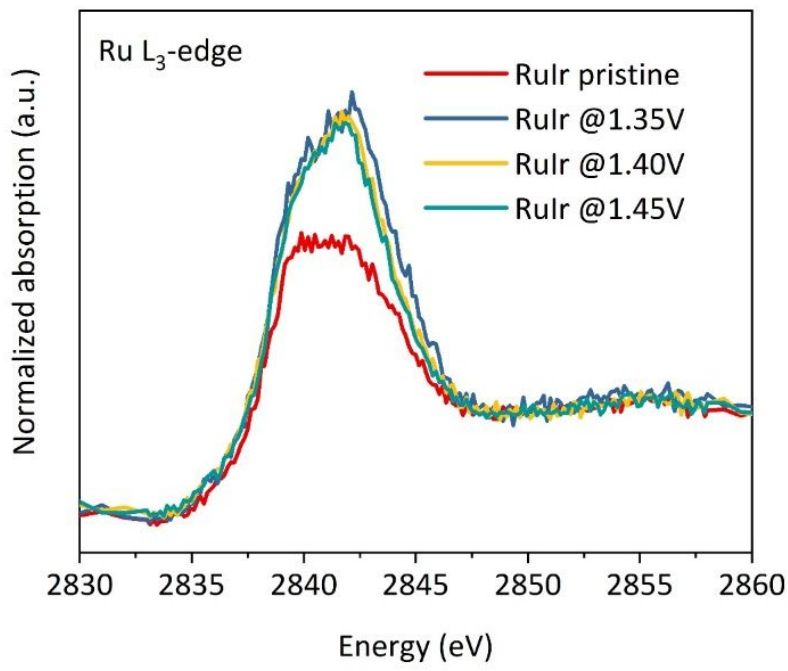

2 Supplementary Figure 31 | The in situ Ru $\mathrm{L}_{3}$-edge XAS spectra of RuIr. The white3 line peak did not vary significantly with various applied potentials.

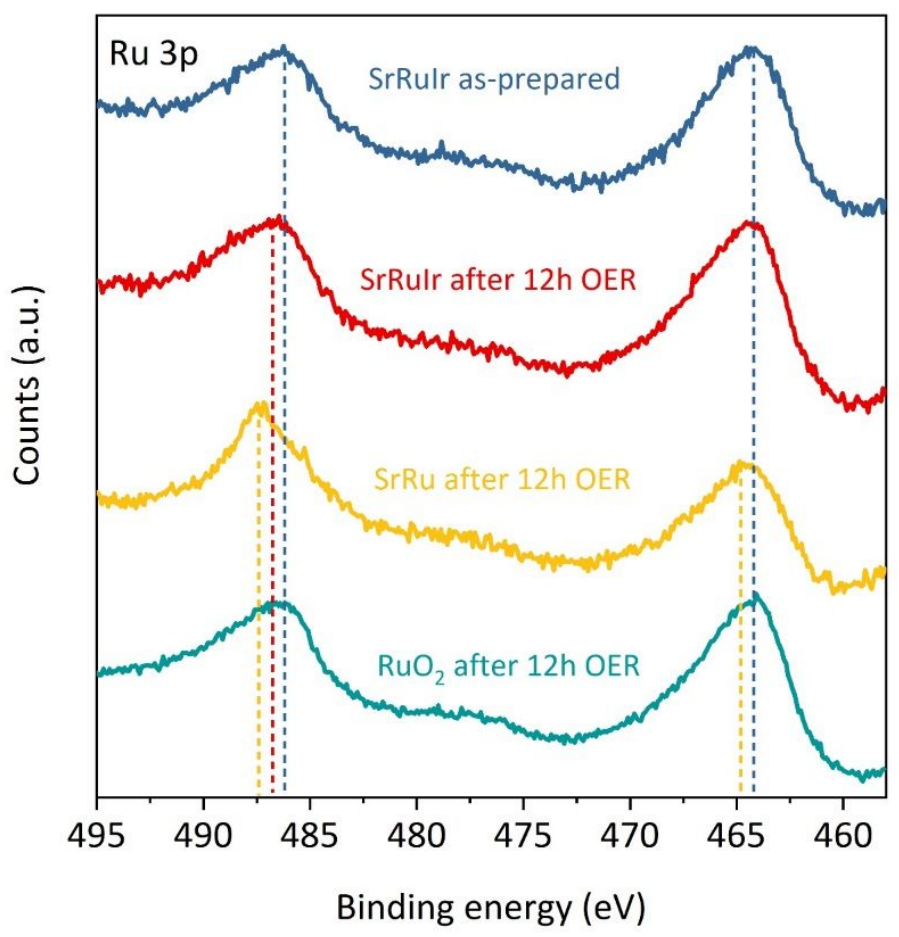

6 Supplementary Figure 32 | The XPS spectra of Ru 3p for different catalysts. The 7 chemical state of $\mathrm{Ru}$ in as-prepared SrRuIr is +4 , same with $\mathrm{RuO}_{2}$. After 12-h 8 electrolysis, a shoulder arise at $c a .487 \mathrm{eV}$, which hinted the formation of $\mathrm{Ru}^{\mathrm{n}+}(\mathrm{n}>+4)$ 9 surface species. 


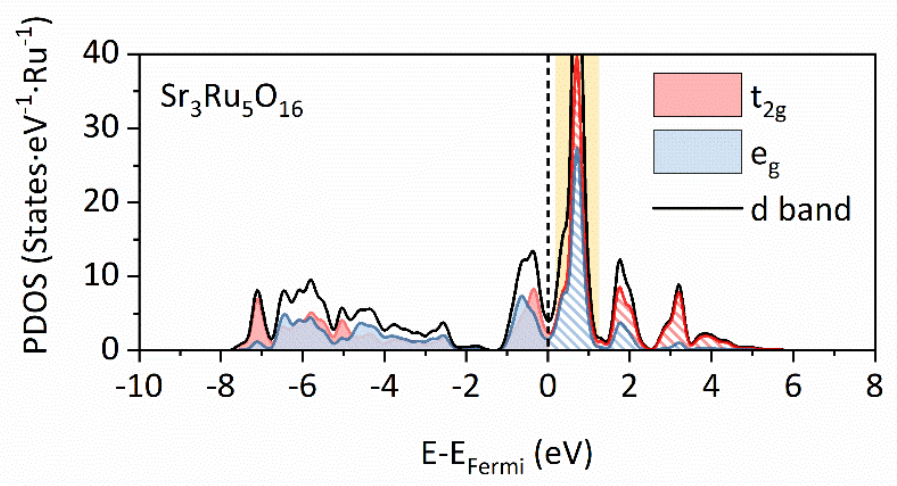

2 Supplementary Figure 33 | PDOS of the active $\mathrm{Ru}$ site on $\mathrm{Sr}_{3} \mathrm{Ru}_{5} \mathrm{O}_{16}$ model. The 3 incorporation of $\mathrm{Sr}$ induced more unoccupied $e_{\mathrm{g}}$ state at $\sim 1 \mathrm{eV}$ above Fermi level. 4

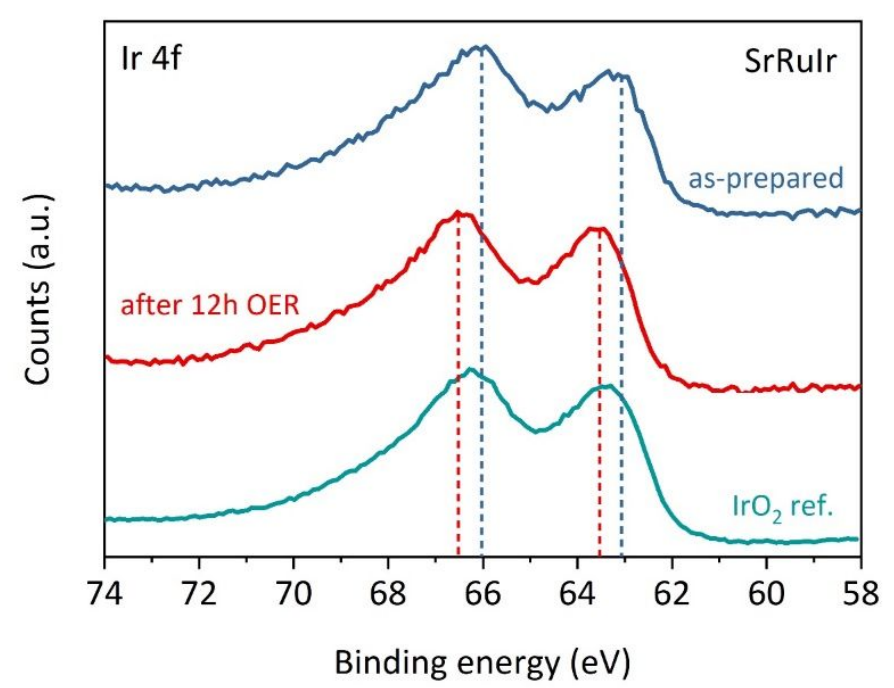

5

6 Supplementary Figure 34 | The XPS spectra of Ir 4f for SrRuIr catalyst before 7 and after OER. The $\mathrm{Ir}$ in pristine catalyst showed a valence of +3 . After performing 8 12-h continuous electrolysis, the Ir was oxidized to chemical state even higher than $\mathrm{IrO}_{2}$ $9(+4)$.

10 


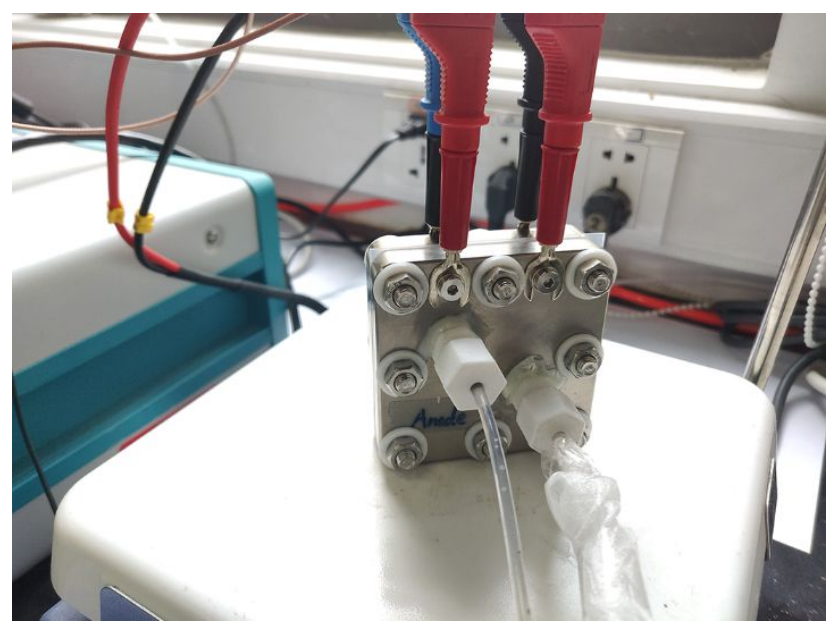

2 Supplementary Figure 35 | Photograph of the PEM set-up used in this work.

3

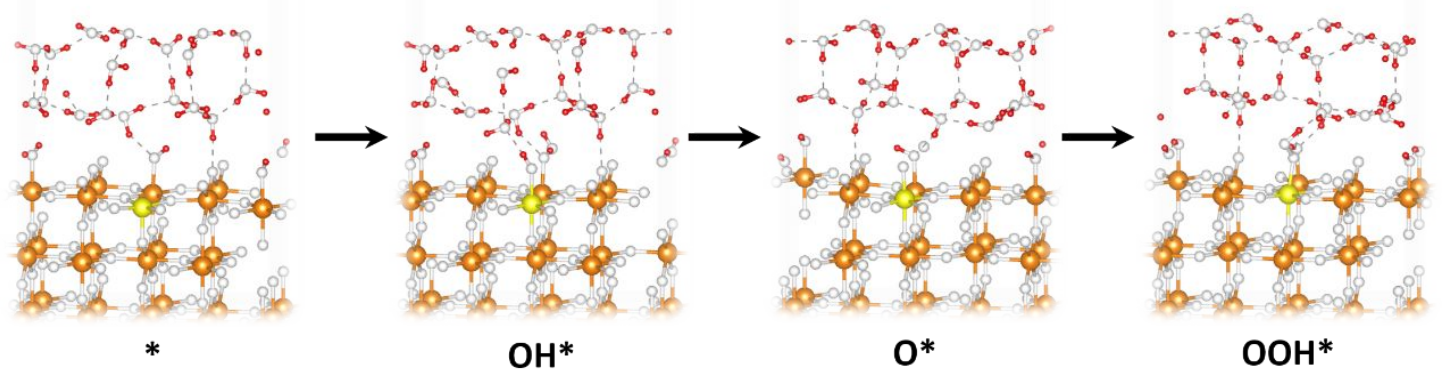

5 Supplementary Figure 36 | The OER pathway of $\mathrm{RuO}_{2}$ on explicit solvent models.

6 The orange balls represent $\mathrm{Ru}$ atoms, and the small red and white balls are hydrogen 7 and oxygen atoms, respectively. The active sites are labeled as yellow. 


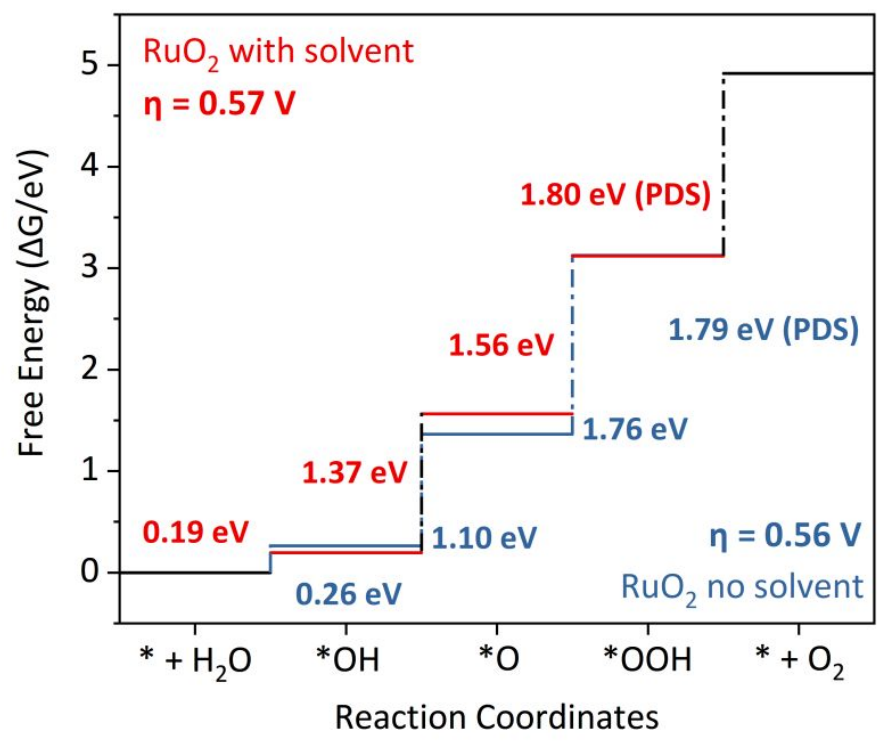

2 Supplementary Figure 37 The comparison of reaction coordinates between 3 models with and without solvent. No significant change was observed after including 4 solvent. PDS is the potential determine step.
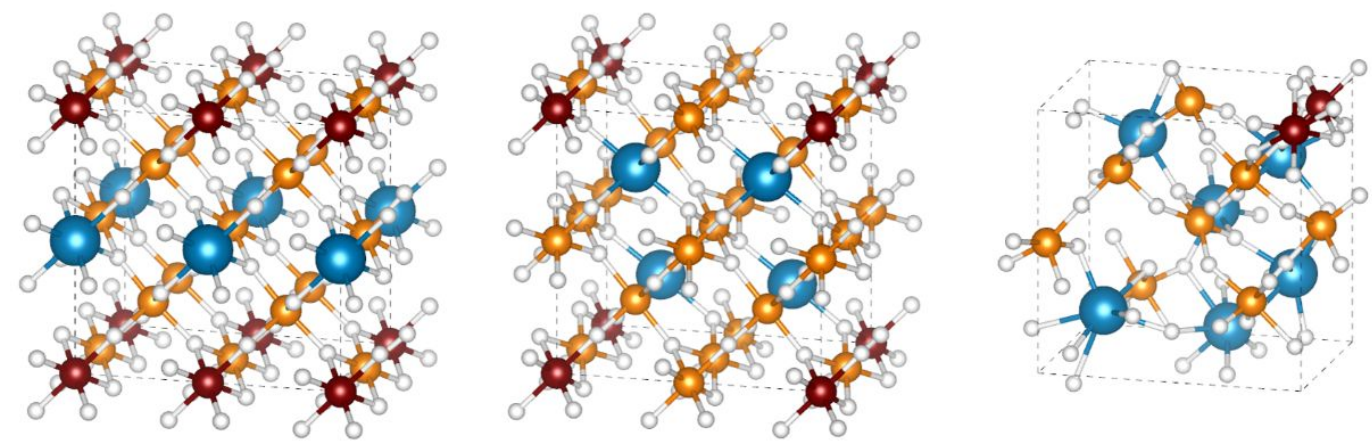

$$
\begin{gathered}
\mathrm{Sr}_{1} \mathbf{R u}_{6} \mathbf{I r}_{1} \mathbf{O}_{16} \\
\mathrm{E}_{\text {total }}=-343.53 \mathrm{eV}
\end{gathered}
$$

$$
\begin{gathered}
\mathrm{Sr}_{2} \mathbf{R u}_{5.5} \mathbf{I r}_{\mathbf{0 . 5}} \mathbf{O}_{16} \\
\mathrm{E}_{\text {total }}=-334.65 \mathrm{eV}
\end{gathered}
$$

$$
\begin{gathered}
\mathrm{Sr}_{3} \mathrm{Ru}_{4} \mathbf{I r}_{1} \mathbf{O}_{16} \\
\mathrm{E}_{\text {total }}=-324.50 \mathrm{eV}
\end{gathered}
$$

7 Supplementary Figure 38 | The structures and total energy of Sr-Ru-Ir crystals 8 with different content of Sr doping. 


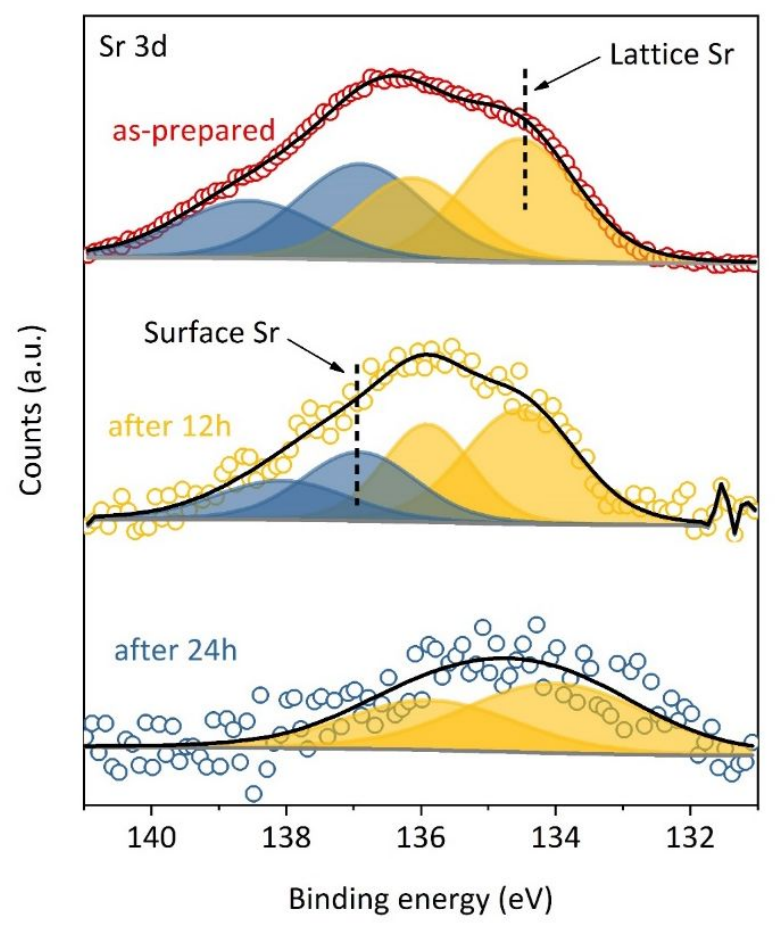

2 Supplementary Figure 39 | Sr 3d XPS spectra of SrRuIr. The results showed that 3 surface $\mathrm{Sr}$ were leached and the rest lattice $\mathrm{Sr}$ were stable during OER.

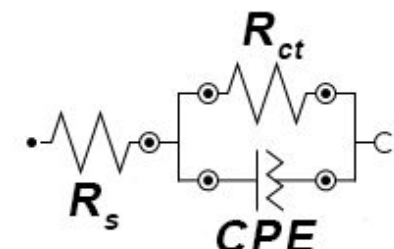

6 Supplementary Figure 40 | Equivalence circuit used in electrochemical impedance 7 spectroscopy (EIS) fits. $\mathrm{R}_{\mathrm{s}}$ refers to the uncompensated resistance of electrolyte. $\mathrm{R}_{\mathrm{ct}}$ 8 refers to the charge-transfer resistance. CPE refers to the constant phase element. 
a

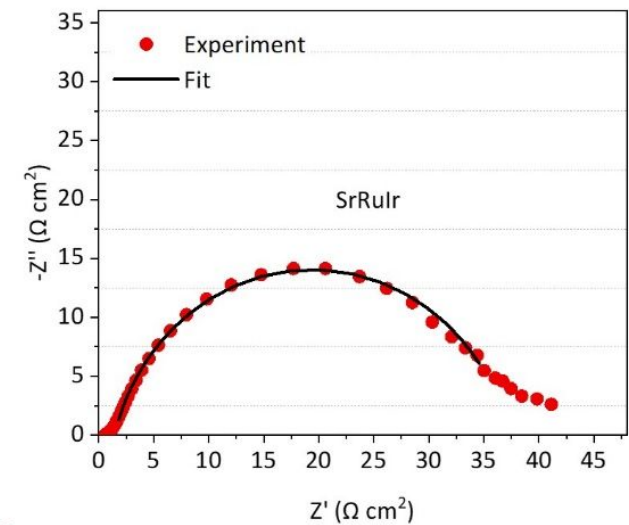

C
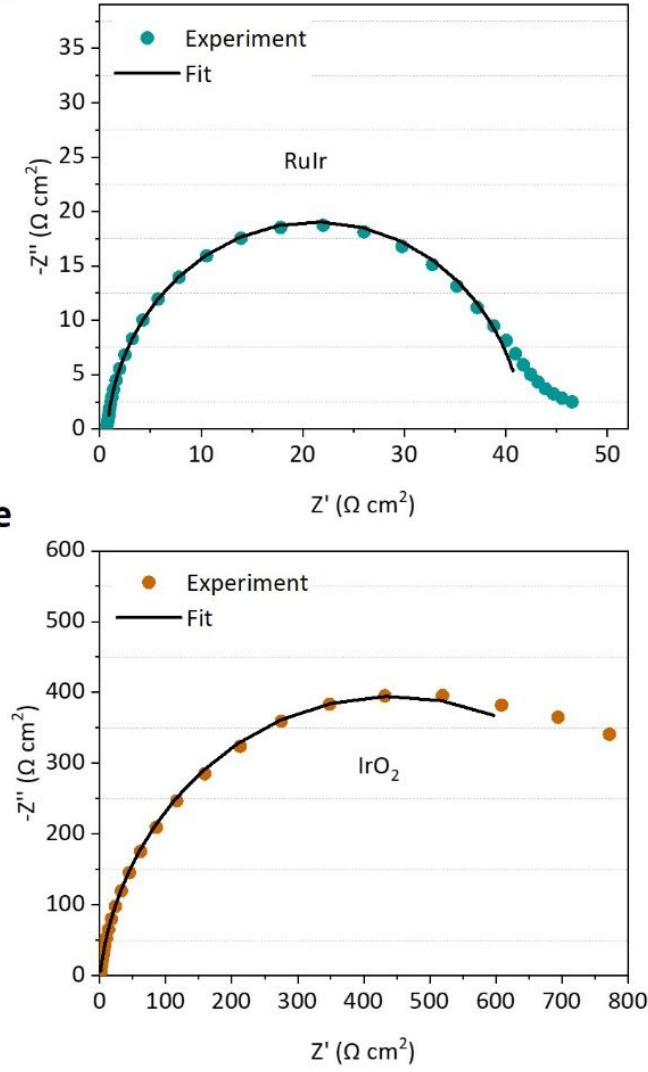

b

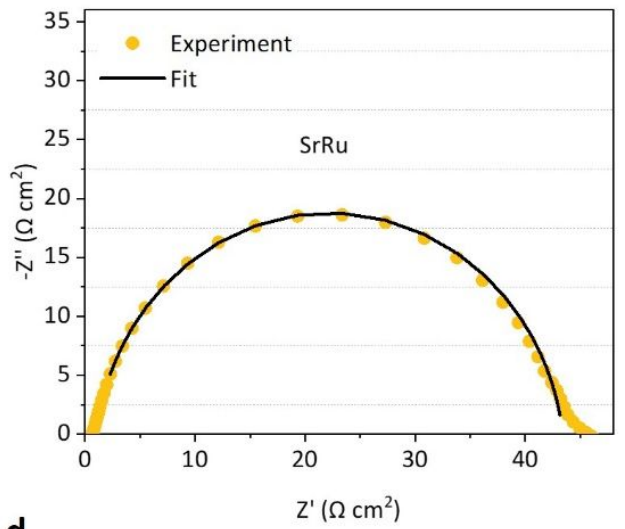

d

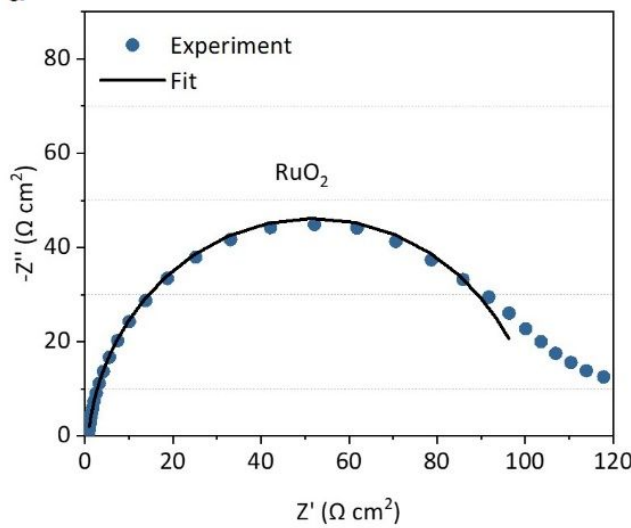

3 catalysts. (a) SrRuIr, (b) SrRu, (c) RuIr, (d) $\mathrm{RuO}_{2}$ and (e) $\mathrm{IrO}_{2}$. Measured on GCE at $4 \quad 1.35 \mathrm{~V}$ vs. RHE. The fitting parameters are summarized in Supplementary Table 15. 

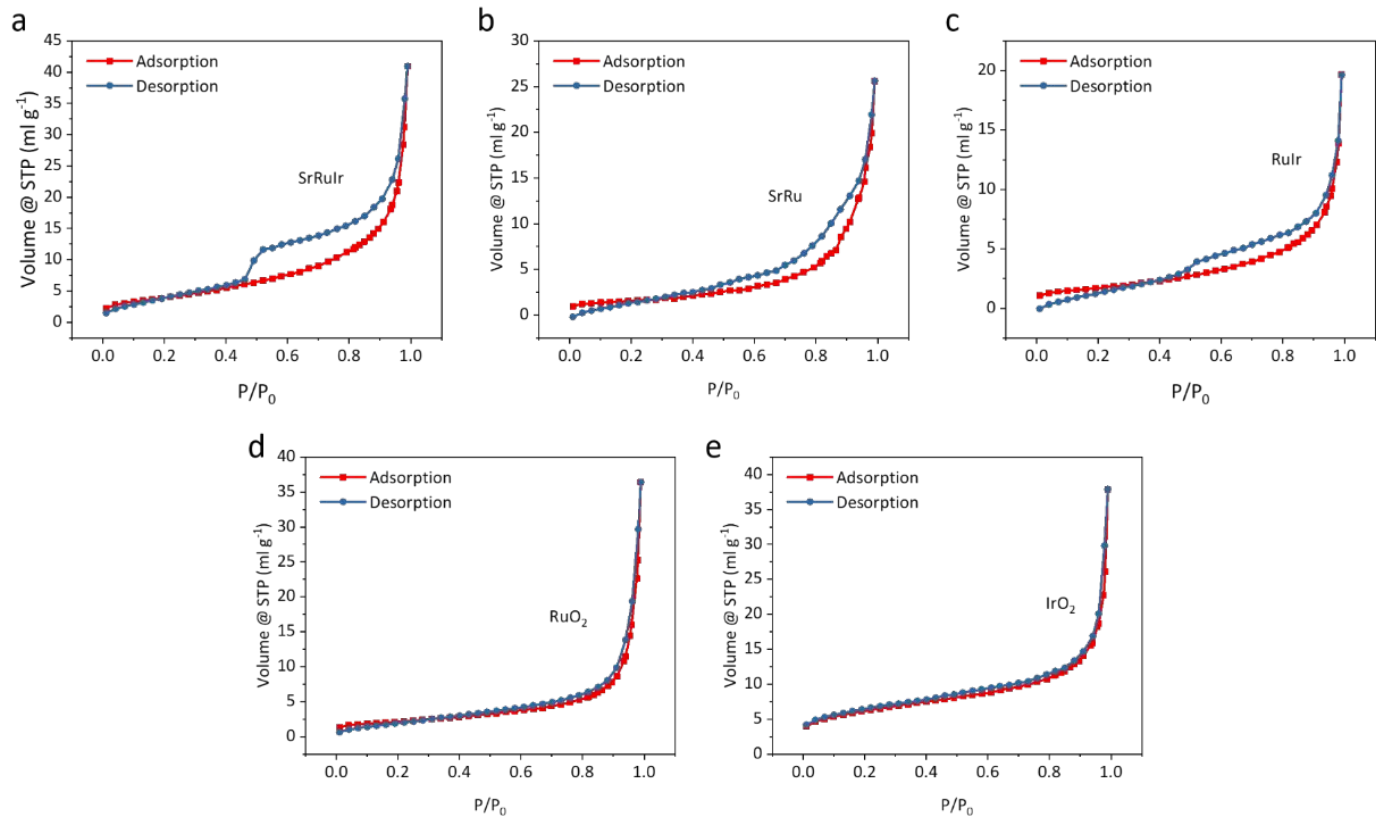

1

Supplementary Figure 42 | BET isotherms of different catalysts. (a) SrRuIr, (b) $3 \mathrm{SrRu}$, (c) RuIr, (d) $\mathrm{RuO}_{2}$ and (e) $\mathrm{IrO}_{2}$.

4

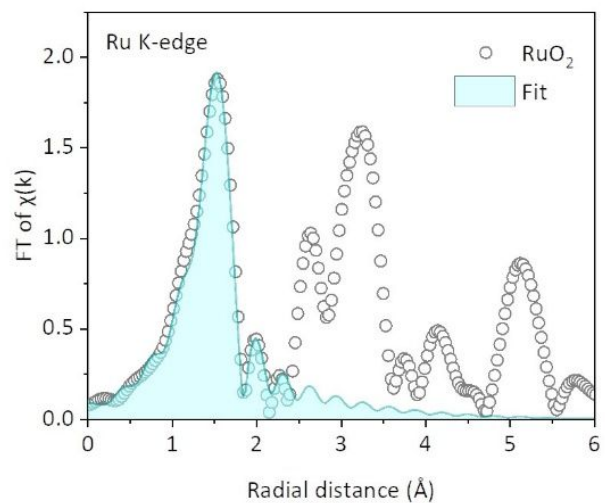

b

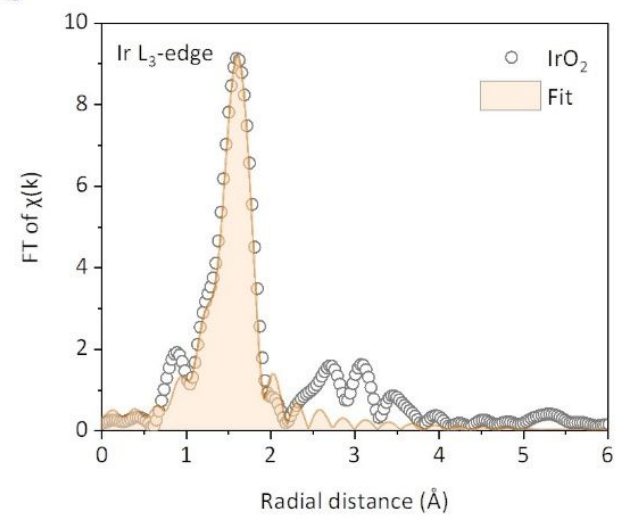

6

7 8

Supplementary Figure 43 | Firset shell EXAFS fitting of $\mathrm{RuO}_{2}$ and $\mathrm{IrO}_{2}$. (a) $\mathrm{Ru} \mathrm{K}$ edge of $\mathrm{RuO}_{2}\left(\mathrm{k}\right.$ weight=2). (b) $\mathrm{Ir} \mathrm{L}_{3}$-edge of $\mathrm{IrO}_{2}(\mathrm{k}$ weight $=3)$. 

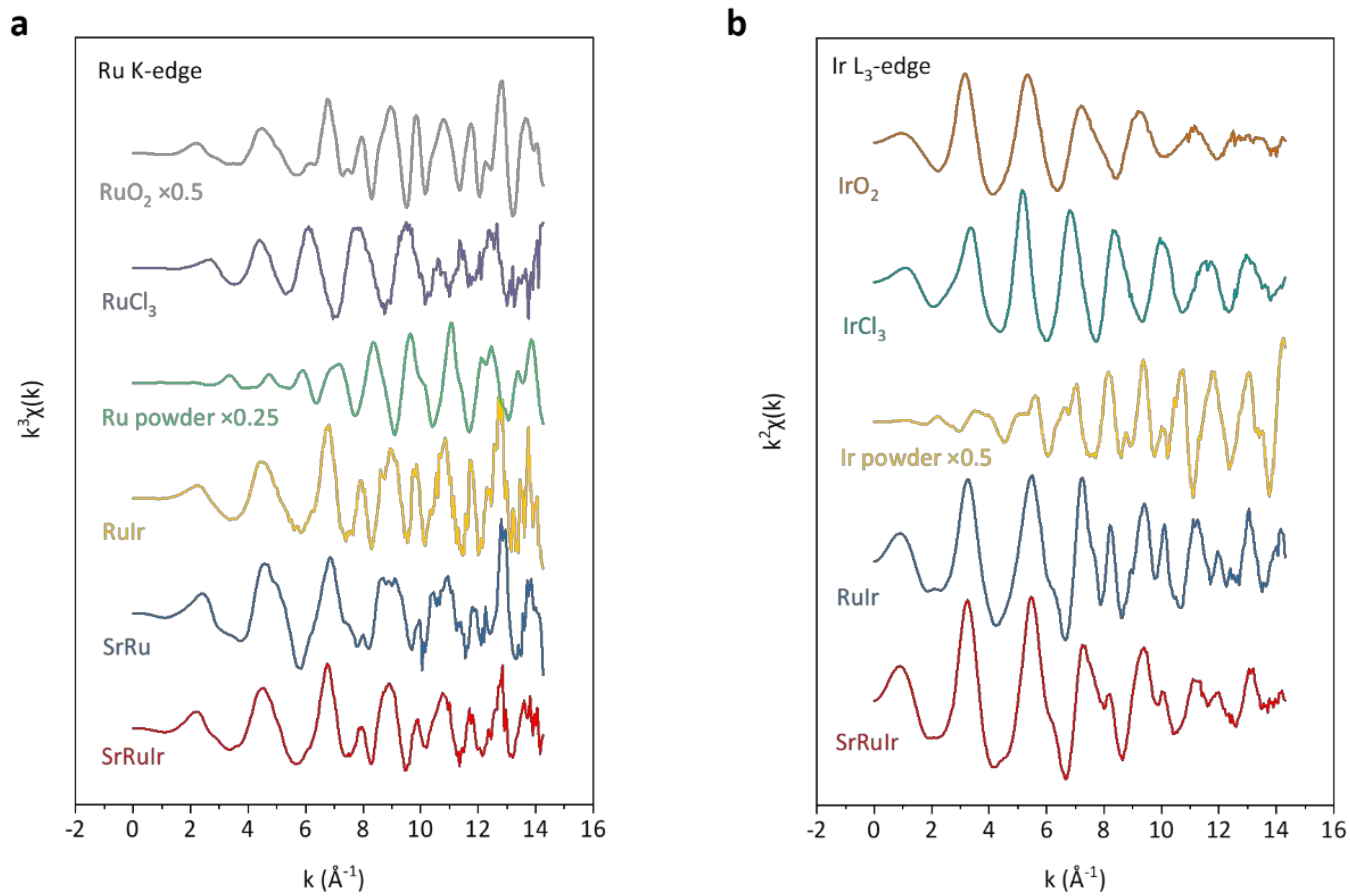

2 Supplementary Figure 44 | EXAFS spectra of different samples in k space. (a) $\mathrm{Ru}$

3 K-edge. (b) Ir $\mathrm{L}_{3}$-edge. All spectra possessed a low signal-to-noise ratio, indicating the 4 EXAFS measurements were reliable.

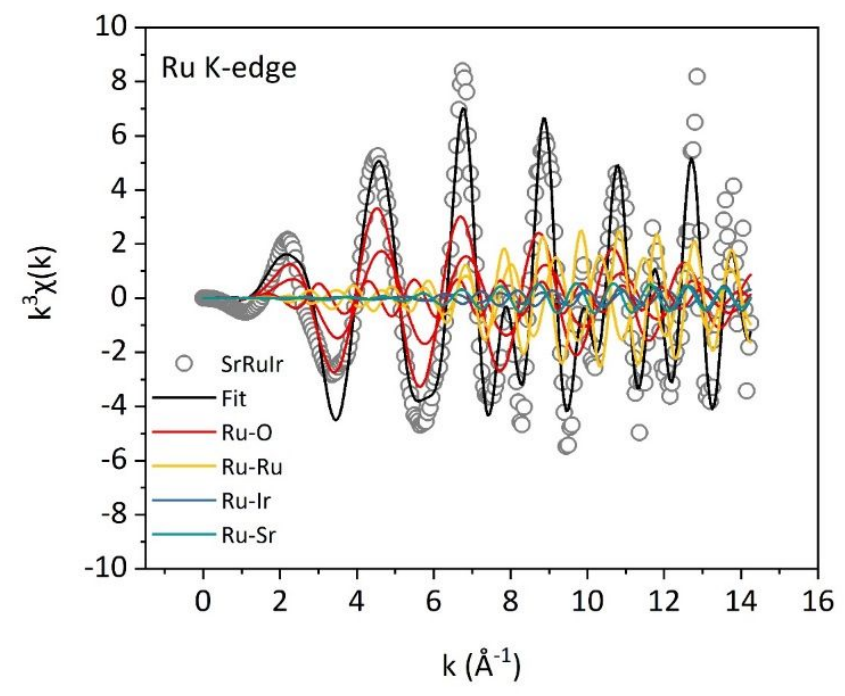

6

7

8

9 


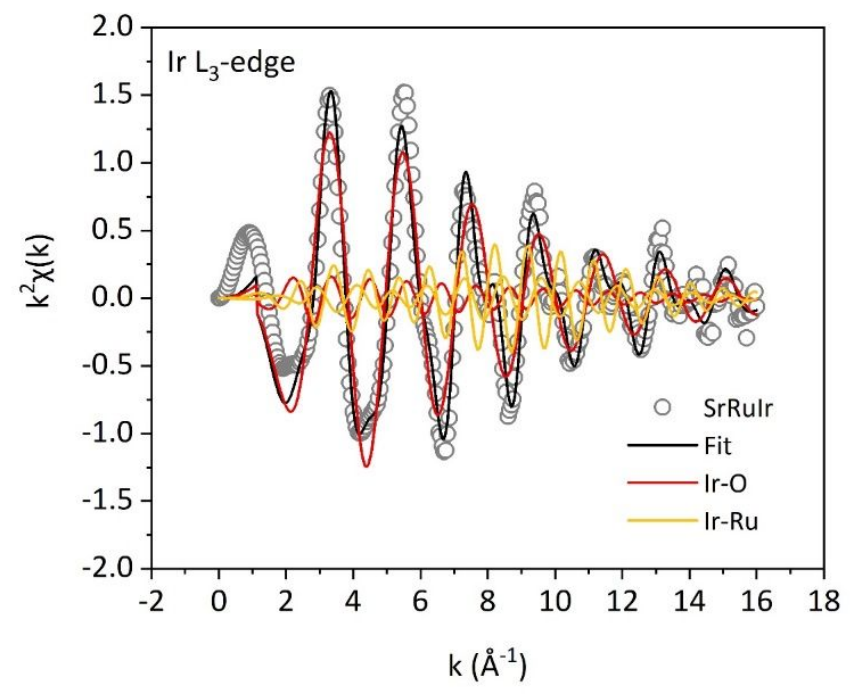

2 Supplementary Figure 46 | Ir $L_{3}$-edge EXAFS spectra and corresponding fits of 3 SrRuIr. K-weight $=2$. The spectrum possessed a low signal-to-noise ratio and the R4 factor of fit was 0.0003, indicating the EXAFS measurements and fitting were reliable. 5 
1 Supplementary Tables (Supplementary Table 1-

2 Supplementary Table 15)

3 Supplementary Table 1 | DFT energies (eV), $\triangle \mathrm{ZPE}(\mathrm{eV})$ and TAS (eV) for OER

4 intermediates adsorbed on the different SrIrRuOx surface $\mathbf{T}=\mathbf{2 9 8 . 1 5 K}$.

\begin{tabular}{|c|c|c|c|c|}
\hline Model & Adsorbates & DFT energies & $\Delta \mathrm{ZPE}$ & $\mathbf{T} \Delta \mathbf{S}$ \\
\hline \multirow{4}{*}{$\mathrm{Sr}_{1} \mathrm{Ru}_{6} \mathrm{Ir}_{1} \mathrm{O}_{16}$} & $*$ & -692.71 & 0 & 0 \\
\hline & $* \mathrm{OH}$ & -703.408 & 0.366 & 0.077 \\
\hline & $* \mathrm{O}$ & -698.339 & 0.071 & 0.057 \\
\hline & $* \mathrm{OOH}$ & -707.915 & 0.435 & 0.132 \\
\hline \multirow{4}{*}{$\mathrm{Sr}_{2} \mathrm{Ru}_{6} \mathrm{O}_{16}$} & $*$ & -680.42 & 0 & 0 \\
\hline & $* \mathrm{OH}$ & -690.848 & 0.364 & 0.079 \\
\hline & $* \mathrm{O}$ & -686.381 & 0.079 & 0.049 \\
\hline & $* \mathrm{OOH}$ & -695.646 & 0.439 & 0.125 \\
\hline \multirow{4}{*}{$\mathrm{Sr}_{2} \mathrm{Ru}_{5.5} \mathrm{Ir}_{0.5} \mathrm{O}_{16}$} & $*$ & -678.257 & 0 & 0 \\
\hline & $* \mathrm{OH}$ & -688.65 & 0.361 & 0.081 \\
\hline & $* \mathrm{O}$ & -683.685 & 0.076 & 0.051 \\
\hline & $* \mathrm{OOH}$ & -693.28 & 0.444 & 0.181 \\
\hline \multirow{4}{*}{$\mathrm{Sr}_{2} \mathrm{Ru}_{5} \mathrm{Ir}_{1} \mathrm{O}_{16}$} & $*$ & -675.819 & 0 & 0 \\
\hline & $* \mathrm{OH}$ & -686.224 & 0.357 & 0.087 \\
\hline & $* \mathrm{O}$ & -681.188 & 0.072 & 0.057 \\
\hline & $* \mathrm{OOH}$ & -690.878 & 0.442 & 0.182 \\
\hline \multirow{4}{*}{$\mathrm{Sr}_{2} \mathrm{Ru}_{3.5} \mathrm{Ir}_{2.5} \mathrm{O}_{16}$} & $*$ & -669.256 & 0 & 0 \\
\hline & $* \mathrm{OH}$ & -679.853 & 0.365 & 0.078 \\
\hline & $* \mathrm{O}$ & -674.819 & 0.075 & 0.054 \\
\hline & $* \mathrm{OOH}$ & -684.364 & 0.439 & 0.131 \\
\hline
\end{tabular}




\begin{tabular}{|c|c|c|c|c|}
\hline \multirow{4}{*}{$\mathrm{Sr}_{2} \mathrm{Ru}_{1.5} \mathrm{Ir}_{4.5} \mathrm{O}_{16}$} & $*$ & -659.240 & 0 & 0 \\
\hline & $* \mathrm{OH}$ & -669.791 & 0.362 & 0.082 \\
\hline & $* \mathrm{O}$ & -664.85 & 0.074 & 0.055 \\
\hline & $* \mathrm{OOH}$ & -674.367 & 0.440 & 0.131 \\
\hline \multirow{4}{*}{$\mathrm{Sr}_{3} \mathrm{Ru}_{5} \mathrm{O}_{16}$} & $*$ & -663.099 & 0 & 0 \\
\hline & $* \mathrm{OH}$ & -672.773 & 0.372 & 0.070 \\
\hline & $* \mathrm{O}$ & -667.567 & 0.079 & 0.039 \\
\hline & $* \mathrm{OOH}$ & -677.132 & 0.449 & 0.147 \\
\hline \multirow{4}{*}{$\mathrm{Sr}_{3} \mathrm{Ru}_{4} \mathrm{Ir}_{1} \mathrm{O}_{16}$} & $*$ & -657.466 & 0 & 0 \\
\hline & $* \mathrm{OH}$ & -667.45 & 0.334 & 0.100 \\
\hline & $* \mathrm{O}$ & -662.227 & 0.074 & 0.045 \\
\hline & $* \mathrm{OOH}$ & -671.874 & 0.447 & 0.151 \\
\hline \multirow{4}{*}{$\mathrm{Sr}_{6} \mathrm{Ru}_{1} \mathrm{Ir}_{1} \mathrm{O}_{16}$} & $*$ & -593.09 & 0 & 0 \\
\hline & $* \mathrm{OH}$ & -602.701 & 0.299 & 0.207 \\
\hline & $* \mathrm{O}$ & -597.813 & 0.071 & 0.062 \\
\hline & $* \mathrm{OOH}$ & -607.109 & 0.398 & 0.230 \\
\hline \multirow{4}{*}{$\mathrm{Sr}_{6} \mathrm{Ir}_{2} \mathrm{O}_{16}$} & $*$ & -581.273 & 0 & 0 \\
\hline & $* \mathrm{OH}$ & -591.854 & 0.373 & 0.053 \\
\hline & $* \mathrm{O}$ & -586.944 & 0.082 & 0.050 \\
\hline & $* \mathrm{OOH}$ & -596.577 & 0.472 & 0.131 \\
\hline
\end{tabular}


1 Supplementary Table 2 | Free energies for each OER reaction steps and the 2 calculated overpotential ( $\eta$ ) on the SrRuIr surface.

\begin{tabular}{cccccc}
\hline Model & $\Delta \mathbf{G}_{\mathbf{1}}$ & $\Delta \mathbf{G}_{\mathbf{2}}$ & $\Delta \mathbf{G}_{\mathbf{3}}$ & $\Delta \mathbf{G}_{\mathbf{4}}$ & $\boldsymbol{\eta}$ \\
\hline $\mathrm{Sr}_{1} \mathrm{Ru}_{6} \mathrm{Ir}_{1} \mathrm{O}_{16}$ & 0.47 & 1.34 & 1.60 & 1.51 & 0.37 \\
\hline $\mathrm{Sr}_{2} \mathrm{Ru}_{6} \mathrm{O}_{16}$ & 0.73 & 1.25 & 1.38 & 1.56 & 0.33 \\
\hline $\mathrm{Sr}_{2} \mathrm{Ru}_{5.5} \mathrm{Ir}_{0.5} \mathrm{O}_{16}$ & 0.77 & 1.26 & 1.53 & 1.36 & 0.30 \\
\hline $\mathrm{Sr}_{2} \mathrm{Ru}_{5} \mathrm{Ir}_{1} \mathrm{O}_{16}$ & 0.75 & 1.33 & 1.44 & 1.40 & 0.21 \\
\hline $\mathrm{Sr}_{2} \mathrm{Ru}_{3.5} \mathrm{Ir}_{2.5} \mathrm{O}_{16}$ & 0.57 & 1.32 & 1.63 & 1.40 & 0.40 \\
\hline $\mathrm{Sr}_{2} \mathrm{Ru}_{1.5} \mathrm{Ir}_{4.5} \mathrm{O}_{16}$ & 0.61 & 1.23 & 1.66 & 1.42 & 0.43 \\
\hline $\mathrm{Sr}_{3} \mathrm{Ru}_{5} \mathrm{O}_{16}$ & 1.51 & 1.49 & 1.58 & 0.34 & 0.35 \\
\hline $\mathrm{Sr}_{3} \mathrm{Ru}_{4} \mathrm{Ir}_{1} \mathrm{O}_{16}$ & 1.13 & 1.57 & 1.50 & 0.72 & 0.34 \\
\hline $\mathrm{Sr}_{6} \mathrm{Ru}_{1} \mathrm{Ir}_{1} \mathrm{O}_{16}$ & 1.37 & 1.35 & 1.75 & 0.45 & 0.52 \\
\hline $\mathrm{Sr}_{6} \mathrm{Ir}_{2} \mathrm{O}_{16}$ & 0.62 & 1.17 & 1.56 & 1.57 & 0.34 \\
\hline $\mathrm{RuO}_{2}$ & 0.26 & 1.10 & 1.76 & 1.79 & 0.56 \\
\hline $\mathrm{IrO}_{2}$ & 0.30 & 1.38 & 1.84 & 1.40 & 0.61 \\
\hline
\end{tabular}


1 Supplementary Table 3 | The energy of ions in the solution used in the Pourbaix 2 diagram calculation.

\begin{tabular}{cc}
\hline Reference & energy $(\mathrm{eV})$ \\
\hline $\mathrm{Sr}^{2+}(\mathrm{aq})$ & -5.844 \\
$\mathrm{RuO}_{4}^{2-}(\mathrm{aq})$ & -3.105 \\
$\mathrm{RuO}^{+}(\mathrm{aq})$ & -0.453 \\
$\mathrm{RuO}(\mathrm{aq})$ & 0.010 \\
$\mathrm{Ru}^{2+}(\mathrm{aq})$ & 1.557 \\
$\mathrm{Ru}^{3+}(\mathrm{aq})$ & 1.797 \\
$\mathrm{Ir}^{3+}(\mathrm{aq})$ & 0.347 \\
$\mathrm{IrO}_{4}^{2-}(\mathrm{aq})$ & -2.038 \\
$\mathrm{H}_{2} \mathrm{O}(\mathrm{aq})$ & -2.458 \\
$\mathrm{H}^{+}(\mathrm{aq})$ & 0.000 \\
\hline
\end{tabular}

3

4 
1 Supplementary Table 4 | Summary of the stoichiometry of different catalysts.

\begin{tabular}{ccccc}
\hline Catalyst & Sr ratio $^{1}$ & Ru ratio & Ir ratio & Formula $^{2}$ \\
\hline SrRuIr & 0.22 & 0.65 & 0.13 & $\mathrm{Sr}_{1.7} \mathrm{Ru}_{5} \mathrm{Ir}_{1} \mathrm{O}_{13.7}$ \\
\hline $\mathrm{SrRu}$ & 0.24 & 0.76 & - & $\mathrm{Sr}_{1.6} \mathrm{Ru}_{5} \mathrm{O}_{11.6}$ \\
\hline $\mathrm{RuIr}$ & - & 0.85 & 0.15 & $\mathrm{Ru}_{5} \mathrm{Ir}_{0.9} \mathrm{O}_{11.8}$
\end{tabular}

$2{ }^{1}$ Quantified according to STEM-EDX.

$3{ }^{2}$ Calculated by assuming the chemical valence of $\mathrm{Sr}, \mathrm{Ru}, \mathrm{Ir}$ and $\mathrm{O}$ are $+2,+4,+4$ and 42 , respectively.

5

6 
1 Supplementary Table 5 | Summary of electrochemical performance of different 2 samples on GCE

\begin{tabular}{cccc}
\hline Catalyst & Overpotential $^{\mathbf{1}}(\mathbf{m V})$ & Tafel slope $\left(\mathbf{m V ~ d e c} \mathbf{~}^{\mathbf{1}}\right)$ & TOF $^{\mathbf{2}}\left(\mathbf{s}^{\mathbf{1}}\right)$ \\
\hline $\mathrm{SrRuIr}$ & $190 \pm 2$ & 39 & $0.197 \pm 0.012$ \\
\hline $\mathrm{SrRu}$ & $238 \pm 1$ & 51 & $0.063 \pm 0.004$ \\
\hline $\mathrm{RuIr}$ & $239 \pm 1$ & 48 & $0.060 \pm 0.002$ \\
\hline $\mathrm{RuO}_{2}$ & $287 \pm 4$ & 53 & $0.016 \pm 0.001$ \\
$\mathrm{IrO}_{2}$ & $339 \pm 4$ & 46 & $0.005 \pm 0.001$
\end{tabular}

$3{ }^{1}$ Overpotential at $10 \mathrm{~mA} \mathrm{~cm}^{-2}$.

$4{ }^{2}$ Calculated according to the mass loading of all atoms. $\eta=300 \mathrm{mV}$.

5

6 
1 Supplementary Table 6 | BET surface area of different catalysts.

\begin{tabular}{cccc}
\hline Sample & BET surface area $\left(\mathbf{m}^{\mathbf{2}} \mathbf{g}^{-1}\right)$ & $\mathbf{C}$ & $\mathbf{R}$ \\
\hline $\mathrm{SrRuIr}$ & 14.41 & 78.9 & 0.9997 \\
\hline $\mathrm{RuIr}$ & 6.06 & 174.8 & 0.9999 \\
\hline $\mathrm{SrRu}$ & 5.37 & 1419.6 & 0.9990 \\
\hline $\mathrm{RuO}_{2}$ & 7.62 & 201.6 & 0.9999 \\
\hline $\mathrm{IrO}_{2}$ & 21.58 & 335.9 & 0.9997
\end{tabular}

2

3 
1 Supplementary Table 7 | Performance summary of previous reported OER catalysts in acidic environment.

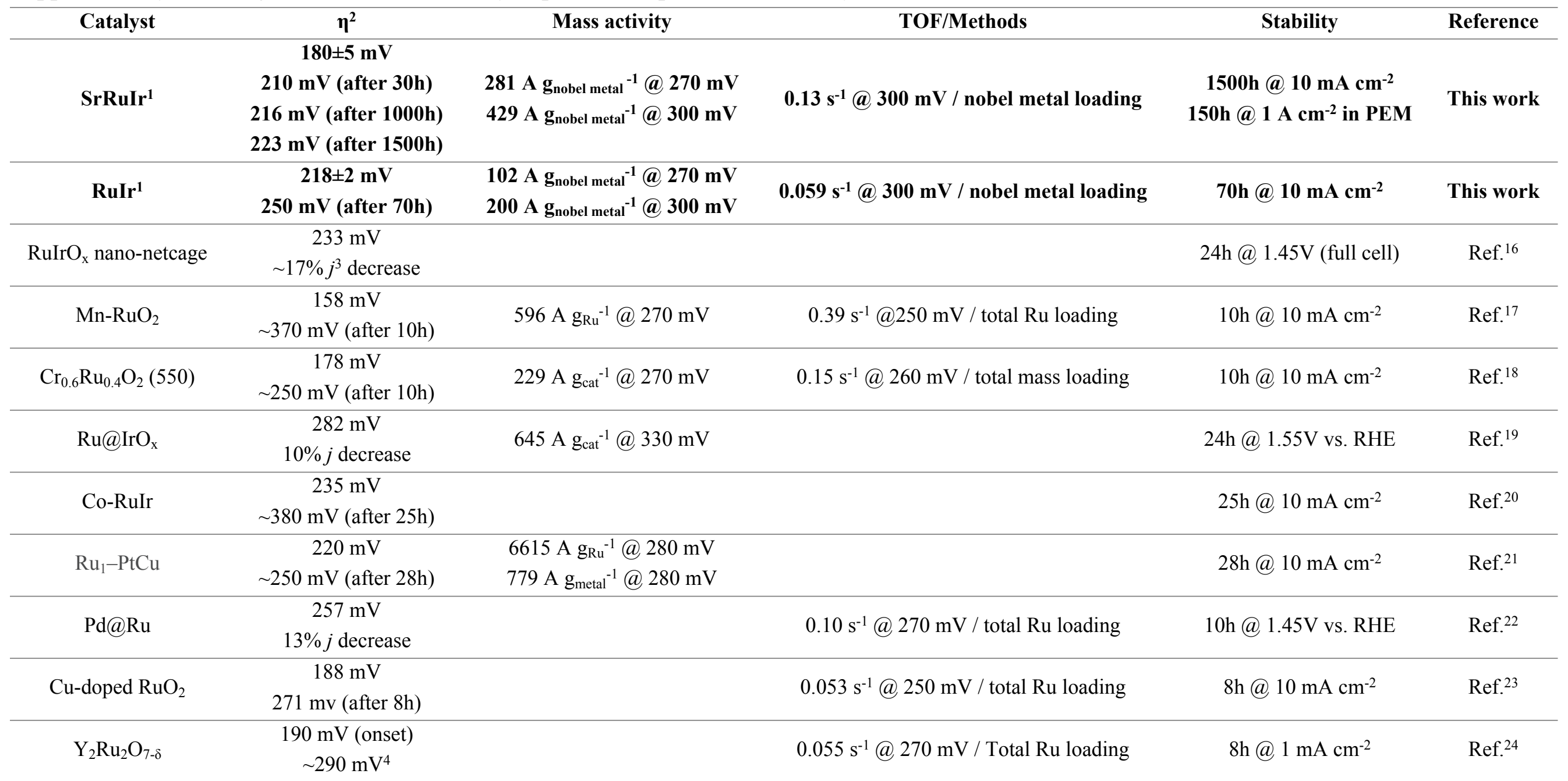

${ }^{1}$ Measured on carbon paper.

${ }^{2}$ Overpotential at $10 \mathrm{~mA} \mathrm{~cm}^{-2}$.

${ }^{3}$ Current density.

$5{ }^{4}$ Overpotential at $1 \mathrm{~mA} \mathrm{~cm}^{-2}$ after $8 \mathrm{~h} \mathrm{V-T}$ test. 
1 Supplementary Table 8 | Stability number (S-number) of different catalysts.

\begin{tabular}{ccc}
\hline Catalysts & S-number after 6 h & S-number after 12 h \\
\hline SrRuIr & 10400 & 19717 \\
SrRu & 265 & 410 \\
\hline
\end{tabular}

2

3 
Supplementary Table 9 | Parameters used in EXAFS fittings.

\begin{tabular}{|c|c|c|c|c|c|c|c|}
\hline Sample & Element & Path & $\mathbf{C N}$ & $\mathbf{S}_{0}^{2}$ & $\sigma^{2}$ & $\mathbf{E}_{0}$ & $\mathbf{R}(\AA)$ \\
\hline \multirow{11}{*}{ SrRuIr } & \multirow{7}{*}{ Ru K-edge } & Ru-O 1\# & 6 (set) & 0.78 & $0.0043 \pm 0.0003$ & $3.16 \pm 1.22$ & $1.990 \pm 0.005$ \\
\hline & & Ru-Ru 1\# & $1.45 \pm 0.44$ & 0.78 & $0.0046 \pm 0.0013$ & $-2.57 \pm 2.42$ & $3.098 \pm 0.020$ \\
\hline & & Ru-Ir 1\# & 0.36 & 0.78 & $0.0046 \pm 0.0013$ & $-2.57 \pm 2.42$ & $3.086 \pm 0.103$ \\
\hline & & Ru-O 2\# & 4 (set) & 0.78 & $0.0046 \pm 0.0013$ & $-2.57 \pm 2.42$ & $3.388 \pm 0.038$ \\
\hline & & Ru-Ru 2\# & $3.34 \pm 1.36$ & 0.78 & $0.0046 \pm 0.0013$ & $-2.57 \pm 2.42$ & $3.546 \pm 0.023$ \\
\hline & & Ru-Ir 2\# & 0.83 & 0.78 & $0.0046 \pm 0.0013$ & $-2.57 \pm 2.42$ & $3.685 \pm 0.036$ \\
\hline & & Ru-Sr 1\# & 0.83 & 0.78 & $0.0046 \pm 0.0013$ & $-2.57 \pm 2.42$ & $3.635 \pm 0.155$ \\
\hline & \multirow{4}{*}{ Ir L $\mathrm{L}_{3}$-edge } & Ir-O 1\# & $6.01 \pm 0.25$ & 0.85 & $0.0028 \pm 0.0004$ & $4.91 \pm 0.82$ & $1.971 \pm 0.005$ \\
\hline & & Ir-Ru 1\# & 2 (set) & 0.85 & $0.0069 \pm 0.0007$ & $1.57 \pm 2.08$ & $3.100 \pm 0.021$ \\
\hline & & Ir-O 2\# & 4 (set) & 0.85 & $0.0028 \pm 0.0004$ & $4.91 \pm 0.82$ & $3.568 \pm 0.045$ \\
\hline & & Ir-Ru 2\# & $7.19 \pm 1.51$ & 0.85 & $0.0069 \pm 0.0007$ & $1.57 \pm 2.08$ & $3.556 \pm 0.018$ \\
\hline $\mathrm{RuO}_{2}$ & Ru K-edge & Ru-O 1\# & 6 (set) & 0.78 & $0.0018 \pm 0.0003$ & $3.81 \pm 0.74$ & $1.983 \pm 0.003$ \\
\hline $\mathrm{IrO}_{2}$ & Ir L $_{3}$-edge & Ir-O 1\# & 6 (set) & 0.85 & $0.0049 \pm 0.0005$ & $3.72 \pm 3.52$ & $2.002 \pm 0.025$ \\
\hline
\end{tabular}


1 Supplementary Table 10 | Mass spectroscopy peak area of different catalysts 2 cycled in ${ }^{18} \mathrm{O}$ labeled electrolyte.

\begin{tabular}{|c|c|c|c|c|c|}
\hline Sample & $\begin{array}{l}\text { Scan } \\
\text { No. }\end{array}$ & $\begin{array}{c}{ }^{34} \mathrm{O}_{2} \text { area } \\
\left(\times 10^{-10} \text { a.u. }\right)\end{array}$ & $\begin{array}{c}{ }^{36} \mathrm{O}_{2} \text { area } \\
\left(\times 10^{-9} \text { a.u. }\right)\end{array}$ & $\begin{array}{l}\text { Area ratio } \\
\left({ }^{34} \mathrm{O}_{2}:{ }^{36} \mathrm{O}_{2}\right)\end{array}$ & $\begin{array}{c}\text { LOM } \\
\text { content }(\%)\end{array}$ \\
\hline \multirow{5}{*}{ SrRuIr } & 1 & 1.982 & 2.368 & 0.084 & 7.72 \\
\hline & 2 & 1.659 & 1.951 & 0.085 & 7.83 \\
\hline & 3 & 1.401 & 1.676 & 0.084 & 7.72 \\
\hline & 4 & 1.312 & 1.494 & 0.088 & 8.07 \\
\hline & 5 & 1.063 & 1.290 & 0.082 & 7.61 \\
\hline \multirow{5}{*}{$\mathrm{RuO}_{2}$} & 1 & 17.880 & 10.818 & 0.165 & 14.18 \\
\hline & 2 & 9.823 & 5.917 & 0.166 & 14.24 \\
\hline & 3 & 7.150 & 4.337 & 0.165 & 14.15 \\
\hline & 4 & 6.469 & 3.780 & 0.171 & 14.61 \\
\hline & 5 & 5.899 & 3.384 & 0.174 & 14.84 \\
\hline
\end{tabular}

3 The mass spectroscopy signals are baseline subtracted.

4 
1 Supplementary Table 11 | The deconvolution of O 1s XPS spectra using CasaXPS

2 software.

\begin{tabular}{cccccc}
\hline \multirow{2}{*}{ Sample } & Peak & Lineshape & Position (eV) & FWHM & Area \\
\hline \multirow{3}{*}{ SrRuIr } & lattice O & $\operatorname{LA}(1.53,243)$ & 529.94 & 2.15 & 28842.15 \\
\cline { 2 - 6 } & ads. $\mathrm{OH}$ & $\operatorname{LA}(1.53,243)$ & 531.84 & 3.03 & 49249.27 \\
\cline { 2 - 6 } & ads. $\mathrm{H}_{2} \mathrm{O}$ & $\mathrm{LA}(1.53,243)$ & 534.21 & 2.74 & 27015.19 \\
\hline \multirow{2}{*}{$\mathrm{RuO}_{2}$} & lattice $\mathrm{O}$ & $\mathrm{LA}(1.53,243)$ & 529.24 & 1.31 & 19026.94 \\
\cline { 2 - 6 } & ads. $\mathrm{OH}$ & $\operatorname{LA}(1.53,243)$ & 531.14 & 2.89 & 78033.58 \\
\cline { 2 - 6 } & ads. $\mathrm{H}_{2} \mathrm{O}$ & $\operatorname{LA}(1.53,243)$ & 533.6 & 3.53 & 34039.74
\end{tabular}

3 The peak area ratio of adsorbted OH:lattcie O is 1.7 for SrRuIr and 4.1 for $\mathrm{RuO}_{2}$, 4 respectively.

5

6 
1 Supplementary Table 12 | The quantification parameters of $\mathrm{Sr} 3 \mathrm{dd}, \mathrm{Ru} 3 \mathrm{p}$ and $\mathrm{Ir}$

2 4f XPS spectra using CasaXPS software.

\begin{tabular}{|c|c|c|c|c|c|}
\hline Sample & Peak & R.S.F.* & Raw Area & $\begin{array}{c}\text { Atomic } \\
\text { concentration }\end{array}$ & Sr:Ru:Ir \\
\hline \multirow{3}{*}{$\begin{array}{c}\text { SrRuIr } \\
\text { after } 12 \mathrm{~h}\end{array}$} & $\operatorname{Sr} 3 d$ & 5.29 & 2699.8 & 0.06 & \multirow{3}{*}{$0.44: 5: 1.95$} \\
\hline & Ir $4 \mathrm{f}$ & 14.33 & 32319.5 & 0.27 & \\
\hline & $\mathrm{Ru} 3 \mathrm{p}^{*}$ & 2.84 & 16384.2 & 0.67 & \\
\hline \multirow{3}{*}{$\begin{array}{c}\text { SrRuIr } \\
\text { after } 24 \mathrm{~h}\end{array}$} & Sr 3d & 5.29 & 870.4 & 0.05 & \multirow{3}{*}{$0.38: 5: 1.6$} \\
\hline & Ir $4 f$ & 14.33 & 16539.4 & 0.23 & \\
\hline & $\mathrm{Ru} 3 \mathrm{p}$ & 2.84 & 10247.2 & 0.72 & \\
\hline
\end{tabular}

$3 *$ R.S.F $=$ Relative sensitivity factor

$4 \quad *$ The amount of $\mathrm{Ru}$ was quantified according to $\mathrm{Ru} 3 \mathrm{p}_{1 / 2}$ peak area.

5

6 
1 Supplementary Table 13 | Bader charge analysis in $\mathrm{RuO}_{2}$ and SrRuIr surfaces.

\begin{tabular}{cc}
\hline Model & Charge on active site Ru \\
\hline $\mathrm{RuO}_{2}$ & +1.50 \\
\hline $\mathrm{Sr}_{1} \mathrm{Ru}_{6} \mathrm{Ir}_{1} \mathrm{O}_{16}$ & +1.59 \\
\hline $\mathrm{Sr}_{2} \mathrm{Ru}_{5} \mathrm{Ir}_{1} \mathrm{O}_{16}$ & +1.64 \\
\hline $\mathrm{Sr}_{2} \mathrm{Ru}_{5.5} \mathrm{Ir}_{0.5} \mathrm{O}_{16}$ & +1.64 \\
\hline $\mathrm{Sr}_{2} \mathrm{Ru}_{1.5} \mathrm{Ir}_{4.5} \mathrm{O}_{16}$ & +1.64 \\
\hline $\mathrm{Sr}_{2} \mathrm{Ru}_{3.5} \mathrm{Ir}_{2.5} \mathrm{O}_{16}$ & +1.62 \\
\hline $\mathrm{Sr}_{2} \mathrm{Ru}_{6} \mathrm{O}_{16}$ & +1.64
\end{tabular}

2

3 
1 Supplementary Table $14 \mid$ Performance of PEM cells tested at $80^{\circ} \mathrm{C}, 1 \mathrm{~A} \mathrm{~cm}^{-2}$.

\begin{tabular}{|c|c|c|c|}
\hline Catalysts & Cell voltage@1 $1 \mathrm{~cm}^{-2}$ & Stability test & Reference \\
\hline SrRuIr & $1.50 \mathrm{~V}$ & $150 \mathrm{~h} @ 1 \mathrm{~A} \mathrm{~cm} \mathbf{c m}^{-2}$ & This work \\
\hline $\mathrm{Ir}_{0.7} \mathrm{Ru}_{0.3} \mathrm{O}_{\mathrm{x}}$ & $1.59 \mathrm{~V}$ & 1000h@1 A cm-2 & Ref. $^{25}$ \\
\hline $\mathrm{Ru}_{0.7} \mathrm{Ir}_{0.3} \mathrm{O}_{2}$ & $1.60 \mathrm{~V}$ & & Ref. $^{26}$ \\
\hline YBRO-0.15 & $1.64 \mathrm{~V}\left(60^{\circ} \mathrm{C}\right)$ & $15 \mathrm{~h} @ 150 \mathrm{~mA} \mathrm{~cm}-2$ & $\operatorname{Ref}^{27}$ \\
\hline $\mathrm{Ir}_{0.7} \mathrm{Ru}_{0.3} \mathrm{O}_{\mathrm{x}}$ & $1.70 \mathrm{~V}$ & 400h@1 $\mathrm{A} \mathrm{cm}^{-2}$ & Ref. $^{28}$ \\
\hline $\mathrm{Ir}_{0.6} \mathrm{Sn}_{0.4} \mathrm{O}_{2}$ & $1.70 \mathrm{~V}$ & 100h@1 $\mathrm{A} \mathrm{cm}^{-2}$ & Ref. $^{29}$ \\
\hline $\mathrm{IrO}_{2}$ & $1.65 \mathrm{~V}$ & 1000h@1 A cm-2 & $\operatorname{Ref}^{30}$ \\
\hline $\mathrm{Ir}_{0.4} \mathrm{Ru}_{0.6} \mathrm{Mo}_{\mathrm{x}} \mathrm{O}_{\mathrm{y}}$ & $1.61 \mathrm{~V}$ & & Ref. $^{31}$ \\
\hline
\end{tabular}

2

3 
1 Supplementary Table 15 | Summary of parameters used in EIS fittings on GCE.

\begin{tabular}{cccccc}
\hline Parameters & SrRuIr & SrRu & RuIr & RuO $_{2}$ & IrO $_{2}$ \\
\hline $\mathrm{R}_{\mathrm{s}}(\Omega)$ & 8.45 & 9.05 & 8.52 & 9.92 & 8.31 \\
\hline $\mathrm{R}_{\mathrm{ct}}(\Omega)$ & 508.2 & 600.4 & 581.4 & 1447.5 & 12557 \\
\hline $\mathrm{CPE} . \mathrm{Y}_{0}\left(\mathrm{mF} \mathrm{s}^{\alpha-1}\right)$ & 1.26 & 0.23 & 0.87 & 0.56 & 0.19 \\
\hline CPE. $\alpha$ & 0.85 & 0.92 & 0.95 & 0.94 & 0.93 \\
\hline $\mathrm{C}_{\mathrm{dl}}(\mathrm{mF})$ & 642.0 & 145.0 & 691.3 & 398.6 & 116.8 \\
\hline ECSA $\left(\mathrm{cm}^{2}\right)$ & 18.34 & 4.14 & 19.75 & 11.39 & 3.34 \\
\hline
\end{tabular}

2

3 


\section{References}

(1) Zhang, B.; Zheng, X.; Voznyy, O.; Comin, R.; Bajdich, M.; Garcia-Melchor, M.; Han, L.; Xu, J.; Liu, M.; Zheng, L.; Garcia de Arquer, F. P.; Dinh, C. T.; Fan, F.; Yuan, M.; Yassitepe, E.; Chen, N.; Regier, T.; Liu, P.; Li, Y.; De Luna, P.; Janmohamed, A.; Xin, H. L.; Yang, H.; Vojvodic, A.; Sargent, E. H., Homogeneously dispersed multimetal oxygen-evolving catalysts. Science 2016, 352 (6283), 333-337.

(2) McCrory, C. C.; Jung, S.; Peters, J. C.; Jaramillo, T. F., Benchmarking heterogeneous electrocatalysts for the oxygen evolution reaction. J. Am. Chem. Soc. 2013, 135 (45), 16977-16987.

(3) Geiger, S.; Kasian, O.; Ledendecker, M.; Pizzutilo, E.; Mingers, A. M.; Fu, W. T.; Diaz-Morales, O.; Li, Z.; Oellers, T.; Fruchter, L.; Ludwig, A.; Mayrhofer, K. J. J.; Koper, M. T. M.; Cherevko, S., The stability number as a metric for electrocatalyst stability benchmarking. Nat. Catal. 2018, 1 (7), 508-515.

(4) Ravel, B.; Newville, M., ATHENA, ARTEMIS, HEPHAESTUS: data analysis for X-ray absorption spectroscopy using IFEFFIT. J. Synchrotron Rad. 2005, 12, 537 541.

(5) Xia, Z.; Zhang, H.; Shen, K.; Qu, Y.; Jiang, Z., Wavelet analysis of extended Xray absorption fine structure data: Theory, application. Physica B: Condensed Matter 2018, 542, 12-19.

(6) Funke, H.; Scheinost, A. C.; Chukalina, M., Wavelet analysis of extended X-ray absorption fine structure data. Phys. Rev. B 2005, 71 (9), 094110.

(7) Xia, Z. A tool to make wavelet transformation of EXAFS. https://github.com/hellozhaoming/wtexfas.

(8) Funke, H.; Chukalina, M.; Scheinost, A. C., A new FEFF-based wavelet for EXAFS data analysis. J. Synchrotron Rad. 2007, 14 (Pt 5), 426-432.

(9) Boman, C.-E.; Danielsen, J.; Haaland, A.; Jerslev, B.; Schäffer, C. E.; Sunde, E.; Sørensen, N. A., Refinement of the crystal structure of ruthenium dioxide. Acta Chem. Scand. 1970, 24, 116-122.

(10) Seitz, L. C.; Dickens, C. F.; Nishio, K.; Hikita, Y.; Montoya, J.; Doyle, A.; Kirk, C.; Vojvodic, A.; Hwang, H. Y.; Norskov, J. K.; Jaramillo, T. F., A highly active and stable $\mathrm{IrO}_{\mathrm{x}} / \mathrm{SrIrO}_{3}$ catalyst for the oxygen evolution reaction. Science 2016, 353 (6303), 1011-1014. 
1 (11) Chang, S. H.; Danilovic, N.; Chang, K. C.; Subbaraman, R.; Paulikas, A. P.; Fong, D. D.; Highland, M. J.; Baldo, P. M.; Stamenkovic, V. R.; Freeland, J. W.; Eastman, J. A.; Markovic, N. M., Functional links between stability and reactivity of strontium ruthenate single crystals during oxygen evolution. Nat. Commun. 2014, 5, 4191.

(12) Chen, Y.; Li, H.; Wang, J.; Du, Y.; Xi, S.; Sun, Y.; Sherburne, M.; Ager, J. W., 3rd; Fisher, A. C.; Xu, Z. J., Exceptionally active iridium evolved from a pseudocubic perovskite for oxygen evolution in acid. Nat. Commun. 2019, 10 (1), 572.

(13) Gauthier, J. A.; Dickens, C. F.; Chen, L. D.; Doyle, A. D.; Nørskov, J. K., Solvation effects for oxygen evolution reaction catalysis on $\mathrm{IrO}_{2}(110)$. J. Phys. Chem. C 2017, 121 (21), 11455-11463.

(14) Zhang, Y.; Huang, L.; Arunagiri, T. N.; Ojeda, O.; Flores, S.; Chyan, O.; Wallace, R. M., Underpotential deposition of copper on electrochemically prepared conductive ruthenium oxide surface. Electrochem. Solid-State Lett. 2004, 7 (9).

(15) Zagalskaya, A.; Alexandrov, V., Role of defects in the interplay between adsorbate evolving and lattice oxygen mechanisms of the oxygen evolution reaction in $\mathrm{RuO}_{2}$ and $\mathrm{IrO}_{2}$. ACS Catal. 2020, 10 (6), 3650-3657.

(16) Zhuang, Z.; Wang, Y.; Xu, C. Q.; Liu, S.; Chen, C.; Peng, Q.; Zhuang, Z.; Xiao, H.; Pan, Y.; Lu, S.; Yu, R.; Cheong, W. C.; Cao, X.; Wu, K.; Sun, K.; Wang, Y.; Wang, D.; Li, J.; Li, Y., Three-dimensional open nano-netcage electrocatalysts for efficient pH-universal overall water splitting. Nat. Commun. 2019, 10 (1), 4875.

(17) Chen, S.; Huang, H.; Jiang, P.; Yang, K.; Diao, J.; Gong, S.; Liu, S.; Huang, M.; Wang, H.; Chen, Q., Mn-doped $\mathrm{RuO}_{2}$ nanocrystals as highly active electrocatalysts for enhanced oxygen evolution in acidic media. ACS Catal. 2019, $10(2), 1152-1160$.

(18) Lin, Y.; Tian, Z.; Zhang, L.; Ma, J.; Jiang, Z.; Deibert, B. J.; Ge, R.; Chen, L., Chromium-ruthenium oxide solid solution electrocatalyst for highly efficient oxygen evolution reaction in acidic media. Nat. Commun. 2019, 10 (1), 162.

(19) Shan, J.; Guo, C.; Zhu, Y.; Chen, S.; Song, L.; Jaroniec, M.; Zheng, Y.; Qiao, S.Z., Charge-redistribution-enhanced nanocrystalline $\mathrm{Ru} @ \mathrm{IrO}_{\mathrm{x}}$ electrocatalysts for oxygen evolution in acidic media. Chem 2019, 5 (2), 445-459. 
1 (20) Shan, J.; Ling, T.; Davey, K.; Zheng, Y.; Qiao, S. Z., Transition-metal-doped RuIr bifunctional nanocrystals for overa
Mater. 2019, 31 (17), e1900510.

(21) Yao, Y.; Hu, S.; Chen, W.; Huang, Z.-Q.; Wei, W.; Yao, T.; Liu, R.; Zang, K.; Wang, X.; Wu, G.; Yuan, W.; Yuan, T.; Zhu, B.; Liu, W.; Li, Z.; He, D.; Xue, Z.; Wang, Y.; Zheng, X.; Dong, J.; Chang, C.-R.; Chen, Y.; Hong, X.; Luo, J.; Wei, S.; Li, W.-X.; Strasser, P.; Wu, Y.; Li, Y., Engineering the electronic structure of single atom $\mathrm{Ru}$ sites via compressive strain boosts acidic water oxidation electrocatalysis. Nat. Catal. 2019, 2 (4), 304-313.

(22) Hu, Y.; Luo, X.; Wu, G.; Chao, T.; Li, Z.; Qu, Y.; Li, H.; Wu, Y.; Jiang, B.; Hong, $\mathrm{X}$., Engineering the atomic layer of $\mathrm{RuO}_{2}$ on $\mathrm{PdO}$ nanosheets boosts oxygen evolution catalysis. ACS Appl. Mater. Interfaces 2019, 11 (45), 42298-42304.

(23) Su, J.; Ge, R.; Jiang, K.; Dong, Y.; Hao, F.; Tian, Z.; Chen, G.; Chen, L., Assembling ultrasmall copper-doped ruthenium oxide nanocrystals into hollow porous polyhedra: Highly robust electrocatalysts for oxygen evolution in acidic media. Adv. Mater. 2018, e1801351.

(24) Kim, J.; Shih, P. C.; Tsao, K. C.; Pan, Y. T.; Yin, X.; Sun, C. J.; Yang, H., Highperformance pyrochlore-type yttrium ruthenate electrocatalyst for oxygen evolution reaction in acidic media. J. Am. Chem. Soc. 2017, 139 (34), 1207612083.

(25) Siracusano, S.; Baglio, V.; Van Dijk, N.; Merlo, L.; Aricò, A. S., Enhanced performance and durability of low catalyst loading PEM water electrolyser based on a short-side chain perfluorosulfonic ionomer. Appl. Energy 2017, 192, 477-489.

(26) Xu, W.; Scott, K., The effects of ionomer content on PEM water electrolyser membrane electrode assembly performance. Int. J. Hydrogen Energy 2010, 35 (21), 12029-12037.

(27) Feng, Q.; Zou, J.; Wang, Y.; Zhao, Z.; Williams, M. C.; Li, H.; Wang, H., Influence of surface oxygen vacancies and ruthenium valence state on the catalysis of pyrochlore oxides. ACS Appl. Mater. Interfaces 2020, 12 (4), 4520-4530.

(28) Wang, L.; Saveleva, V. A.; Zafeiratos, S.; Savinova, E. R.; Lettenmeier, P.; Gazdzicki, P.; Gago, A. S.; Friedrich, K. A., Highly active anode electrocatalysts derived from electrochemical leaching of $\mathrm{Ru}$ from metallic $\mathrm{Ir}_{0.7} \mathrm{Ru}_{0.3}$ for proton exchange membrane electrolyzers. Nano Energy 2017, 34, 385-391. 
1 (29) Jiang, G.; Yu, H.; Hao, J.; Chi, J.; Fan, Z.; Yao, D.; Qin, B.; Shao, Z., An effective oxygen electrode based on $\mathrm{Ir}_{0.6} \mathrm{Sn}_{0.4} \mathrm{O}_{2}$ for PEM water electrolyzers. J. Energy Chem. 2019, 39, 23-28.

4 (30) Siracusano, S.; Baglio, V.; Grigoriev, S. A.; Merlo, L.; Fateev, V. N.; Aricò, A. S., The influence of iridium chemical oxidation state on the performance and durability of oxygen evolution catalysts in PEM electrolysis. J. Power Sources 2017, 366, 105-114.

(31) Cheng, J.; Zhang, H.; Ma, H.; Zhong, H.; Zou, Y., Preparation of $\mathrm{Ir}_{0.4} \mathrm{Ru}_{0.6} \mathrm{Mo}_{\mathrm{x}} \mathrm{O}_{\mathrm{y}}$ for oxygen evolution by modified Adams' fusion method. Int. J. Hydrogen Energy 2009, 34 (16), 6609-6613. 